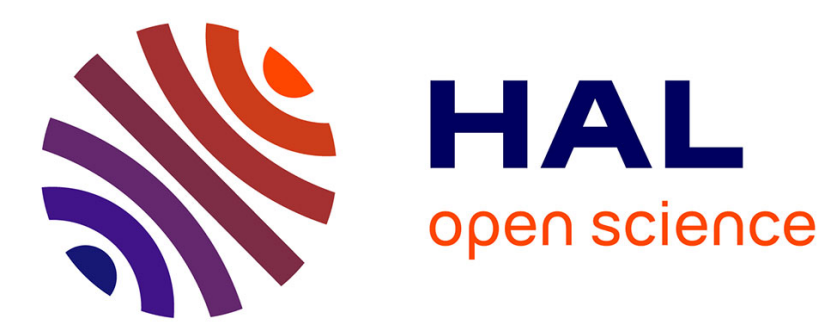

\title{
Formation of lunar mare domes along crustal fractures: Rheologic conditions, dimensions of feeder dikes, and the role of magma evolution
}

Christian Wöhler, Raffaello Lena, Jim Phillips

\section{- To cite this version:}

Christian Wöhler, Raffaello Lena, Jim Phillips. Formation of lunar mare domes along crustal fractures: Rheologic conditions, dimensions of feeder dikes, and the role of magma evolution. Icarus, 2007, 189 (2), pp.279. 10.1016/j.icarus.2007.01.011 . hal-00499069

\section{HAL Id: hal-00499069 https://hal.science/hal-00499069}

Submitted on 9 Jul 2010

HAL is a multi-disciplinary open access archive for the deposit and dissemination of scientific research documents, whether they are published or not. The documents may come from teaching and research institutions in France or abroad, or from public or private research centers.
L'archive ouverte pluridisciplinaire HAL, est destinée au dépôt et à la diffusion de documents scientifiques de niveau recherche, publiés ou non, émanant des établissements d'enseignement et de recherche français ou étrangers, des laboratoires publics ou privés. 


\section{Accepted Manuscript}

Formation of lunar mare domes along crustal fractures: Rheologic conditions, dimensions of feeder dikes, and the role of magma evolution

Christian Wöhler, Raffaello Lena, Jim Phillips

PII: $\quad$ S0019-1035(07)00056-5

DOI: $\quad$ 10.1016/j.icarus.2007.01.011

Reference: $\quad$ YICAR 8182

To appear in: Icarus

Received date: 26 October 2006

Revised date: 27 January 2007

Accepted date: 30 January 2007

Please cite this article as: C. Wöhler, R. Lena, J. Phillips, Formation of lunar mare domes along crustal fractures: Rheologic conditions, dimensions of feeder dikes, and the role of magma evolution, Icarus (2007), doi: 10.1016/j.icarus.2007.01.011

This is a PDF file of an unedited manuscript that has been accepted for publication. As a service to our customers we are providing this early version of the manuscript. The manuscript will undergo copyediting, typesetting, and review of the resulting proof before it is published in its final form. Please note that during the production process errors may be discovered which could affect the content, and all legal disclaimers that apply to the journal pertain. 


\title{
Formation of lunar mare domes along crustal fractures: Rheologic conditions, dimensions of feeder dikes, and the role of magma evolution
}

\author{
Christian Wöhler \\ DaimlerChrysler Group Research, Machine Perception \\ P. O. Box 2360, 89013 Ulm, Germany \\ christian.woehler@daimlerchrysler.com \\ Raffaello Lena \\ Via Cartesio 144, sc. D, 00137, Rome, Italy \\ lena@glrgroup.org \\ Jim Phillips \\ 101 Bull Street, Charleston, SC 29401, USA \\ thefamily90@hotmail.com \\ Geologic Lunar Research (GLR) group
}

80 pages, 7 tables, 14 figures 


\section{Proposed running head:}

Formation of lunar mare domes along crustal fractures

\section{Editorial correspondence to:}

Dr. Christian Wöhler

Laichinger Str. 9/1

D-72535 Heroldstatt

Germany

Phone: +49-7389-906040

E-mail: christian.woehler@web.de

christian.woehler@daimlerchrysler.com 


\section{Abstract}

In this study we examine a set of lunar mare domes located in the Hortensius/Milichius/T. Mayer region and in northern Mare Tranquillitatis with respect to their formation along crustal fractures, their rheologic properties, the dimensions of their feeder dikes, and the importance of magma evolution processes during dome formation. Many of these domes display elongated summit vents oriented radially with respect to major impact basins, and several dome locations are also aligned in these preferential directions. Analysis of Clementine UVVIS and Lunar Prospector gamma ray spectrometer data reveals that the examined mare domes formed from low-Si basaltic lavas of high $\mathrm{FeO}$ and low to moderate $\mathrm{TiO}_{2}$ content. Based on their morphometric properties (diameter, height, volume) obtained by photoclinometric and shape from shading analysis of telescopic CCD images, we derive rheologic quantities (lava viscosity during eruption, effusion rate, duration of the effusion process, magma rise speed) and the dimensions of the feeder dikes. We establish three rheologic groups characterised by specific combinations of rheologic properties and dike dimensions, where the most relevant discriminative parameter is the lava viscosity $\eta$. The first group is characterised by $10^{4} \mathrm{~Pa} \mathrm{~s}<\eta<10^{6} \mathrm{~Pa}$ s and contains the domes with elongated vents in the Milichius/T. Mayer region and two similar domes in northern Mare Tranquillitatis. The second group with $10^{2} \mathrm{~Pa} \mathrm{~s}<\eta<10^{4} \mathrm{~Pa}$ s comprises the very low aligned domes in northern Mare Tranquillitatis, and the third group with $10^{6} \mathrm{~Pa} \mathrm{~s}<\eta<10^{8} \mathrm{~Pa} \mathrm{~s}$ the relatively steep domes near Hortensius and in the T. Mayer region. The inferred dike dimensions in comparison to lunar crustal thickness data indicate that the source regions of the feeder dikes are situated within the upper crust for six of the domes in northern Mare Tranquillitatis, while they are likely to be located in the lower crust and in the upper mantle for the other examined domes. By comparing the time scale of magma ascent with the time scale on which heat is conducted from the magma into the host rock, we find evidence that the importance of magma evolution processes during ascent such as cooling and crystallisation increases with lava viscosity. We conclude that different degrees of evolution of initially fluid basaltic magma are able to explain the broad range of lava viscosities inferred for the examined mare domes. The spectral data reveal that differences in $\mathrm{TiO}_{2}$ content may additionally account for the system- 
atic difference in lava viscosity between the two examined lunar regions. We show that the described mechanisms are likely to be valid also for other lunar mare domes situated near Cauchy and Arago, regarded for comparison. On the other hand, we find for the Gruithuisen and Mairan highland domes that despite their inferred high lava viscosities of $10^{8}-10^{9} \mathrm{~Pa} \mathrm{~s}$, no significant magma cooling in the dike occurred during ascent, supporting previous findings that the highland domes were formed during a specific phase of non-mare volcanism by highly silicic viscous lavas.

Key words: Moon; volcanism; geological processes 


\section{Introduction}

Most lunar domes are volcanic features with low profiles, commonly topped by small smooth-rimmed craters. The apparent internal origin of the domes was a major factor in endogenic interpretations of the maria, and their low profiles suggest a volcanism characteristic of fluid mafic magmas (Wilhelms, 1987). The extrusive origin of lunar domes and their similarity to terrestrial features like small shield volcanoes have been described in the literature (Head and Gifford, 1980; Basaltic Volcanism Study Project, 1981). Domes representing volcanic sources are smooth-surfaced and usually have a summit crater pit. Most vents related to domes appear to be associated with surrounding lava plains of known volcanic origin or in association with pyroclastic deposits. The presence of a summit crater pit argues against an intrusive or laccolithic origin for the majority of these features. The issue of intrusive lunar domes and how they are possibly related to equivalent terrestrial features is not yet well understood. They were probably formed by subsurface intrusions, similar to laccoliths on Earth, where magma has flowed under a surface of solidified lava and lifted it up (Head and Gifford, 1980; Basaltic Volcanism Study Project, 1981).

Comprehensive overviews about lunar domes are provided by Cattermole (1996) and by Mursky (1996). According to these descriptions, constructional volcanic features formed during the later stages of volcanism on the Moon, characterised by a decreasing rate of lava extrusion and comparably low temperature of eruption, resulting in the formation of effusive domes. Early stage lavas were very fluid due to their high temperatures, massive volumes, and mineralogy. The low viscosities of lunar lavas suggest that low domes were produced by lavas erupting at rates less than those which produced terrestrial shield volcanoes (Whitford-Stark and Head, 1977).

Low mare domes are concentrated in Mare Tranquillitatis (e. g. Cauchy and Vitruvius region) and in western Mare Insularum (Hortensius/Milichius/T. Mayer region) but occur in other maria as well. Many of the lunar domes located in the Hortensius/Milichius/T. Mayer region display a summit crater pit likely representing the vent of the volcano which was enlarged by withdrawal of magma and later erosion. Other domes do not have a circular summit pit but their summit is crossed by a rimless elongated vent or fissure (Wilhelms, 1987). The different dome shapes indicate that 
they were formed by lavas of different viscosities and effusion rates.

Head and Gifford (1980) define seven classes of lunar domes. Classes 1, 2, and 3 refer to volcanic features resembling terrestrial shield volcanoes. Class 1 domes have circular to elliptic outlines, their diameters are between 5.5 and $15 \mathrm{~km}$, they exhibit slopes smaller than $5^{\circ}$, and they have summit craters without raised rims. Class 2 domes differ from class 1 domes essentially by their pancake-like cross-sectional shape. The distinction between classes 1 and 2 basically relies on a qualitative estimate of 3D shape. Class 3 domes are similar to those of classes 1 and 2 but exhibit a lower topographic relief. Several low domes near Cauchy are good examples of this class. Class 4 denotes domes associated with mare ridges and arches, which may be of tectonic origin, while class 5 describes domes originating from lava mantling of pre-existing highland topography. Class 6 includes domes with higher albedo than mare material and comparably steep slopes, like Gruithuisen $\gamma$ and $\delta$. Class 7 describes complex mare domes with irregular outline and topography, such as Arago $\alpha$ and $\beta$ and many of the domes observed in the Marius Hills region.

A classification scheme for effusive lunar mare domes complementary to the scheme by Head and Gifford (1980), especially referring to their classes $1-3$, is suggested in the study by Wöhler et al. (2006), which will be denoted by "paper 1" in the following. Their data are based upon a combined spectrophotometric and morphometric analysis of the dome fields near Cauchy, Arago, Hortensius, and Milichius. Clementine UVVIS multispectral data utilised for soil composition analysis, in particular $\mathrm{TiO}_{2}$ content, high-resolution CCD ground-based imagery, and 3D surface reconstruction based on shadow analysis, photoclinometry, and shape from shading form the basis for this classification scheme. It is shown that each class is characterised by specific configurations of lava viscosity, effusion rate, and duration of the effusion process, according to the model by Wilson and Head (2003). Class A domes are shallow, small domes formed by low viscosity lavas of high $\mathrm{TiO}_{2}$ content erupting at high effusion rates over very short periods of time. Class $B_{1}$ domes have steep flank slopes and formed from lavas of low to moderate $\mathrm{TiO}_{2}$ content erupting at low to moderate effusion rates over a long period of time. Class $\mathrm{B}_{2}$ domes formed during shorter periods of time than those of class $\mathrm{B}_{1}$, resulting in shallow flanks with lower volumes. Class $\mathrm{C}_{1}$ domes have a low 
$\mathrm{TiO}_{2}$ content and were formed by low viscosity lavas at high effusion rates resulting in large diameters, shallow flanks and thus pancake-like 3D shapes. Domes of class $\mathrm{C}_{2}$ are similar to $\mathrm{C}_{1}$ domes but with a higher $\mathrm{TiO}_{2}$ content. Class $\mathrm{D}$ domes are large, shallow, voluminous domes like Arago $\alpha$ and $\beta$ as well as several domes in the Marius Hills region, which likely formed during several stages of effusion. An additional class is made up by large, steep, and voluminous highland domes such as the Gruithuisen and Mairan domes. The latter two classes correspond to classes 7 and 6 of the scheme by Head and Gifford (1980), respectively.

In paper 1 it is suggested that the Gruithuisen highland domes and the shallow class A mare domes in Mare Tranquillitatis represent endmembers of the dome formation process, spanning a broad continuous range of associated rheologic parameters: lava viscosities between $10^{2}$ and $10^{9} \mathrm{~Pa} \mathrm{~s}$, effusion rates between about 25 and at least $600 \mathrm{~m}^{3} \mathrm{~s}^{-1}$, and durations of the effusion process between a few weeks and about 40 years. The evident differences in dome shapes and rheologic parameters raise broad questions concerning the source regions of the various dome types and the corresponding implications for local and regional lunar volcanism, the reasons why certain types of lunar domes are concentrated in certain areas of the lunar surface, why especially domes with gentle flank slopes tend to be aligned, and which differences in the lunar interior are responsible for the different lunar dome properties observed on the surface.

In this study we will examine for a variety of lunar mare domes the relationship between the conditions in the magma source regions and the resulting eruption conditions at the surface. For this purpose, we will regard the spatial distribution of mare domes along with their spectrophotometric and morphometric properties for the Hortensius/Milichius/T. Mayer region, relying on the corresponding data in paper 1 and on additional data obtained based on new telescopic CCD imagery. Furthermore, we will provide new morphometric data for a group of aligned domes situated in northern Mare Tranquillitatis. These analyses will be complemented by an in-depth investigation of the compositional properties of the mare basalts out of which the domes were formed, relying on Clementine UVVIS spectrophotometry and Lunar Prospector data. What is more, we will examine possible effects of impact basin topography and related crustal fractures on the ascent of magma and discuss how factors like lava composition and 
dike geometry may have controlled the viscosity of the erupting lava and thus in turn the observed sizes and shapes of the lunar mare domes.

\section{Geologic setting of the examined volcanic regions and their relation to impact basins}

The Cauchy region, northern Mare Tranquillitatis, Mare Insularum, and parts of Oceanus Procellarum display dense concentrations of lunar mare domes. Two dome fields, comprised in the Hortensius/Milichius/T. Mayer region, cover an extensive part of northern Mare Insularum south of the outer rim of the Imbrium basin (Fig. 1a). Although these domes share some characteristics, they display significant differences in their 3D shapes and the appearance of their summit crater pits or elongated vents, indicating variations in eruption style. In paper 1, geologic maps of these regions are reproduced.

\section{[Figure 1]}

Spectrally, large parts of Mare Insularum are influenced by basalt lavas of low to moderate $\mathrm{TiO}_{2}$ content on which ejecta of the craters Copernicus, Kepler, and Eratosthenes are superimposed (Hiesinger et al., 2003). The geologic map by Wilhelms and McCauley (1971) shows that most basalts of this region are Imbrian mare materials with some units showing characteristics of Eratosthenian mare (Em) material. The Hortensius domes have been described to be of Eratosthenian age due to apparent superposition on Imbrian mare material, but possibly contemporaneous with uppermost mare material (Wilhelms and McCauley, 1971), while some domes in the Milichius region are classified as Eratosthenian mare dome material (Emd) and included as part of an Em unit. The Em unit is described as a probably relatively thin cover of younger lava flows or pyroclastic materials over thicker accumulations of Imbrian mare material (Wilhelms and McCauley, 1971; Wenker, 1999).

The second dome field regarded in this study is the northern part of Mare Tranquillitatis (Fig. 1e). Some individual graben have mare domes situated directly next to them. Domes associated with graben along strike have been interpreted to be formed by dikes situated at very shallow depths below the surface, less than a few tens of me- 
tres, and may have penetrated the surface in places (Petrycki and Wilson, 1999). Rima Cauchy II shows further evidence of near-surface extrusion, such as numerous small domes parallel to the rille, interpreted as the surface manifestation of dike intrusion to a very shallow depth (Petrycki and Wilson, 1999).

North of Rima Cauchy another alignment of lunar mare domes is situated, here termed "Northern Tranquillitatis Alignment" (NTA). These aligned domes include the well-known edifices Diana and Grace as well as at least six more unnamed domes. This particular alignment of domes extending just at the southern end of Mons Esam is not visible in Lunar Orbiter and Clementine images but only in telescopic CCD images acquired at low solar altitude. The domes Diana and Grace were described by Weitz and Head (1999) using available topographic maps derived from Apollo 15-17 orbital stereo imagery. The Lunar Topophotomap LT 61A2S1 (50) shows detailed topography for these two domes (cf. also Section 3.3).

The domes associated with Rima Cauchy II are dated as Imbrian or Eratosthenian in age, while the volcanic craters also closely associated with the rille are dated as of Eratosthenian or Copernican age (Wilhelms, 1987). In the USGS lunar geologic map I-722, the NTA domes, including Diana and Grace, have been mapped as the five distinct units EImd, EIId, EIdd, EIrd, EIdc, on the basis of profile, roughness, and albedo.

The domes in the Cauchy dome field are approximately aligned parallel to the Cauchy rilles (Fig. 1e), demonstrating that they may have been emplaced along a fracture system (Wilhelms, 1972). Like the distribution of domes, this system of rilles is radial to the Imbrium basin and may have resulted from a reactivation of the structural weaknesses produced by the impact that formed the Imbrium basin. The Imbrium impact occurred $3.85 \mathrm{Ga}$ ago, creating fractures in the surrounding rock layers and spreading ejecta throughout the Cauchy region. In the classical model of dome formation it is assumed that the magma ascended in dikes which gained surface access at some points, eventually leading to effusion of lava (Petrycki and Wilson, 1999; Wilson and Head, 2003). The formation of dikes at depth requires a stress that greatly exceeds the strength of the host rock or a stress distribution producing a local stress intensity that exceeds its fracture toughness, the latter depending on tensile strength and ambi- 
ent stress (Rubin, 1993b). In this model, the plane of the dike is perpendicular to the direction of minimum compressive stress, leading to dikes following the same paths as pre-existing fractures. The seismic profiles obtained at the Apollo 12 and 14 landing sites indicate that impact-induced fractures in the lunar crust are closed at depths of $\sim 20 \mathrm{~km}$ (Wieczorek et al., 2001) and thus do not extend as far down as the mantle source zones of most dikes. But according to the model by Rubin (1993b) the dike orientations were guided by the same stress fields that caused the crustal fractures, leading to dikes extending radially with respect to the centres of the major basins. Dikes reaching shallow depths below the surface or erupting at some places led to the formation of a variety of volcanic features such as vents, cones, domes, pyroclastic deposits, and effusive flows (Petrycki and Wilson, 1999).

\section{[Figure 2]}

Like nearby Rupes and Rima Cauchy, the NTA domes are oriented radially with respect to the Imbrium basin (Figs. 1e and 2c) and were probably also formed by feeder dikes aligned due to the stress field that generated the associated crustal fractures.

Aligned volcanic features can also be found in the Mare Insularum and eastern Procellarum region (cf. Section 3). According to Spudis (1993), Mare Insularum lies inside an ancient, strongly degraded multi-ring impact basin. Wilhelms (1987) and Wieczorek and Phillips (1998) provide lunar mapping and lunar gravity interpretations, respectively, which indicate that the Procellarum basin, a roughly circular region which underlies Oceanus Procellarum, Sinus Roris, Mare Imbrium, and a number of smaller maria, reflects a very large basin forming event that predates all other identifiable old large basins. Cadogan (1975) postulates the existence of a large, ancient basin termed "Gargantuan basin". This possible basin is also studied by Whitaker (1981) and described as "Procellarum basin". De Hon (1979) examines the thickness of western mare basalts and the configuration of the western mare basins, relying on measurements of the exposed rim heights of craters partially buried by mare basalt. He subdivides the western maria into seven regions comprised of older, partially obliterated basins. Especially, the identification of a relatively thick lens of basalt centred at $36^{\circ} \mathrm{W}$ and $26^{\circ} \mathrm{N}$ indicates the presence of a pre-Imbrian basin, termed "Eastern Procellarum basin" by de Hon (1979). 


\section{Observations}

\subsection{Lunar Orbiter imagery: Dome alignments and elongated vents}

Lunar Orbiter high-resolution image IV-133-H2 (cf. Fig 2a) shows the mare domes in the Milichius/T. Mayer region. The corresponding image sections are shown in Fig. 2d. The names of the domes in this region are adopted from paper 1. A more comprehensive lunar dome catalogue has been published by Kapral and Garfinkle (2005). In this study, for the domes examined in paper 1 we adopt the data obtained in that work. An overview of the origin of the data analysed in this study is given in Table 1 . The selenographic coordinates of the examined domes are listed in Table 2.

\section{[Table 1] [Table 2] [Table 3]}

We found that the vents of the domes M3-M6, M10, and M15 are elongated towards an average azimuth angle of $63^{\circ} \pm 8^{\circ}$ (cf. Table 3). Fig. $2 \mathrm{~d}$ shows that the similarly elongated vent of dome $\mathrm{H} 7$ north of Hortensius E, visible in Lunar Orbiter image IV126- $\mathrm{H} 1$, is oriented towards $72^{\circ}$ azimuth. The dome pair M8 and M9 is aligned in nearly the same direction ( $65^{\circ}$ azimuth). The domes M3, M4, M10, and M15 are forming a chain of length $210 \mathrm{~km}$ which is aligned towards an azimuth angle of $68^{\circ}$. As a note of interest, several nearby mare ridges are running in about the same direction (Whitaker, 1981, cf. Fig. 1 therein). As apparent in Fig. 3, these preferential directions are approximately radial with respect to the location $18^{\circ} \mathrm{W}$ and $9^{\circ} \mathrm{N}$ of the Insularum basin (Spudis, 1993) and also with respect to the suspected Eastern Procellarum basin located at $36^{\circ} \mathrm{W}$ and $26^{\circ} \mathrm{N}$ according to de Hon (1979).

\section{[Figure 3]}

Some volcanic features in the Milichius/T. Mayer region display a second preferential direction. The vent of dome M1 is elongated towards an azimuth angle of $129^{\circ}$, and for the pair of cones MC1 the direction of alignment is $113^{\circ}$ (Fig. 2d). Hence, these features are oriented radially with respect to the Imbrium basin. Several other fissure-like objects in this region, which are, however, not associated with domes, are elongated in about the same direction.

Fig. 2b shows a section of Lunar Orbiter high-resolution image IV-133-H1, dis- 
playing the well-known dome suite immediately north of the $14.6 \mathrm{~km}$ diameter crater Hortensius, here termed H1-H6. All of them have pronounced circular summit crater pits.

The northern Mare Tranquillitatis domes Diana, Grace, and NTA3-NTA6 exhibit elongated vents, oriented towards the average azimuth angle $68^{\circ} \pm 18^{\circ}$, as apparent in Lunar Orbiter high resolution image IV-073-H2 (cf. Figs. 2c and 2d). The chain of the NTA domes has a length of $100 \mathrm{~km}$ and is running radially with respect to the Imbrium basin at an azimuth angle of $55^{\circ}$. Hence, like in the Milichius/T. Mayer region, the direction into which the vents are elongated approximately corresponds to the direction into which the chain of domes is aligned, where both preferential directions indicate a radial orientation towards the centre of a large impact basin.

\subsection{Clementine imagery and Lunar Prospector data: Surface composition}

The Clementine UVVIS multispectral image data were obtained at wavelengths of 415, 750, 900, 950, and $1000 \mathrm{~nm}$. We utilise the Clementine global mosaic generated by Eliason et al. (1999). In this data set, the corresponding UVVIS reflectances are normalised to an incidence angle of $30^{\circ}$ and an emission angle of $0^{\circ}$, and calibrated with respect to the laboratory spectrum of Apollo 16 sample 62331. We examined the extracted Clementine UVVIS data in terms of reflectance at $750 \mathrm{~nm}$, denoted by $R_{750}$, and the $R_{415} / R_{750}$ and $R_{950} / R_{750}$ spectral ratios (Weitz and Head, 1999; cf. also Gaddis et al., 2003). The size of the sample area on the lunar surface was set to $2 \times 2 \mathrm{~km}^{2}$.

The first studies aiming at the characterisation of lunar soil types were performed based on reflectance spectra acquired with earth-based telescopes (Adams and McCord, 1970; McCord et al., 1972; McCord and Adams, 1973). Variations in soil composition, maturity, particle size, and viewing geometry are indicated by the reflectance $R_{750}$ at $750 \mathrm{~nm}$ wavelength.

The second spectral parameter, the UV/VIS spectral ratio e. g. given by $R_{415} / R_{750}$, is correlated with the variations in $\mathrm{TiO}_{2}$ content of mare soils. A corresponding relation was established by Charette et al. (1974), revealing by comparison with the analysis of returned samples that units of very high $\mathrm{TiO}_{2}$ content occur in northwestern Mare 
Tranquillitatis, with decreasingly lower $\mathrm{TiO}_{2}$ content in northern Mare Tranquillitatis, south-western Mare Serenitatis, and central Mare Serenitatis. A comprehensive characterisation of spectral features attributable to titanium in lunar soils is provided by Burns et al. (1976). Later studies of $\mathrm{TiO}_{2}$ variations in this region confirmed and refined the strong correlation between UV/VIS spectral ratio and $\mathrm{TiO}_{2}$ content $(\mathrm{McCord}$ et al., 1976; Pieters, 1978; Melendrez et al., 1994; Staid et al., 1996). However, the Charette relation is much less reliable when regarding other lunar mare regions; for example, it fails to accurately predict the low $\mathrm{TiO}_{2}$ content of the basalts returned by the Luna 24 spacecraft. Relying on $\mathrm{TiO}_{2}$ abundance data obtained with the Lunar Prospector neutron spectrometer, Gillis and Lucey (2005) demonstrate that other factors such as ilmenite grain size or FeO content may give a significant contribution to the UV/VIS ratio. According to these analyses, $\mathrm{TiO}_{2}$ content is monotonously increasing with $R_{415} / R_{750}$ ratio, but the correlation is only moderate and the data display a strong scatter. Gillis and Lucey (2005) establish a trend with a higher slope, valid for $R_{415} / R_{750}$ ratios of larger than $\sim 0.62$ and a $\mathrm{TiO}_{2}$ content of more than 2 wt\%, represented e. g. by the Mare Tranquillitatis soils, and a distinct second trend with a lower slope, valid for smaller $R_{415} / R_{750}$ ratios and represented e. g. by several regions in Oceanus Procellarum.

The third spectral parameter, the $R_{950} / R_{750}$ ratio, is related to the strength of the mafic absorption band, representing a measure for the $\mathrm{FeO}$ content of the soil and being also sensitive to the optical maturity of mare and highland materials (Lucey et al., 1998).

\section{[Table 4] [Figure 4] [Figure 5]}

The dome M15 and the domes in northern Mare Tranquillitatis are not regarded in paper 1, except Grace, designated C7 in that work. The spectral parameters of these domes are listed in Table 4. Typical UVVIS spectra of domes in the Hortensius/Milichius/T. Mayer region and northern Mare Tranquillitatis along with the spectra of several locations in the nearby mare plains as indicated in Fig. $2 \mathrm{a}-\mathrm{c}$ are shown in Fig. 4. These examples illustrate that the mare domes are spectrally very similar to the surrounding mare plains. The spectral signatures of the complete examined set of domes are shown in Fig. 5. They are typical of mare soils (cf. Gaddis et al., 
2003). The $R_{750}$ vs. $R_{950} / R_{750}$ diagram (Fig. 5b) indicates that the FeO content is high and similar for all examined soils (Lucey et al., 1998, Fig. 3 therein). The $R_{750}$ and $R_{950} / R_{750}$ values are in the same range for the domes near Milichius and T. Mayer and for the NTA domes, indicating a high soil maturity for these regions. Lower values of $R_{950} / R_{750}$ between 0.99 and 1.0 are observed for Grace and NTA4, which is presumably due to the presence of small fresh impact craters on their surfaces.

For all mare domes examined in this study we have $0.58<R_{415} / R_{750}<0.62$, where the domes near Milichius and T. Mayer cover the lower half of the interval with $0.58<R_{415} / R_{750}<0.60$, while we have $0.60<R_{415} / R_{750}<0.62$ for the Hortensius and the NTA domes (cf. Fig. 5a). With these values, the data by Gillis and Lucey (2005) yield $0.5-1.5 \mathrm{wt} \% \mathrm{TiO}_{2}$ for the domes near Milichius and T. Mayer. For the Hortensius domes, only a loose upper limit of $4 \mathrm{wt} \% \mathrm{TiO}_{2}$ can be given (cf. Procellarum 2, 3, 4 soils in their Fig. 2) as the correlation with $\mathrm{TiO}_{2}$ content is very weak for the corresponding $R_{415} / R_{750}$ range between 0.60 and 0.62 . For the NTA domes we obtain 3-4 wt\% $\mathrm{TiO}_{2}$ when extrapolating the trend established for Mare Tranquillitatis by Gillis and Lucey (2005) towards $R_{415} / R_{750}$ values between 0.60 and 0.62 .

Additionally, we added the spectral parameters of the Gruithuisen and Mairan highland domes to Fig. 5. Compared to the mare domes, their soils exhibit high $R_{750}$ albedos between 0.14 and 0.2 , low $R_{415} / R_{750}$ values of $0.55-0.59$, and high $R_{950} / R_{750}$ values between 1.04 and 1.07. This behaviour indicates a substantially different soil composition of the highland domes, especially a very low $\mathrm{FeO}$ and $\mathrm{TiO}_{2}$ content, reflected by different rheologic conditions and feeder dike properties (cf. Sections 4.2 and 4.3).

A further important compositional parameter of lunar mare basalts is their Si content. Recent work by Berezhnoy et al. (2006) describes the determination of Si abundance based on Lunar Prospector gamma ray spectrometer data. Their calibration relies on a comparison between the elemental composition of landing sites measured by Lunar Prospector and the analysis of returned samples. However, the resolution of the Lunar Prospector gamma ray spectrometer data amounts to $150 \times 150 \mathrm{~km}^{2}$ per pixel and is thus very low. The Si abundance map by Berezhnoy et al. (2006) yields a Si content of 21.0 wt\% for the region around Hortensius, Milichius, and T. Mayer, 
while a slightly lower value of $20.3 \mathrm{wt} \%$ is derived for the region in which the NTA domes are situated. If we assume that $\mathrm{Si}$ is chemically bound as $\mathrm{SiO}_{2}$, this translates into $45.0 \mathrm{wt} \%$ and $43.5 \mathrm{wt} \% \mathrm{SiO}_{2}$, respectively.

\subsection{Ground-based observations: Morphometric dome proper- ties}

Telescopic CCD images of the dome fields examined in this study, all acquired under strongly oblique illumination, are shown in Fig. 1. They were taken with telescopes of 130 and $200 \mathrm{~mm}$ aperture. For image acquisition we employed a Philips ToUCam Pro CCD camera, an Atik CCD camera (both with $640 \times 480$ pixels image size and $5.6 \mu \mathrm{m}$ pixel size) and a Lumenera LU075M industrial CCD camera $(640 \times 480$ pixels image size, $7.4 \mu \mathrm{m}$ pixel size). Each image was generated by stacking several hundreds of video frames. For this purpose we made use of the Registax and Giotto software packages, employing a cross-correlation technique similar to the one described by Baumgardner et al. (2000). In that work, however, digitised analog video tapes were processed, while we directly acquired digital video frames. The scale of the images is between 300 and $600 \mathrm{~m}$ per pixel on the lunar surface. Due to atmospheric seeing, however, the effective resolution (corresponding to the width of the point spread function) is not much better than $1 \mathrm{~km}$. All images are oriented with north to the top and west to the left.

Fig. 1a, acquired on December 11, 2005, at 17:46 UT with a $200 \mathrm{~mm}$ reflector and a Philips ToUCam Pro CCD camera, shows an overview image of the Hortensius/Milichius/T. Mayer region. The domes M4 and M15, situated near T. Mayer C and D, and the surrounding rugged terrain are shown in Fig. 1b (May 07, 2006, 21:32 UT, $130 \mathrm{~mm}$ refractor with Lumenera LU075M CCD camera). The large dome M15 with its very low flank slope and its characteristic summit fissure is shown under an illumination angle of $2.0^{\circ}$ at larger scale in Fig. 1c, taken on February 08, 2006, at 02:26 UT with a $200 \mathrm{~mm}$ refractor and an Atik CCD camera. This dome does not appear in USGS geologic map I-515 of the T. Mayer region and was first reported by Lena et al. (2006a). The three aligned domes A4-A6 north of Arago in western Mare Tranquillitatis, which are well-known but rather elusive due to their low flank slopes, are apparent in Fig. 1d (May 03, 2006, 20:13 UT, 200 mm reflector, Lumen- 
era LU075M CCD camera) under an illumination angle of only $1.2^{\circ}$. They will be discussed for comparison purposes in Section 5.4. A large part of the northern half of Mare Tranquillitatis is covered by Fig. 1e, acquired on May 02, 2006, at 20:27 UT with a $200 \mathrm{~mm}$ reflector and a Lumenera LU075M CCD camera. In its northern part, this image displays the dome chain comprising Diana, Grace, and NTA1-NTA6, situated south-west of the $7 \mathrm{~km}$ diameter crater Lucian. Further south, the graben Rima Cauchy and the tectonic fault Rupes Cauchy along with the conspicuous domes C2 and C3 (Cauchy $\omega$ and $\tau$ ) and the less pronounced domes C1 and C4 are apparent. This image illustrates that the dome chain, Rima Cauchy, and Rupes Cauchy are all oriented in parallel, radially with respect to the Imbrium basin.

To determine the morphometric properties of lunar domes, we make use of an imagebased 3D reconstruction approach which relies on a combination of photoclinometry and shape from shading techniques as described in detail in paper 1. This method takes into account the geometric configuration of camera, light source, and the surface normal, as well as the reflectance properties of the surface to be reconstructed. We make use of the Lunar-Lambert reflectance function as described by McEwen (1991). Neither Lunar Orbiter images nor the high-resolution orbital images taken with hand-held and aerial cameras from the Apollo command modules are suitable for 3D reconstruction of lunar surface parts based on photometric methods. The reason is that these images were acquired on photographic film, such that the relation between incident flux and pixel greyvalue is nonlinear and unknown. The Clementine images are photometrically calibrated but acquired under high solar elevation angles, thus not revealing suble relief features like lunar domes. Hence, for generating the digital elevation map (DEM) of a dome we have to rely on telescopic CCD images.

[Figure 6]

From the DEM of a dome its height $h$ can be readily inferred. As an example, the DEM of dome NTA3 is shown in Fig. 6. The flank slope $\zeta$ is then defined as $\zeta=\arctan (2 h / D)$ with $D$ as the dome diameter. The dome volume $V$ is computed by integrating the DEM over an area corresponding to a circular region of diameter $D$ around the summit of the dome. In paper 1 it is pointed out that the relative standard error amounts to $10 \%$ for the inferred dome height $h$ and is better than $20 \%$ for the 
dome volume $V$.

[Table 2]

For this study, we adopt the morphometric values previously derived in paper 1 for the Hortensius/Milichius/T. Mayer domes (cf. Tables 1 and 2). The dome M15 has been reported more recently by Lena et al. (2006a). The morphometric properties of Diana, Grace, and NTA1-NTA6 were obtained based on the image shown in Fig. 1e. While no previous height or slope measurements of NTA1-NTA6 are available, the domes Diana and Grace appear in the high-resolution Lunar Topophotomap LT 61A2S1 (50). The Lunar Topophotomaps were derived by means of stereophotogrammetry from images acquired with modified aerial cameras from the Apollo 15-17 command modules. For Diana, this elevation map yields a height difference with respect to the surrounding mare plain of $80 \mathrm{~m}$ on the western and $50 \mathrm{~m}$ on the eastern flank. The corresponding values for Grace are $100 \mathrm{~m}$ on the western and $140 \mathrm{~m}$ on the eastern flank. Based on the described combined photoclinometry and shape from shading technique applied to our telescopic CCD image, we obtained height values of $70 \mathrm{~m}$ and $140 \mathrm{~m}$ for Diana and Grace, respectively, which is in good accordance with the result derived from orbital imagery. We did not adopt the morphometric values of Grace given in paper 1 but recomputed them based on Fig. 1e since in that work they were derived from an image of relatively low resolution acquired under a comparably high solar illumination angle.

\section{Conditions in the lunar interior governing dome formation}

In this section we will classify the examined mare domes in terms of the scheme by Head and Gifford (1980) and the scheme recently introduced in paper 1. Then we will estimate the rheologic conditions during the lava effusion process and divide the domes into three appropriate rheologic groups. Furthermore, we will derive the dimensions of the feeder dikes and determine on which time scales magma ascent and cooling in the dike occurred and to which extent magma evolution was relevant for mare dome formation. 


\subsection{Classification of the examined domes}

The most commonly used classification scheme for lunar domes is the one by Head and Gifford (1980). Their classes 1, 2 and 3 refer to volcanic edifices resembling terrestrial shield volcanoes. The domes with elongated vents in the Milichius and T. Mayer region, i. e. M1-M6, M10, M15, and H7, belong to their class 2, displaying a large diameter, low flank slope, and pancake-shaped cross-section. The same is true for H1 and H3 near Hortensius and Diana and Grace in northern Mare Tranquillitatis. The domes H2, H4-H6, M8, M9, M11 and M12 have somewhat smaller diameters and steeper flank slopes and thus belong to class 1 . With their extremely low profiles, the domes NTA1NTA6 and also M7 are of class 3. Classes 4-7 are essentially based on the morphologic setting of the domes. They represent domes assiciated with mare ridges and arches, domes originating from lava mantling of pre-existing highland topography, highland domes with steep flanks and high albedos, and complex edifices like the Marius domes, respectively. None of the mare domes examined in this study belongs to classes 4-7.

In paper 1, a classification scheme for lunar domes is devised which is based on the inferred spectral and morphometric quantities. To determine the class of a dome, the three spectral features $R_{750}, R_{415} / R_{750}$, and $R_{950} / R_{750}$ along with the five morphometric features flank slope, diameter, height, edifice volume, and form factor are projected into a subspace of $M$ dimensions of the original parameter space of dimension $N=$ 8 by means of a principal component analysis (PCA). The parameters of the PCA are determined in paper 1 based on a set of 33 effusive and 6 intrusive mare domes, including several domes regarded in this study. Setting the dimension of the subspace to $M=3$ retains $87 \%$ of the information contained in the original parameter space of dimension $N=8$. In this subspace, the examined domes form several clusters which can be identified based on the correspondingly transformed dome coordinates $\left(P_{1}, P_{2}, P_{3}\right)$ as shown in Fig. 7. Domes belonging to the same cluster share certain characteristic spectral and morphometric properties.

\section{[Figure 7]}

The original classification scheme as outlined in paper 1 comprises four classes AD. Classes A-C denote morphologically simple and likely monogenetic edifices which do not show individual lava flows or other traces of several eruption events. Class A 
domes display small to moderate diameters between 5 and $13 \mathrm{~km}$ with very low flank slopes and volumes and were formed by spectrally strongly blue lavas of high $R_{415} / R_{750}$ spectral ratio. Class B domes have small to moderate diameters between 6 and $15 \mathrm{~km}$ and were formed from lavas of low to moderate $R_{415} / R_{750}$ spectral ratio. Steep and voluminous class $\mathrm{B}$ domes with flank slopes larger than $2^{\circ}$ are assigned to subclass $\mathrm{B}_{1}$ while the lower edifices with flank slopes below $2^{\circ}$ make up subclass $\mathrm{B}_{2}$. Class $\mathrm{C}$ domes are larger (diameter between 8 and $20 \mathrm{~km}$ ) with relatively low flank slopes typically below $2^{\circ}$. Edifices formed from spectrally red lavas of low to moderate $R_{415} / R_{750}$ ratio, having large diameters between 13 and $20 \mathrm{~km}$ and large edifice volumes of several tens of $\mathrm{km}^{3}$, are assiged to subclass $\mathrm{C}_{1}$, while spectrally bluer domes of moderate to high $R_{415} / R_{750}$ ratio, smaller diameters between 8 and $13 \mathrm{~km}$, and lower edifice volumes of less than $17 \mathrm{~km}^{3}$ are assigned to subclass $\mathrm{C}_{2}$. A further group made up by three domes with exceptionally small diameters below $6 \mathrm{~km}$ and very low edifice volumes below $1.2 \mathrm{~km}^{3}$ is described as representing intermediate objects between lunar domes and cones but remains unnamed in paper 1. In this study, we introduce class E for these domes. In analogy to class $\mathrm{B}$, we further subdivide class $\mathrm{E}$ into subclasses $\mathrm{E}_{1}$ and $\mathrm{E}_{2}$, denoting the steep-sided (flank slope larger than $2^{\circ}$ ) and the shallow edifices of this class, respectively. Class D represents edifices of more complex morphology, displaying large diameters, low flank slopes, and very high edifice volumes, such as the well-known domes Arago $\alpha$ and $\beta$ which probably formed during several effusion phases. Table 5 summarises the spectral and morphometric dome properties associated with the different mare dome classes, where the class-specific ranges for the $R_{415} / R_{750}$ spectral ratio were adopted from Lena et al. (2006b). For completeness, we have added a further class, G, to Table 5, representing the Gruithuisen and Mairan highland domes and corresponding to class 6 of the Head and Gifford (1980) scheme.

\section{[Table 5]}

Fig. 7 illustrates the assignment of the examined set of mare domes to the previously defined classes in the principal component space of dimension $M=3$. For the domes in the Milichius/T. Mayer region we adopt the class assignments obtained in paper 1. The domes displaying elongated vents, with their spectrally red soils, moderate to large diameters, and low flank slopes belong to the classes $\mathrm{C}_{1}$ (M1, M3, M5, M6, M10, 
M15) and $\mathrm{B}_{2}(\mathrm{M} 4, \mathrm{H} 7)$. The dome M2 is somewhat steeper and has no elongated vent but still belongs to class $\mathrm{C}_{1}$. The low dome $\mathrm{H} 1$ near Hortensius is comprised by class $\mathrm{B}_{2}$, while the domes M7-M9 make up the newly defined class E, where M7 belongs to class $\mathrm{E}_{2}$ and M8 and M9 to class $\mathrm{E}_{1}$. The comparably steep-sided domes H2-H6 near Hortensius as well as M11 and M12 near T. Mayer and Milichius, respectively, displaying similarly steep flank slopes, belong to class $\mathrm{B}_{1}$.

Based on the spectral and morphometric data obtained in this study, the dome Grace in northern Mare Tranquillitatis clearly belongs to class $\mathrm{C}_{2}$, while its neighbour Diana with its smaller diameter, lower flank slope, and very low edifice volume is situated between classes $\mathrm{A}, \mathrm{C}_{2}$, and $\mathrm{E}_{2}$. The large but very low dome NTA1, a typical class $\mathrm{C}$ representative with respect to its morphometric properties, consists of material of intermediate $R_{415} / R_{750}$ ratio and is situated between classes $\mathrm{C}_{1}$ and $\mathrm{C}_{2}$. Due to their small diameters below $6 \mathrm{~km}$ and low flank slopes, domes NTA2 and NTA5 are intermediate objects between classes $\mathrm{A}$ and $\mathrm{E}_{2}$. The domes NTA3 and NTA4 are smaller and have moderate diameters typical of class $\mathrm{B}_{2}$ and low flank slopes typical of class $\mathrm{C}_{1}$, such that they are situated between these two classes. Dome NTA6 displays morphometric properties typical of class A, but it is located near the margin of class A towards class $\mathrm{E}_{2}$ in Fig. 7 due to its spectrally atypically red soil. To give an impression of the horizontal and vertical extent of the mare dome classes $\mathrm{A}-\mathrm{C}$ and $\mathrm{E}$ denoting monogenetic edifices, Fig. 8 shows images and cross-sections of typical representatives of these classes, also illustrating the intermediate domains between them.

[Figure 8]

Our classification results for the NTA domes show that classes A and E are not detached from each other in the space of spectral and morphometric features. While the domes of both classes display relatively small diameters and very low edifice volumes, they span a continuous range of properties from spectrally strongly blue (class A) to red (class E) soils and from very low (class A) to steep (class $\mathrm{E}_{1}$ ) flank slopes. The class E domes represent the smallest volcanic edifices formed by effusive mechanisms observed to date. Lunar cones, which are assumed to have formed essentially from explosive eruptions (Wood, 1979), have diameters still smaller by a factor of at least 2-3 and volumes lower by nearly an order of magnitude, compared to the class E domes. 


\section{ACCEPTED MANUSCRIPT}

Classes $\mathrm{B}_{2}$ and $\mathrm{C}_{1}$ represent another continuous range of spectral and morphometric properties, from rather small to very large diameters and edifice volumes, always exhibiting spectrally red soils and low flank slopes below $2^{\circ}$ (cf. Fig. 8). We will show that the formation of class $\mathrm{B}_{2}$ and $\mathrm{C}_{1}$ mare domes was governed by similar physical conditions during the lava effusion process.

\subsection{Rheologic conditions during dome formation}

Wilson and Head (2003) characterise a lunar dome in terms of its rheologic properties, represented by the the lava viscosity $\eta$, the lava effusion rate $E$, i. e. the erupted volume per second, and the duration $T_{e}$ of the effusion process. These parameters are closely related to the physical and compositional properties of the erupted magma.

\subsubsection{Basic mechanisms of magma evolution}

The three main types of terrestrial lava are basaltic, andesitic, and rhyolitic. Terrestrial basaltic flows erupt at temperatures between 1000 and $1400^{\circ} \mathrm{C}$. The viscosity of basaltic lava amounts to $10^{2}-10^{3} \mathrm{~Pa} \mathrm{~s}$ at the liquidus temperature (Murase and McBirney, 1970). Basaltic lavas are high in $\mathrm{Ca}, \mathrm{Mg}$, and Fe, and low in $\mathrm{Si}, \mathrm{Na}$, and $\mathrm{K}$. The high temperature and low silica content allow basaltic lavas to flow readily. Rhyolitic lavas display viscosities of $\sim 10^{6} \mathrm{~Pa}$ s at their liquidus temperature (Murase and McBirney, 1970). These lavas are rich in $\mathrm{K}, \mathrm{Na}$, and $\mathrm{Si}$, at the same time showing a low $\mathrm{Ca}, \mathrm{Mg}$, and Fe content. Typically they erupt at comparably low temperatures between 800 and $1000{ }^{\circ} \mathrm{C}$. Terrestrial andesitic lavas have a composition intermediate between basaltic and rhyolitic lava. Andesite is hence classified as an intermediate lava producing flows more readily than rhyolitic lava, but not as readily as basaltic lava. Its viscosity at liquidus temperature obtains values around $\sim 10^{4} \mathrm{~Pa}$ s. The density of terrestrial basaltic, andesitic, and rhyolitic lava typically amounts to 2700-2800, 2500, and $2400 \mathrm{~kg} \mathrm{~m}^{-3}$, respectively (Spera, 2000).

Terrestrial basaltic lavas have a typical $\mathrm{SiO}_{2}$ content of $51 \%$, while it is $59 \%$ for andesitic lavas and $72 \%$ for rhyolitic lavas. In the series basaltic-andesitic-rhyolitic, the $\mathrm{TiO}_{2}$ content decreases from $1.5 \mathrm{wt} \%$ for basaltic lavas to $0.8 \mathrm{wt} \%$ for andesites. The abundances of $\mathrm{Ca}, \mathrm{Mg}$, and Fe decrease in a similar manner. Compared to terrestrial 
lavas, lunar lavas may display a much higher $\mathrm{TiO}_{2}$ content. For example, in certain lunar mare regions such as central and western Mare Tranquillitatis, the $\mathrm{TiO}_{2}$ content of the basaltic lavas may be as high as 11 wt\% (Staid et al., 1996).

In the following, we will outline the essential mechanisms governing the interdependencies between magma evolution, composition, and viscosity. These principles were inferred by the analysis of terrestrial lavas but are supposed to apply also to the Moon and the other terrestrial planets. As a general rule, the viscosity of a magma depends on eruption temperature, pressure, and chemical composition. It influences the eruption rate, the distance the lava will travel, the morphology of the volcanic edifices, and the eruption style (Basaltic Volcanism Study Project, 1981). The amount of $\mathrm{SiO}_{2}$ controls the viscosity due to polymerisation of molecules. This means that the molecules cluster and form larger complexes by repeated linking of identical molecular groups. Because of their low $\mathrm{Si}$ and $\mathrm{Al}$ content and high $\mathrm{Fe}$ and $\mathrm{TiO}_{2}$ content, most lunar basalt lavas were characterised by higher temperatures, lower viscosities, and higher densities than terrestrial basalt lavas (Williams et al., 2000).

Temperature has a strong influence on lava viscosity. As temperature increases, viscosity decreases, an effect particularly evident in lava flows. For a temperature $T$ above the liquidus temperature, magma viscosity is commonly described in terms of the Arrhenian model

$$
\eta=\eta_{0} \exp \left[\left(E_{a}+p V_{a}\right) / R T\right]
$$

(Spera, 2000). In Eq. (1), $p$ is the magma pressure, $\eta_{0}$ the asymptotic viscosity at infinite temperature, $E_{a}$ the activation energy of a viscous flow, which is constant for an Arrhenian fluid, $V_{a}$ the activation volume for a viscous flow, and $R$ the gas constant. For example, an increase in temperature from 1100 to $1300{ }^{\circ} \mathrm{C}$ decreases the viscosity of basaltic lava by typically an order of magnitude (Spera, 2000).

An initially fluid pure melt that segregates from its source region becomes an increasingly viscous, crystal-rich (and sometimes also bubble-rich) fluid as it cools down while approaching the surface. This process is termed "evolution" of the magma (Marsh, 2000; Schmincke, 2004). At subliquidus magma temperatures, viscosity strongly increases due to the increase of crystallinity and the change of melt composition as a result of crystallisation (Marsh, 2000). The effect of the presence of 
crystals can be estimated by the Einstein-Roscoe equation

$$
\frac{\eta(\phi)}{\eta(0)}=\left(1-\frac{\phi}{\phi_{m}}\right)^{-n}
$$

where $\phi$ denotes the crystal fraction in the magma and $\phi_{m}$ the maximum possible crystal fraction leading to saturation of the magma with crystals. Commonly accepted empirical parameter values are $\phi_{m}=0.6$ and $n=2.5$ (Marsh, 1981; Sato, 2005). In real magmas, however, the effect of crystallinity on magma viscosity may be several times larger than predicted by Eq. (2) (Sato, 2005), especially for values of $\phi / \phi_{m}$ close to 1 (Lepage and Pearce, 2002). Hence, crystallisation can readily account for an increase of viscosity by several orders of magnitude relative to its value at liquidus temperature. Crystallisation is favoured by a low magma rise speed due to the long time the magma needs to reach the surface, implying a long period of slow motion and gentle cooling (cf. Section 4.3).

During crystallisation, the $\mathrm{SiO}_{2}$ content of the remaining melt increases, which may lead to a further increase of viscosity by several orders of magnitude. Especially for long durations of the effusion process, another silica-rich component may be introduced into the magma by assimilation of crustal wallrock (Spera, 2000). The resulting heat transfer from the magma into the wallrock is a factor that again increases the magma viscosity.

\subsubsection{Rheologic modelling of lunar domes based on their morphometric properties}

For the lunar mare domes regarded in this study, it is appropriate to assume that they were formed by extrusion of magma onto a flat plane spreading in all directions from the vent, in contrast to lava flows resulting from lava extrusion onto an inclined surface. A quantitative treatment of such dome-forming eruptions is given by Wilson and Head (2003), whose approach we will follow here. They treat the cooling magma as a Bingham plastic characterised by the yield strength $\tau$ and the plastic viscosity $\eta$. The yield strength is given by

$$
\tau=\frac{0.323 h^{2} \rho g}{D / 2}
$$


where $\rho$ is the lava density, for which Wilson and Head (2003) assume and justify a value of $2000 \mathrm{~kg} \mathrm{~m}^{-3}, g=1.63 \mathrm{~m} \mathrm{~s}^{-2}$ the acceleration due to gravity, $h$ the height of the dome, and $D$ its diameter. The plastic viscosity can be estimated by the empirical relation

$$
\eta(\tau)=6 \times 10^{-4} \tau^{2.4}
$$

where $\tau$ is expressed in $\mathrm{Pa}$ and $\eta$ in $\mathrm{Pa}$ s. Assuming a higher density $\rho$ will increase the viscosity by a constant factor. For the high magma density of $\rho=2800 \mathrm{~kg} \mathrm{~m}^{-3}$, this factor amounts to 2.2, compared to the values obtained with $\rho=2000 \mathrm{~kg} \mathrm{~m}^{-3}$, which is not too significant when regarding the broad range of viscosities inferred for the examined set of mare domes. Hence, we compute the lava viscosities for $\rho=$ $2000 \mathrm{~kg} \mathrm{~m}^{-3}$, but in the subsequent determination of dike properties (cf. Section 4.3.2) we will consider the effects of higher density and thus viscosity values.

An estimate of the lava effusion rate $E$ is obtained based on the assumption that the advance of the front of a flow unit is limited by cooling once a critical depth of penetration of the cooled boundary layer into the flow is reached. For a dome with a parabolic cross-section, Wilson and Head (2003) derive the expression

$$
E=\frac{0.323^{1 / 2} 300 \kappa(D / 2)^{2}}{0.65^{5 / 2} 0.72 h}
$$

with $\kappa \approx 10^{-6} \mathrm{~m}^{2} \mathrm{~s}^{-1}$ as the thermal diffusivity of the lava and $E$ measured in $\mathrm{m}^{3} \mathrm{~s}^{-1}$. The duration $T_{e}$ of the lava effusion process amounts to

$$
T_{e}=V / E
$$

Eqs. (3)-(6) are valid for domes that formed from a single flow unit (monogenetic volcanoes). Otherwise, the computed values for $\tau, \eta$, and $E$ are upper limits to the respective true values.

\subsubsection{Definition of rheologic groups}

The inferred rheologic properties of the examined mare domes are listed in Table 6 (cf. also paper 1). Three distinct rheologic groups can be established, which are clearly apparent in the diagrams in Fig. 9, essentially defined by the lava viscosity $\eta$.

[Table 6] [Figure 9] 


\section{ACCEPTED MANUSCRIPT}

The first rheologic group, denoted by $\mathrm{R}_{1}$, comprises the domes M1, M3-M6, M10, M15, and H7 with their elongated vents in the Milichius/T. Mayer region as well as Diana and Grace in northern Mare Tranquillitatis. They are typically characterised by lava viscosities between about $10^{4}$ and $10^{6} \mathrm{~Pa}$ s, high effusion rates between 100 and $700 \mathrm{~m}^{3} \mathrm{~s}^{-1}$, and intermediate durations of the effusion process between less than 1 year and 3 years. The dome M7, displaying a circular vent, was also added to this group due to its consistent rheologic properties. Therefore, it is depicted by the same up-triangle symbol as the domes in the Milichius/T. Mayer region with elongated vents in Figs. 5, 7, 9, and 12-14.

The second rheologic group, $\mathrm{R}_{2}$, is made up by the very shallow domes NTA1NTA6 in northern Mare Tranquillitatis with their low lava viscosities between $10^{2}$ and $10^{4} \mathrm{~Pa} \mathrm{~s}$, their high effusion rates that may still exceed those inferred for group $\mathrm{R}_{1}$ (up to $1000 \mathrm{~m}^{3} \mathrm{~s}^{-1}$ ), and their very short durations of the effusion process between 2 and 10 weeks.

The third rheologic group, $\mathrm{R}_{3}$, consists of the comparably steep-sided domes H1-H6 near Hortensius and M2, M8, M9, M11, and M12 in the Milichius/T. Mayer region. For these domes we inferred typical lava viscosities of several $10^{6} \mathrm{~Pa}$ s but also values of several $10^{7} \mathrm{~Pa}$ s for the steep and voluminous domes H5 and H6. Effusion rates are between $25 \mathrm{~m}^{3} \mathrm{~s}^{-1}$ for the small edifices of M8 and M9 and reach $100 \mathrm{~m}^{3} \mathrm{~s}^{-1}$ for the domes near Hortensius, while the duration of the effusion process is always longer than 1 year, even for M8 and M9, and reach values as high as 18 years.

A pictorial description of the rheologic groups $R_{1}-R_{3}$ in terms of the threedimensional shape characteristics of the dome edifice and the inferred dike geometry (cf. Section 4.3) is given in Fig. 10.

[Figure 10]

Some rheologic properties derived for several members of group $\mathrm{R}_{3}$, especially $\mathrm{H} 5$ and H6, resemble those obtained by Wilson and Head (2003) for the Gruithuisen and Mairan highland domes (cf. Table 6). The inferred lava viscosities have large values of up to $\sim 10^{9} \mathrm{~Pa}$ s for Gruithuisen $\delta$ and NW and Mairan T, while the viscosity values for Mairan "middle" and "south" are around $2 \times 10^{8} \mathrm{~Pa}$ s and thus only slightly higher than those inferred for the mare domes H5 and H6. The effusion rates of the 
highland domes span a broad interval between 5 and $120 \mathrm{~m}^{3} \mathrm{~s}^{-1}$. For several mare domes belonging to rheologic groups $R_{1}$ and $R_{3}$ we obtain similar effusion rates. For the highland domes, the durations of the effusion process span a range between 9 and 45 years, which is well above all values derived for the examined mare domes except H5 and H6.

A comparison with the mare dome classification results of Section 4.1 shows that the domes of rheologic group $R_{1}$ belong to classes $B_{2}, C$, and $E_{2}$, those of group $R_{2}$ are situated between classes $\mathrm{A}$ and $\mathrm{E}_{2}$, and the rheologic group $\mathrm{R}_{3}$ comprises domes of classes $\mathrm{B}_{1}$ and $\mathrm{E}_{1}$. Accordingly, we find that beyond dividing the domes into appropriate spectral and morphometric classes, our classification scheme also reflects the rheologic conditions valid during dome formation.

\subsubsection{Mechanisms behind the observed range of magma viscosities}

None of the examined mare domes shows a strong spectral contrast with respect to its surrounding mare lava, indicating no significant differences in soil composition. A basaltic composition was determined for all lunar samples returned from landing sites such as Apollo 11 situated in mare regions (Basaltic Volcanism Study Project, 1981).

The differences in lava viscosity between the Milichius/T. Mayer region and northern Mare Tranquillitatis may in part be due to a higher $\mathrm{TiO}_{2}$ content of the NTA domes indicated by their spectrally bluer appearance (Melendrez et al., 1994). Indeed, a correlation between inferred lava viscosity and $R_{415} / R_{750}$ spectral ratio is found in paper 1 , but this correlation is not strong, indicating on the one hand that the correlation between $R_{415} / R_{750}$ spectral ratio and $\mathrm{TiO}_{2}$ content is weak when several mare regions broadly distributed across the Moon are regarded (Gillis and Lucey, 2005), on the other hand that the lava viscosities are governed by factors beyond $\mathrm{TiO}_{2}$ content.

A difference in Si content between the Milichius/T. Mayer region and northern Mare Tranquillitatis has been inferred from Lunar Prospector data by Berezhnoy et al. (2006) (cf. Section 3.2). It is questionable, however, if the reported relative difference of only $3.3 \%$ can be responsible for the inferred strong differences in lava viscosity between these two regions. Probably one would have to postulate larger differences in Si content on smaller scales of significantly less than $150 \mathrm{~km}$, the resolution of the Si map 
presented by Berezhnoy et al. (2006), which are not revealed by the Lunar Prospector gamma spectrometer data. On the other hand, on large scales the Si content appears to be identical for the Milichius/T. Mayer and the Hortensius region, while we found significant differences in the viscosities of the lavas that formed the domes in these regions.

Murase and McBirney (1970) found that the mare plains were formed by lava flows of very low viscosity around $1 \mathrm{~Pa}$. The viscosity of terrestrial basaltic lava at temperatures above the liquidus temperature is essentially governed by Eq. (1) and rarely exceeds values of $\sim 10^{2}-10^{3} \mathrm{~Pa}$ s. Hence, the broad range of lava viscosities between $10^{2}$ and $10^{7} \mathrm{~Pa}$ s inferred for the mare domes examined in this study implies that the lavas forming the domes of the rheologic groups $\mathrm{R}_{1}$ and $\mathrm{R}_{3}$ erupted at subliquidus temperatures, where the viscosity is mainly characterised by the crystal content according to the Einstein-Roscoe equation (2).

Assimilation of and heat transfer to crustal wallrock during magma ascent (Spera, 2000) is a possible mechanism that may have decreased the magma temperature and increased its viscosity during ascent to the surface. The fraction of assimilated wallrock, however, cannot be significant, since otherwise a corresponding spectral signature would have to be apparent due to the strong differences in bulk composition between mare lava and crustal material.

Hence, we assume that the main mechanism responsible for the high lava viscosities inferred for the Hortensius/Milichius/T. Mayer mare domes but also for Diana and Grace in northern Mare Tranquillitatis is the evolution of "primitive" basaltic magma during ascent to the surface. The required values of $\phi / \phi_{m}$ are around 0.8-0.9 according to Eq. (2), leading to a viscosity increase of $2-3$ orders of magnitude. For $\phi / \phi_{m}$ close to 1 , experimental evaluations have shown that the increase of viscosity may even be higher than predicted by Eq. (2) (Lepage and Pearce, 2002), also depending on the shape of the crystals (Sato, 2005). In the following section we will examine in more detail the physical conditions under which the ascent of magma and its evolution may have occurred. 


\subsection{Properties of feeder dikes}

\subsubsection{Mechanisms governing the ascent of basaltic magma}

Most petrologic models of lunar basaltic magmas suggest an origin by partial melting at 200-400 km depth (Ringwood and Kesson, 1976). A classical model predicts that basaltic melts are less dense than the lunar mantle but denser than the overlying crust. Hence, basaltic diapirs would rise buoyantly through the lunar mantle, but would stall at the base of the crust and would not erupt onto the surface if they simply followed fracture zones in the crust (Head and Wilson, 1992; Wilson and Head, 1996). Without an excess pressure in the source region, the magma was able to rise above the base of the crust to a distance where the negative buoyancy component from the magma above the crust-mantle boundary compensated the positive buoyancy from the magma below the boundary. The excess pressure required to propagate a dike to the surface is of the order $15 \mathrm{MPa}$ for $\mathrm{a} \sim 64 \mathrm{~km}$ thick nearside crust and about $20 \mathrm{MPa}$ for a $\sim 86 \mathrm{~km}$ thick farside crust. To erupt magma onto the surface, slightly higher pressures of 21 and $28 \mathrm{MPa}$, respectively, are required. The excess pressure occurs as a consequence of the volume increase during partial melting. In the nearside case, the corresponding average pressure gradient amounts to $328 \mathrm{~Pa} \mathrm{~m}^{-1}$. These conditions correspond to dike widths of a few to several hundred metres. This model predicts that volcanic material should preferentially occur on the lunar nearside where the crust is thinner and more dikes can reach the surface (Wilson and Head, 1996).

The internal structure of the Moon has been studied based on Clementine data by Zuber et al. (1994). Wieczorek and Phillips (1998) derive a dual-layered model of the lunar crust and estimate the thickness of the lower and the upper crust based on the analysis of gravity anomalies. Wieczorek et al. (2001) argue that also basaltic magmas may have been positively buoyant in the lower lunar crust and show that since the lunar crust becomes more mafic with depth, basaltic magma should be less dense than the material of the lower crust. Hence, in places where the upper anorthositic crust was removed by an impact event, basaltic magma could have been driven to the surface by its positive buoyancy alone. This assumption is supported by the observation that

mare basalts are present where geophysical models of crustal thickness predict the upper crust to be absent. 
A driving pressure gradient of $g \Delta \rho \approx 320 \mathrm{~Pa} \mathrm{~m}^{-1}$ is obtained assuming a density difference of $\Delta \rho \approx 200 \mathrm{~kg} \mathrm{~m}^{-3}$ between the lower crust and magmas of low $\mathrm{TiO}_{2}$ content at liquidus temperature (Wieczorek et al., 2001). This value is very similar to the magnitude of the excess pressure gradient required in the model by Wilson and Head (1996). For denser magmas of higher $\mathrm{TiO}_{2}$ content at liquidus temperature, the model by Wieczorek et al. (2001) yields a pressure gradient due to positive buoyancy in the lower crust which is smaller by about a factor of two. Especially in the case of Oceanus Procellarum with its extended plains of high- $\mathrm{TiO}_{2}$ mare basalts, where modelling results indicate a thickness of the upper crust of up to 15-20 km (Wieczorek and Phillips, 1998; Wieczorek et al., 2006), it appears questionable if buoyancy alone is able to erupt the magma onto the surface if a magma temperature close to the liquidus point is assumed. Hence, Wieczorek et al. (2001) put forward the hypothesis that the ascending magma was superheated to about $1700^{\circ} \mathrm{C}$, leading to a density low enough to give rise to a positive buoyancy even in the upper crust.

With respect to the numerical results obtained with the dike model employed in this section, only the value of the pressure gradient driving the ascending magma is important but not the physical mechanism that generates it. We have shown above that assuming realistic values for the crustal and magma densities will lead to comparable values for the driving pressure gradient, independent of whether the crustal model by Head and Wilson (1992) or the one by Wieczorek et al. (2001) is used.

Magma ascent is related to impact-induced fracture and fault zones, with the location of conduits having been affected by impact structures, or it may result from the reactivation of pre-existing pre-Imbrian faults produced by the impact that formed the Imbrium basin. It is unlikely that basin-induced fractures would have remained open for the extended periods of time (several hundred million years) which are indicated for extrusion of lavas by radiometrically dated samples and crater counts (Hiesinger et al., 1999). Previous studies have shown that the maximum thickness of the crust where basalts occur is $50-60 \mathrm{~km}$ and imply that crustal thickness is a limiting factor for the eruption of lunar basalts onto the surface (Yingst and Head, 1997; Head and Wilson, 1996; Scott and Wilson, 2001). Wieczorek et al. (2006) obtain thicknesses of the upper crust of $22 \mathrm{~km}$ and $32 \mathrm{~km}$ and total crustal thicknesses of $50 \mathrm{~km}$ and $55 \mathrm{~km}$ for the 
Hortensius/Milichius/T. Mayer region and northern Mare Tranquillitatis, respectively. Ascending magmas preferentially extrude to the surface where the crust is thin, i. e. on the lunar nearside or in the impact basins. On the farside the crustal thickness is larger and therefore the magmas stalled and cooled in dikes before they reached the surface. On the basis of these observations it can be concluded that in areas with a thinner crust dikes could still reach the surface later in lunar history whereas in other regions the dikes stalled in the crust and could not propagate to the surface.

\subsubsection{Modelling of dike geometries}

Mare volcanic eruptions are fed from source regions at the base of the crust or deeper in the lunar mantle. According to Wilson and Head (1996), some dikes intruded into the lower crust while others penetrated to the surface, being the sources for extensive outpourings of lava. Thus the surface manifestation of dike emplacement in the crust is depending on the depth below the surface to which the dike penetrates. Wilson and Head (1996) state that if a dike does not propagate near the surface but stalls at greater depth, the strain will be insufficient to cause any dislocation near the surface. If a dike propagates at intermediate depths the strain will cause extensional deformation, eventually leading to graben formation. On the contrary, if a dike propagates at shallow depth and gains surface access at some points, a subsequent lava effusion will occur and the surface manifestation of the dike will be a fracture. Depending on the magma density relative to the density of the crust and the mantle, and also on the stress state of the lithosphere, some dikes erupt at the surface while others penetrate to depths shallow enough to produce linear graben.

In the scenario of dikes producing effusion of lava, an important parameter is the magma rise speed $U$ at which the dike propagates. Thus, the value of $U$ is governed by a combination of the pressure in the dike, the buoyancy and the viscosity of the magma, and the dimensions of the dike. The rise speed $U$ along with the dike width $W$ and its length $L$ will influence the effusion rate when the dike gains surface access. According to Wilson and Head (2003), the magma rise speed is found by balancing the driving vertical pressure gradient $d p / d z$ against the wall friction, taking into account 
the need to overcome the yield strength $\tau$ :

$$
U=\frac{W^{2}}{12 \eta}\left[\frac{d p}{d z}-\frac{2 \tau}{W}\right]
$$

For the examined set of mare domes we adopt the value $d p / d z=328 \mathrm{~Pa} \mathrm{~m}^{-1}(\mathrm{cf}$. Section 4.3.1). For the Gruithuisen and Mairan highland domes, Wilson and Head (2003) assume no excess pressure but a pressure gradient $d p / d z=g\left(\rho_{c}-\rho\right)$ which is due to the positive buoyancy of the magma, with $\rho_{c}$ as the density of the crustal material and $\rho$ as the magma density. They arrive at a value of $d p / d z=1300 \mathrm{~Pa} \mathrm{~m}^{-1}$. A positive buoyancy can be assumed in the case of the highland domes since they were formed from non-basaltic magma which may be less dense than the crustal material. In the case of basaltic magma reaching the bottom of the lunar crust, the two models of magma ascent discussed in Section 4.3.1 yield similar values for the pressure gradient $d p / d z$ although different underlying mechanisms are assumed.

The magma rise speed $U$, the dike geometry defined by the width $W$ and the length $L$, and the eruption rate $E$ are related by

$$
E=U W L
$$

However, $L$ and $W$ are not independent. A detailed model for the dependence between lava viscosity and the ratio $L / W$ is suggested by Rubin (1993a) which yields a solution for the ratio $L / W$, regarding a pressurised dike propagating in a linear viscoelastic medium. In this model, the first essential parameter governing the growth of the dike is $p_{0} / G$, representing a measure for the elastic response of the host rock, where $p_{0}$ is the magma pressure at the dike entrance minus the least compressive stress in the host rock and $G$ the elastic stiffness of the host rock. The second parameter is $\eta / \eta_{r}$, where $\eta$ is the magma viscosity and $\eta_{r}$ the host rock viscosity. Rubin (1993a) points out that the value of $p_{0} / G$ is situated between $10^{-4}$ and $10^{-3}$. Wilson and Head (2003), who also apply this model, assume $\eta_{r}=10^{18} \mathrm{~Pa}$ s for their estimation of the dike properties of the Gruithuisen and Mairan highland domes and arrive at $L / W=200$ for the inferred lava viscosities around $5 \times 10^{8} \mathrm{~Pa} \mathrm{~s}$, which corresponds to setting $p_{0} / G=10^{-3.5}$. Fig. 11 shows the relation between magma viscosity $\eta$ and the ratio $L / W$ across the broad range of lava viscosities inferred for the mare domes. The bend of the curve reflects the transition from essentially viscous to essentially elastic interaction between 
the magma in the dike and the host rock. Using the determined value of $L / W$ and inserting Eq. (8) into Eq. (7) we obtain the relation

$$
W^{4}=\frac{12 \eta E}{(L / W)[d p / d z-(2 \tau / W)]},
$$

which can be numerically solved for $W$ e. g. with the nested intervals method. The influence of the vertical pressure gradient $d p / d z$ is such that decreasing $d p / d z$ yields an increasing dike width and length.

\section{[Table 7] [Figure 11] [Figure 12]}

For the lunar domes examined in this study we computed the dike dimensions based on Eqs. (7)-(9) as listed in Table 7. Fig. 12 illustrates the dependence of the magma rise speed $U$ and the dike dimensions $W$ and $L$ on the lava viscosity $\eta$, obtained based on Eqs. (7) and (9). The values of $U, W$, and $L$ are strongly correlated with the lava viscosity $\eta$. Fitting power laws to the data points representing the mare domes yields

$$
\begin{aligned}
U=5.76 \eta^{-0.920} & \left(r^{2}=0.94\right) \\
W=0.151 \eta^{0.408} & \left(r^{2}=0.99\right) \\
L=0.880 \eta^{0.377} & \left(r^{2}=0.99\right)
\end{aligned}
$$

with $\eta$ in $\mathrm{Pa} \mathrm{s}, U$ in $\mathrm{m} \mathrm{s}^{-1}, W$ in $\mathrm{m}, L$ in $\mathrm{km}$, and $r^{2}$ as the squared correlation coefficient in the respective log-log diagram. In Eq. (12) the fit was performed only for the mare domes of rheologic groups $\mathrm{R}_{1}$ and $\mathrm{R}_{2}$ with $\eta<10^{6} \mathrm{~Pa}$ s.

In Eq. (4) we have set the magma density to $\rho=2000 \mathrm{~kg} \mathrm{~m}^{-3}$. Increasing the density will in turn increase the viscosity by a constant factor, which is, however, not larger than 2.2 for realistic values lower than $2800 \mathrm{~kg} \mathrm{~m}^{-3}$. We found that under such a moderate variation of the lava viscosities the inferred magma rise speeds and dike dimensions and thus the exponents of the power laws (10)-(12) and the time scales regarded in Section 4.3.3 would remain essentially unchanged, since the data points in Fig. 12 would be shifted largely uniformly to the right by less than half an order of magnitude.

The Gruithuisen and Mairan highland domes do not fit well into the relations (10)(12) due to the higher assumed pressure gradient $d p / d z$. However, if we decrease the pressure gradient by a factor of about two, i. e. $d p / d z=650 \mathrm{~Pa} \mathrm{~m}^{-1}$, which would correspond to magma densities typical of terrestrial andesitic, dacitic, and rhyolitic 
magmas (Spera, 2000), the model yields dike widths and lengths increased by a factor of about two for the highland domes, compared to the values listed in Table 7 , which would then be more consistent with the trends established for the mare domes. However, under this assumption the dike lengths would become significantly larger than the dome diameters, similar to the behaviour found for the mare domes.

For the domes with elongated vents in the Milichius/T. Mayer region and Diana and Grace in northern Mare Tranquillitatis (rheologic group $\mathrm{R}_{1}$ ), the model yields rise speeds between $10^{-4}$ and $10^{-2} \mathrm{~m} \mathrm{~s}^{-1}$, dike widths between 5 and $30 \mathrm{~m}$, and dike lengths between 20 and $150 \mathrm{~km}$. For the domes NTA1-NTA6 in northern Mare Tranquillitatis (rheologic group $\mathrm{R}_{2}$ ) we found comparably high rise speeds between $4 \times 10^{-3}$ and $4 \times 10^{-2} \mathrm{~m} \mathrm{~s}^{-1}$, dike widths around $3 \mathrm{~m}$, and dike lengths of $7-16 \mathrm{~km}$. The domes H1-H6 near Hortensius and the steeper domes in the Milichius/T. Mayer region (rheologic group $R_{3}$ ) are characterised by very low rise speeds between $10^{-6}$ and several $10^{-5} \mathrm{~m} \mathrm{~s}^{-1}$, dike widths within a factor of 3 of $100 \mathrm{~m}$, and dike lengths of $130-190 \mathrm{~km}$.

The Reynolds number

$$
R e=\rho U l_{c} / \eta
$$

computed with a characteristic length $l_{c}$ equal to the dike width $W$, obtains typical values of $\sim 10^{-4}$ for rheologic group $R_{1}, \sim 10^{-2}$ for $R_{2}$, and $\sim 10^{-6}$ for $R_{3}$. Still smaller values around $10^{-8}$ are found by Wilson and Head (2003) for the Gruithuisen and Mairan highland domes. Hence, magma ascent can be treated as a non-turbulent flow phenomenon for all lunar domes examined in this study.

For most examined domes, the length $L$ of the dike is several times larger than the dome diameter. A similar effect is observed by Wilson and Head (2003) for the Gruithuisen and Mairan highland domes for certain parameter settings. However, for terrestrial dikes it is common for eruptions to localise so that only a part of the initial fissure remains active throughout the eruption (Richter et al., 1970). For the domes of rheologic groups $\mathrm{R}_{1}$ and $\mathrm{R}_{2}$, these active fissure parts presumably correspond to the elongated vents.

To obtain a better match between the computed dike length and the fissure length estimated based on dome morphology and arrangement, Wilson and Head (2003) propose for the Gruithuisen and Mairan highland domes that the neighbouring pairs 


\section{ACCEPTED MANUSCRIPT}

Gruithuisen $\gamma+\mathrm{NW}$ and Mairan "middle" + "south" formed along the same dike, respectively. Similarly, in the set of mare domes examined in this study we observe pairs of closely neighbouring or even overlapping domes. These dome pairs are $\mathrm{H} 3+\mathrm{H} 4$, H5+H6, M8+M9, and Diana+Grace. The corresponding dike dimensions are given in Table 7 . These values were obtained based on the average lava viscosity and the sum of the effusion rates for each dome pair, respectively.

Inspection of the telescopic CCD images in Fig. 1 reveals that the dome pair Diana+Grace is aligned radially with respect to the Imbrium basin, while the possible dome pairs in the Hortensius/Milichius/T. Mayer region are aligned radially with respect to the location of the Insularum basin and to that of the suspected Eastern Procellarum basin.

Applying the same approach to the four aligned domes M3, M4, M10, and M15 yields a dike length of about $100 \mathrm{~km}$, which is not long enough to imply the formation of all four domes along the same dike. However, for the dome pairs M3+M10 and M4+M15 we obtain dike lengths of 106 and $84 \mathrm{~km}$, respectively, which are larger than the pairwise distances of $46 \mathrm{~km}$ between M3 and M10 and $76 \mathrm{~km}$ between M4 and M15. These two dome pairs may have been formed by two dikes oriented in the same direction.

As a comparison to other mare domes, we added to Table 7 the assignment to the rheologic groups and the values for $U, W$, and $L$ for the domes C1-C6 near Cauchy (cf. Fig. 1) and for the three aligned domes A4-A6 north of Arago. They were determined based on the rheologic properties reported in paper 1. Domes C2 and C3 (traditionally known as Cauchy $\omega$ and $\tau$ ) are situated near the tectonic fault Rupes Cauchy, which is oriented radially with respect to the Imbrium basin and may be the surface manifestation of a crustal structural weakness generated by the Imbrium impact. The domes C5 and C6 are aligned along a strike with Rupes Cauchy. With their inferred moderate lava viscosities and effusion rates, domes C2, C3, and C5 share the properties of rheologic group $R_{1}$. Accordingly, the magma rise speed amounts to several $10^{-4} \mathrm{~m} \mathrm{~s}^{-1}$, and their feeder dikes were several tens of metres wide and between 50 and $120 \mathrm{~km}$ long. The low lava viscosities, high effusion rates, and short durations of the effusion process determined for $\mathrm{C} 1, \mathrm{C} 4, \mathrm{C} 6$, and A4-A6 indicate that these domes belong to rheologic 
group $R_{2}$. Similar to the NTA domes, the magma rise speed amounts to $\sim 10^{-2} \mathrm{~m} \mathrm{~s}^{-1}$, while the feeder dikes were $1-5 \mathrm{~m}$ wide and 5-20 km long. Interestingly, the domes A4-A6 are aligned radially with respect to the Imbrium basin, and the orientations of their feeder dikes were probably guided by the stress field generated by the Imbrium impact.

As a further comparison, we added to Table 7 and also to Fig. 12 the values for magma rise speed and dike dimensions inferred for the Gruithuisen and Mairan highland domes based on the lava viscosities and effusion rates computed by Wilson and Head (2003). We adopt their value of $d p / d z=1300 \mathrm{~Pa} \mathrm{~m}^{-1}$ for the driving pressure gradient but recomputed $U, W$, and $L$ with the values for $L / W$ obtained based on the model by Rubin (1993a) (cf. Fig. 11) since Wilson and Head (2003) approximate the $L / W$ ratio by the constant value 200 (obtained from the model for $p_{0} / G=10^{-3.5}$ and $\eta=5 \times 10^{8} \mathrm{~Pa} \mathrm{~s}$ ) for the range of lava viscosities of one order of magnitude inferred for the Gruithuisen and Mairan highland domes. We obtain very low magma rise speeds around $10^{-5} \mathrm{~m} \mathrm{~s}^{-1}$ and large dike widths between 80 and $200 \mathrm{~m}$, values which are very close to those reported by Wilson and Head (2003). For the dike lengths we obtain values between 25 and $35 \mathrm{~km}$, while the values reported by Wilson and Head (2003) are spanning a broader interval between 16 and $41 \mathrm{~km}$. Recomputed values of $U, W$, and $L$ for the possible pairs Gruithuisen $\gamma+\mathrm{NW}$ and Mairan "middle" + "south" are also given in Table 7 and Fig. 12 .

Regarding the presented modelling results, the question remains open of how realistic they are. In-situ measurements of lunar dike dimensions have been impossible so far, such that only a comparison to terrestrial dikes is feasible. In the study by Wada (1994), direct field measurements of dike widths are performed on the Oki-Dozen islands and in the Tango dike swarm, both located in southwest Japan, and in the Ocros dike swarm in southern Peru. For the same dikes, lava viscosities are inferred from chemical composition. No attempts are made to measure the dike lengths as it is not possible to obtain accurate values due to the fact that the dikes may be partially buried. The measurements by Wada (1994) indicate an increase of the dike width with increasing lava viscosity. For dike widths of $1 \mathrm{~m}$, lava viscosities of $10^{1}-10^{2} \mathrm{~Pa} \mathrm{~s}$ are obtained, while larger dike widths of typically $10-30 \mathrm{~m}$ but in some cases up to 


\section{ACCEPTED MANUSCRIPT}

$100 \mathrm{~m}$ are associated with lava viscosities of $10^{4}-10^{6} \mathrm{~Pa}$. The correlation between dike width and lava viscosity is not very strong, such that Wada (1994) establishes an interval rather than a single regression curve in the width vs. viscosity diagram. We have included this interval into the corresponding diagram shown in Fig. 12 and found that it comprises well our modelled dike width values. Wada (1994) also regards a set of about 10-100 m wide dikes associated with terrestrial flood basalts, i. e. very high effusion rates and erupted volumes, which were formed by mafic lavas with viscosities of only $10^{2}-10^{3} \mathrm{~Pa}$ s. Some of the dikes of this second type fall outside the width vs. viscosity interval inferred from the first type, a behaviour which Wada (1994) attributes to an extremely high magma pressure. The lunar dome-forming dikes presumably do not belong to the second type due to the comparably moderate associated effusion rates and erupted volumes.

\subsubsection{Time scales governing magma evolution during ascent}

To estimate the relevance of magma cooling during its ascent to the surface it is useful to introduce two time scales. Assuming that the vertical extension of a dike is similar to its length $L$ (Jackson et al., 1997), the period of time $\tau_{r}$ during which the magma rises from the dike source to the surface corresponds to

$$
\tau_{r}=L / U
$$

The second time scale, denoted by $\tau_{c}$, describes cooling of stationary magma in a dike, which is governed by conduction of heat from the hot magma into the cool surrounding host rock. For the non-flow case, corresponding to $U \rightarrow 0$ and thus $\tau_{r} \rightarrow \infty$, Carrigan et al. (1992) assume an initially uniform time-dependent temperature distribution $T(x, t)$, where $x$ denotes the direction perpendicular to the dike walls and $x=0$ corresponds to the middle of the dike. It is thus $T(x, 0)=T_{m}$ for $|x|<W / 2$ and $T(x, 0)=T_{r}$ elsewhere, with $T_{m}$ denoting the magma temperature at the dike source and $T_{r}$ the (much lower) initial temperature of the host rock. For $t>0$, heat is conducted from the magma into the host rock. In a dike of $3 \mathrm{~m}$ width, the magma temperature in the dike centre decreases on a time scale of $\tau_{c} \approx 10^{6} \mathrm{~s}$ from the value $T_{m}$ towards a value $\bar{T}$ close to $\left(T_{m}+T_{r}\right) / 2$ (cf. Fig. 13). As long as $t$ is of the order of $\tau_{c}$, it is $T(x, t)>\bar{T}$ inside the dike $(|x|<W / 2)$ and $T(x, t)<\bar{T}$ otherwise. The temperature 
distribution $T(x, t)$ then shows an approximate point symmetry around the points of contact between magma and host rock at $x= \pm W / 2$, where the temperature is largely constant with $T( \pm W / 2, t)=\bar{T}$.

\section{[Figure 13]}

We assume that as long as $W \ll L$, heat transport by conduction occurs in a direction perpendicular to the dike walls since the temperature gradient is negligible in vertical direction and parallel to the walls if the initial magma temperature is uniform. The conduction of heat can thus be described by the one-dimensional diffusion equation

$$
\frac{\partial T(x, t)}{\partial t}=\kappa \frac{\partial^{2} T(x, t)}{\partial x^{2}}
$$

where $\kappa$ is the thermal diffusivity of the magma. The solution of Eq. (15) for the initial conditions $T(x, 0)=T_{m}$ for $x<W / 2$ and $T(x, 0)=T_{r}$ for $x \geq W / 2$ with $T_{m}>T_{r}$ is shown in Fig. 13, assuming thermal diffusivities of $3 \times 10^{-7}$ and $7 \times 10^{-7} \mathrm{~m}^{2} \mathrm{~s}^{-1}$ for the magma and the crust, respectively. These values were estimated based on the thermal conductivity $\lambda$, specific heat $c$, and density $\rho$ tabulated by Spera (2000) for typical magma and crustal materials, employing the relation $\kappa=\lambda /(\rho c)$. We do not report results for temperature-dependent values of $\kappa$ since the corresponding effects on $T(x, t)$ are fairly minor in the regarded scenario.

Note that if $T(x, t)$ is a solution of Eq. (15), then $a T(x, t)+b$ with constant $a$ and $b$ is also a solution. Hence, the temperature distribution scaled as shown in Fig. 13 is valid for arbitrary values of $T_{m}$ and $T_{r}$ as long as $T_{m}>T_{r}$. Similarly, if we have a temperature distribution $T(x, t)$ for a dike of width $W$, it follows from Eq. (15) that for a dike of width $a W$ and identical values of $T_{m}$ and $T_{r}$ a "rescaled" version $T\left(x / a, t / a^{2}\right)$ of the original distribution $T(x, t)$ is obtained.

Assuming a dike of width $a W$ with the same relative initial temperature distribution $\tilde{T}(x, 0)$ such that $\tilde{T}(x, 0)=T(x / a, 0)$, Eq. (15) reveals that the temporal derivative $\partial T / \partial t$ of the temperature changes by a factor of $a^{2}$. Accordingly, the cooling time scale $\tau_{c}$ of stationary magma in a dike of width $W$ is proportional to $W^{2}$, which yields

$$
\tau_{c}=10^{6} \mathrm{~s} \cdot\left(\frac{W}{3 \mathrm{~m}}\right)^{2}
$$

(cf. also Fedotov, 1976). Fig. 14 shows that for the examined set of lunar mare domes, both time scales $\tau_{r}$ and $\tau_{c}$ increase with increasing lava viscosity $\eta$. The $\eta$-dependence 
of the ratio $\tau_{r} / \tau_{c}$ is also shown in Fig. 14, revealing that $\tau_{r} / \tau_{c}$ increases with $\eta$ according to

$$
\frac{\tau_{r}}{\tau_{c}}=0.110 \eta^{0.419} \quad\left(r^{2}=0.67\right)
$$

for the mare domes, where $\eta<10^{8} \mathrm{~Pa}$ s, and decreases again for higher lava viscosities.

\section{[Figure 14]}

Carrigan et al. (1992) show that if the magma rises so quickly through the dike that it reaches the surface long before it has lost a significant amount of its heat to the host rock by conduction, the temperature distribution in the dike is largely uniform and the magma temperatures at the surface and at the dike source are nearly identical. A slightly lower temperature is only observed in the immediate vicinity of the dike walls. This situation corresponds to $\tau_{r} \ll \tau_{c}$ or $\tau_{r} \approx \tau_{c}$.

In contrast, for $\tau_{r} \gg \tau_{c}$ a strong temperature decrease will occur before the magma reaches the surface. For orientation, Fig. 13 shows the temporal behaviour of the temperatures $T(0, t)$ in the dike centre and $T( \pm W / 2, t)$ at the dike border for stationary magma, obtained from Eq. (15) using the magma and crustal material-specific parameters stated above. This stationary solution may be a good approximation for the domes of rheologic group $\mathrm{R}_{3}$, characterised by extremely low magma rise speeds. Detailed numerical modelling is necessary to confirm this assumption, which goes, however, beyond the scope of this work. In the general case, the thermal behaviour of the magma is complex and governed by the relative importance of factors such as cooling due to conduction of heat into the host rock, heat transport within the dike by transversal flow of magma, and heating by viscous dissipation (Carrigan, 2000).

Viscous dissipation is caused by friction occurring inside the moving magma, leading to a conversion of flow energy into heat as a result of high magma viscosity (Carrigan, 2000). Heating by viscous dissipation becomes relevant if the dimensionless Brinkmann number

$$
B r=\frac{\eta U^{2}}{\lambda \Delta T}
$$

exceeds a value of about 2. In Eq. (18), $\Delta T$ is the temperature difference between the contact point between magma and host rock and the centreline of the dike. We assume a thermal conductivity of the magma of $\lambda=1 \mathrm{~W} \mathrm{~m}^{-1} \mathrm{~K}^{-1}$. In the stationary case, values of $\Delta T$ in the range $10-100 \mathrm{~K}$ are found for $\tau_{r} / \tau_{c}$ of the order 10 if the 
initial temperature difference $T_{m}-T_{r}$ between magma and host rock is of the order $1000{ }^{\circ} \mathrm{C}$. For $\tau_{r} / \tau_{c} \approx 100$, temperature differences $\Delta T$ as low as $1-2{ }^{\circ} \mathrm{C}$ are obtained in the stationary case (cf. Fig. 13). If we assume the above values for $\Delta T$, the magma rise speeds $U$ inferred for the mare domes with magma viscosities larger than $\sim 10^{4} \mathrm{~Pa} \mathrm{~s}$ (cf. Table 7) are too low by about two orders of magnitude for viscous dissipation to become a relevant heating mechanism. Under these conditions, viscous dissipation would become significant only for unrealistically high driving pressure gradients above $\sim 3000 \mathrm{~Pa} \mathrm{~m}^{-1}$.

The simulations by Carrigan et al. (1992) reveal that the temperature differences across the dike inferred for stationary magma are an upper limit to those obtained for vertically ascending magma. A mechanism that also decreases the value of $\Delta T$, compared to the stationary case, is lateral motion of magma in the dike towards the walls, leading to a more uniform temperature distribution across the magma especially near the dike walls and thus preventing solidification of magma in the boundary layer. In the numerical model by Carrigan et al. (1992), lateral motion is taken into account basically by introducing an increased effective thermal conductivity of the magma in the dike, leading to a decrease of $\Delta T$. Such transverse flows may be caused by boundary roughness, the rise of gas bubbles in the magma, or the flow-induced sorting of solids, e. g. crystals, in the magma (Carrigan, 2000). It is questionable, however, if the extremely slow magma motion in the dikes for $\tau_{r} \gg \tau_{c}$ is able to generate the extremely homogeneous temperature profile across the dike (with $\Delta T$ reduced by about four orders of magnitude, compared to the stationary case) required to make viscous dissipation an efficient heating mechanism for the given viscosities and magma rise speeds (cf. Eq. (18)).

For small values of $\Delta T$ of only a few degrees already in the stationary case, lateral motion in the dike does not transport a perceivable amount of heat from the dike centre towards the walls. As a consequence, if $\Delta T$ is small but not small enough for viscous dissipation to become relevant (see above), it may be necessary that prior to dike intrusion the host rock is preheated to a temperature $T_{r}$ around $650-700{ }^{\circ} \mathrm{C}$ to prevent solidification of magma in the dike during ascent. Here we assume that the magma temperature $T_{m}$ at the dike source is in the range of typical liquidus tempera- 
tures of about $1200-1400{ }^{\circ} \mathrm{C}$ (Wieczorek et al., 2001) and that the magma solidifies at $\sim 800{ }^{\circ} \mathrm{C}$ (Spera, 2000). According to Carrigan et al. (1992), a preheated crust is a realistic assumption if the region has previously undergone an extended phase of active volcanism. Numerical modelling of high-viscosity magma with a considerable crystalline fraction ascending through dikes of large width at low velocities is necessary to examine in more detail the relative importance of cooling by heat conduction, heating by lateral magma motion and viscous dissipation, and the possible necessity of the host rock being preheated to prevent magma from solidification.

If the magma temperature falls below the solidus temperature, the magma will not rise to the surface at all. Wilson and Head (1996) propose that lunar linear rilles like Rima Sirsalis and Rima Parry V are the surface manifestations of dikes which have not reached the surface but propagated to shallow depths of 1-2 km, showing that these dikes were capable of producing surface stress fields leading to the development of graben with widths of $1-3 \mathrm{~km}$.

For mare domes of rheologic group $\mathrm{R}_{1}, \tau_{r} / \tau_{c}$ is larger than but close to 1 for lava viscosities around $10^{4} \mathrm{~Pa} \mathrm{~s}$, such that the magma temperature could not strongly decrease during ascent. However, for higher viscosities around $\sim 10^{6} \mathrm{~Pa} \mathrm{~s}, \tau_{r} / \tau_{c}$ obtains values larger than 10, which indicates that magma cooling and crystal formation have occured during ascent, thus resulting in the inferred higher lava viscosity. For the mare domes of group $\mathrm{R}_{2}, \tau_{r}$ is roughly equal to or slightly larger than $\tau_{c}$, such that the bulk temperature of the basaltic magma did not significantly decrease during its ascent to the surface. The lava viscosities of less than $10^{4} \mathrm{~Pa}$ s are plausible when near-liquidus magma temperatures at the dike source are assumed. For most mare domes of group $\mathrm{R}_{3}$, the ratio $\tau_{r} / \tau_{c}$ obtains values around 50 and becomes as high as 140-150 for the pair M8+M9 and the dome M12. Hence, magma evolution and especially crystal formation during ascent were important factors governing the properties of the effusion process of the domes of group $\mathrm{R}_{3}$. Additionally, the formation of crystals was favoured by the long time the magma spent in the dike, indicated by the high values of $\tau_{r}$ of typically $\sim 10^{3}$ years, which is much longer than the duration $T_{e}$ of the effusion process.

For the Gruithuisen and Mairan highland domes, the ratios $\tau_{r} / \tau_{c}$ are close to 1 , such that the magma eruption temperature cannot have been much lower than the 
temperature at the dike source. If we assume a magma temperature above the liquidus point at the dike source, crystallisation and evolution due to cooling during ascent are not supposed to have played a more important role than e. g. for the mare domes of group $R_{1}$. We will show in Section 5.4 that it is plausible to assume for the magmas that formed the Gruithuisen and Mairan highland domes a substantially higher silica content than typical of basaltic magma.

\section{Results and discussion}

\subsection{Dike intrusion along crustal fractures}

In the crust of the Earth, fractures are mostly due to tectonic processes. On the Moon, systems of crustal fractures were generated by major impact events. Impacts create a shock wave that propagates through the lunar surface (Spudis, 1993). If of sufficient energy, these waves can induce faulting in the subsurface bedrock and reactivate faults located elsewhere. Examples of faulting in the subsurface layers are seen around a variety of basins (Wilhelms, 1987). Such faulting can be radial (straight out from the basin centre) or concentric (around the basin sides, e. g. "arcuate rilles").

Faulting radial to a basin was caused by the initial basin impact. Here the shock wave created faults in the subsurface rock at some distance from the basin. While initially covered by ejecta, these were later reactivated. As an example, the tectonic faults Rupes Cauchy and Rupes Recta and the linear rilles Rima Cauchy, Rima Ariadaeus, and Rima Hyginus are oriented roughly radially with respect to the Imbrium basin (Wilhelms, 1972).

On the Earth, the ascent of dikes from the upper mantle through the crust to the surface is favoured by fracture-forming stress fields essentially of tectonic origin (Schmincke, 2004). We put forward the hypothesis that on the Moon, impact-induced stress fields caused by large impact events, manifesting themselves near the surface as crustal fractures, facilitated the ascent of dikes in an analogous manner. It is the stress

field, not the actual presence of the pre-existing fractures, which favoured the formation and ascent of dikes (Rubin, 1993b), since the fractures are closed at depths no larger than $\sim 20 \mathrm{~km}$ (Wieczorek et al., 2001). The resulting low compressive stress normal 


\section{ACCEPTED MANUSCRIPT}

to the dike plane allows an easy flow of magma, implying that the magma temperature does not strongly decrease on its way to the surface. Our spectral data of the examined lunar mare domes indicate that they are of basaltic composition (Fig. 4), implying a very low magma viscosity at the dike source. As a consequence, for many domes formed by dikes ascending under these conditions, crystallisation and other magma evolution effects were not dominant, and the magma retained its low viscosity, erupted at a high effusion rate, and eventually formed a domical edifice of low flank slope like those comprised by rheologic groups $\mathrm{R}_{2}$ and also $\mathrm{R}_{1}$.

Lava eruptions tend to occur at localised points along the dike (Richter et al., 1970). Today, these locations appear as elongated summit vents or fissures on top of lunar domes which sometimes consist of several neighbouring or overlapping circular crater pits. These elongated depressions mark the places where lava poured out onto the surface, successively building up a shield-like volcano arount it. They were generated upon magma withdrawal and subsequent collapse into the vent (Head and Gifford, 1980). For example, the very low dome M15 displays a $10 \mathrm{~km}$ long summit fissure which appears rimless and without a sharp outline, supporting our interpretation that it is of volcanic origin. The observed elongated summit features are characteristic for the domes of rheologic groups $\mathrm{R}_{1}$ and $\mathrm{R}_{2}$.

For the domes of group $\mathrm{R}_{1}$ in the Milichius/T. Mayer region, all elongated vents except that of M1 are oriented radially with respect to the Insularum basin (Spudis, 1993) and the Eastern Procellarum basin postulated by de Hon (1979). Furthermore, the domes M3, M4, M10, and M15 are forming a chain of $210 \mathrm{~km}$ length which is aligned in the same direction. Like the nearby lunar cone MC1 with its associated linear rille, the very shallow vent of M1 is oriented radially with respect to the Imbrium basin.

The domes Diana, Grace, and NTA3-NTA6 in northern Mare Tranquillitatis exhibit similar elongated vents, oriented radially with respect to the Imbrium basin. Like nearby Rima and Rupes Cauchy, the locations of the NTA domes along with Diana and Grace are forming a chain of $100 \mathrm{~km}$ length which is oriented in about the same direction. In Lunar Orbiter image IV-073-H2 the domes NTA1 and NTA2 do not display a summit vent. 


\subsection{Possible mechanisms responsible for the broad range of lava viscosities}

The spectral signatures of all examined mare domes are typical of basaltic mare soils (cf. Figs. 4 and 5). Hence, the broad range of lava viscosities inferred for the domes has to be explained under the precondition that the bulk composition of the magma is basaltic. The eruption style can be assumed to be of effusive nature for all examined domes, since none of them is connected with known regions of pyroclastic activity (Gaddis et al., 2003). We may thus infer a low volatile content of the magma. The only possible exception is M11, which appears to be partially covered by dark material (cf. Fig. 2d) that may indicate the occurrence of explosive eruption phases. Based on geophysical modelling we found in the previous sections that dome morphology is directly related to magma rise speed and feeder dike dimensions. Accordingly, we divided the examined set of lunar mare domes into three rheologic groups with distinct rheologic properties and feeder dike geometries, which are illustrated in Fig. 10.

Domes of rheologic group $R_{1}$ are characterised by high effusion rates, moderate to large erupted lava volumes, low to moderate lava viscosities of $10^{4}-10^{6} \mathrm{~Pa} \mathrm{~s}$, moderate magma rise speeds, dike widths around $10 \mathrm{~m}$, and dike lengths of 20-150 km. In the classification scheme for lunar mare domes introduced in paper 1, relying on the spectral and morphometric dome properties, the rheologic group $R_{1}$ is made up by domes of classes $\mathrm{B}_{2}, \mathrm{C}$, and $\mathrm{E}_{2}$. The newly introduced dome class $\mathrm{E}$, comprising domes with small diameters and steep (subclass $\mathrm{E}_{1}$ ) or low (subclass $\mathrm{E}_{2}$ ) flank slopes, is described in detail in Section 4.1.

Domes of rheologic group $\mathrm{R}_{2}$ display similarly high effusion rates but much lower edifice volumes and thus shorter durations of the effusion process. The lavas of low viscosity between $10^{2}$ and $10^{4} \mathrm{~Pa} \mathrm{~s}$ created feeder dikes around $3 \mathrm{~m}$ wide and 7 $16 \mathrm{~km}$ long. The small dikes and high effusion rates imply high magma rise speeds of $\sim 10^{-2} \mathrm{~m} \mathrm{~s}^{-1}$. The rheologic group $\mathrm{R}_{2}$ is made up by domes that belong to the spectral and morphometric classes $\mathrm{A}$ and $\mathrm{E}_{2}$.

In contrast to the rheologic groups $R_{1}$ and $R_{2}$, domes of group $R_{3}$ do not have elongated vents but pronounced circular crater pits. An exception is the pitless dome H6. These domes are characterised by relatively low lava effusion rates but large 


\section{ACCEPTED MANUSCRIPT}

erupted lava volumes, implying long durations of the effusion process which typically amount to several years but may also be as long as 18 years. During effusion, the lava displayed high viscosities of $\sim 10^{7} \mathrm{~Pa} \mathrm{~s}$, ascending at low speeds of $\sim 10^{-5} \mathrm{~m} \mathrm{~s}^{-1}$ through feeder dikes of $\sim 100 \mathrm{~m}$ width and 130-190 km length. This rheologic group consists of domes belonging to the spectral and morphometric classes $\mathrm{B}_{1}$ and $\mathrm{E}_{1}$.

To better account for the observed dome morphologies, we computed the values of $U, W$, and $L$ and the time scales $\tau_{r}$ and $\tau_{c}$ for several pairs of domes, assuming that they were formed by lava eruption from a single feeder dike, respectively. For this purpose, in the dike model outlined in Section 4.3.2 we set the viscosity to the average of the values inferred for the individual domes and the effusion rate to the sum of the individual effusion rates (Wilson and Head, 2003). The regarded dome pairs are $\mathrm{H} 3+\mathrm{H} 4, \mathrm{H} 5+\mathrm{H} 6, \mathrm{M} 8+\mathrm{M} 9, \mathrm{M} 3+\mathrm{M} 10, \mathrm{M} 4+\mathrm{M} 15$, Diana+Grace, Gruithuisen $\gamma+\mathrm{NW}$, and Mairan "middle" + "south". The resulting magma rise speeds and dike dimensions are similar to the values previously inferred for the respective individual domes (cf. Table 7) and fit well into the established dependence of $U, W, L, \tau_{r}$, and $\tau_{c}$ on lava viscosity (cf. Figs. 12 and 14). Except for the two mentioned possible pairs of highland domes, the dike lengths are larger than the extensions of the pairs of volcanic edifices, indicating that magma may have erupted at two separate locations along the dike. The assumption of dome pairs sharing a dike is confirmed by the fact that the configurations $\mathrm{H} 3+\mathrm{H} 4, \mathrm{H} 5+\mathrm{H} 6, \mathrm{M} 8+\mathrm{M} 9, \mathrm{M} 3+\mathrm{M} 10$, and M4+M15 and thus also the dikes along which they are suggested to have formed are aligned radially with respect to the Insularum basin and Eastern Procellarum basin just like the elongated vents of the domes in the Milichius/T. Mayer region (cf. Fig. 2). Similarly, the dome pair Diana+Grace is aligned approximately towards the Imbrium basin.

For lava viscosities below $10^{6} \mathrm{~Pa} s$, i. e. for rheologic groups $\mathrm{R}_{1}$ and $\mathrm{R}_{2}$, dike length $L$ and lava viscosity $\eta$ are related by Eq. (12). If we assume that the length of a dike approximately equals its vertical extension (Jackson et al., 1997), the basaltic magma that formed the domes of group $\mathrm{R}_{2}$ originated from reservoirs located at shallow depths of $\sim 10 \mathrm{~km}$. This is clearly within the lunar crust, which has a thickness of $22 \mathrm{~km}$ in this region (Wieczorek et al., 2006). These reservoirs may have resulted from the intrusion of basaltic magma into the lower crust, forming magma chambers at the inferred shallow 
depths - this magma may have been driven by its positive buoyancy, when following the line of thought by Wieczorek et al. (2001). Eventually, the magma found its way to the surface through narrow dikes with orientations guided by the impact-induced stress-field (Rubin, 1993b). The high rise speed and the shallow depth of the magma reservoirs resulted in rising times $\tau_{r}$ comparable with the time scale $\tau_{c}$ on which the magma cooled down in the dike by conduction of heat into the host rock. According to Carrigan et al. (1992), fast motion and weak cooling of magma, corresponding to $\tau_{r}<\tau_{c}$, lead to a largely uniform temperature of the magma in the dike and at the surface which approximately equals the temperature at the dike source. The magma did not evolve during ascent and displayed viscosities around $10^{3} \mathrm{~Pa}$ s during eruption, a value which is also observed for terrestrial basaltic lavas (Murase and McBirney, 1970).

For the domes of rheologic group $\mathrm{R}_{1}$ with lower lava viscosities of $\sim 10^{4} \mathrm{~Pa}$ s (M1, M5, M7, M15, Diana), the situation is quite similar since their associated dike lengths imply magma reservoirs at depths of $\sim 30 \mathrm{~km}$. For domes which formed from lavas of somewhat higher viscosities of several $10^{5} \mathrm{~Pa}$ s (H7, M3, M4, M6, M10, Grace) the magma reservoirs are situated at depths between about 60 and $160 \mathrm{~km}$. According to Wieczorek et al. (2006) the total crustal thickness in the Hortensius/Milichius/T. Mayer region amounts to $50 \mathrm{~km}$ while the thickness of the upper crust is $22 \mathrm{~km}$. Hence, the magma reservoirs of the domes in this region that formed from lower-viscosity magmas were located in the lower crust, while the reservoirs of the domes associated with magmas of higher viscosity were situated at or well below the border between lunar mantle and crust. The magma reservoir of the dome Grace, located at about $46 \mathrm{~km}$ depth, is located in the lower crust, regarding the thicknesses of the total and the upper crust of $55 \mathrm{~km}$ and $32 \mathrm{~km}$, respectively, in northern Mare Tranquillitatis (Wieczorek et al., 2006). For the $\mathrm{R}_{1}$ domes with $\eta \approx 10^{4} \mathrm{~Pa} \mathrm{~s}, \tau_{r}$ is always larger than $\tau_{c}$ but $\tau_{r} / \tau_{c}$ is smaller than 10, such that magma evolution processes like crystallisation become more important, in turn resulting in lava viscosities higher than those inferred for group $\mathrm{R}_{2}$ by an order of magnitude. Magma evolution becomes dominant for the $\mathrm{R}_{1}$ domes with higher lava viscosities of up to $10^{6} \mathrm{~Pa} \mathrm{~s}$, where $\tau_{r}$ is about 20 times larger than $\tau_{c}$. Slow lateral motion of magma towards the dike walls, transferring heat to the border 
region between magma and host rock, may have kept the magma at sufficiently high temperatures to prevent it from solidification in the dike (Carrigan, 2000). Detailed numerical modelling of magma ascent under lunar conditions, however, is required to provide a quantitative understanding of the relative importance of the involved cooling and heating mechanisms.

The domes of rheologic group $R_{3}$ are characterised by lava viscosities which are still higher by more than one order of magnitude, reaching values of several $10^{7} \mathrm{~Pa}$. In this viscosity range, dike length and thus vertical extension are nearly viscosityindependent and obtain values between 130 and $190 \mathrm{~km}$, i. e. the dikes originate from below the lunar crust. The values of $\tau_{r} / \tau_{c}$ are of the order 50 for the domes of group $R_{3}$ but span a range of one order of magnitude, reaching maximum values of 140-150 for the pair of small domes M8+M9 and the dome M12. As a consequence, magma evolution processes essentially consisting of cooling and crystallisation during ascent are dominant factors governing the magma properties at the surface, especially its viscosity. Lateral transport may again be the mechanism that kept the magma above its solidus temperature. The magma reservoirs of the $\mathrm{R}_{3}$ domes are typically located at a depth comparable to that of several $R_{1}$ domes. The very low rise speeds then result in the inferred high values of $\tau_{r} / \tau_{c}$. These low rise speeds may be due to the fact that the impact-induced stress fields favouring the formation of the dikes of the $\mathrm{R}_{3}$ domes were less pronounced than those facilitating the formation of the $R_{1}$ and $R_{2}$ domes, such that the ascending magma flowed less easily. At the surface, this may have led to the formation of circular summit pits rather than elongated vents, fissures, or pit chains. The circular pits indicate that the fracture was open only at a single point at the dike through which lava could erupt while the lava that formed the domes of rheologic groups $R_{1}$ and $R_{2}$ presumably erupted at several neighbouring locations along the dike. A further influencing quantity may have been a somewhat lower magma temperature at the dike source, also resulting in lower rise speeds and thus a higher degree of cooling and subsequent crystallisation near the surface. Qualitatively spoken, small differences in magma viscosity at the dike source were "amplified" by the resulting differences in magma rise speed, favouring crystallisation in the magma and in turn generating large viscosity differences at the surface. 
For the examined set of lunar mare domes, the ratio of the time scale $\tau_{r}$ of magma rise and the cooling time scale $\tau_{c}$ increases with lava viscosity $\eta$ according to $\tau_{r} / \tau_{c} \propto \eta^{0.42}$ for $p_{0} / G=10^{-3.5}$. If we follow the intuitive assumption that magma evolution processes, especially cooling and subsequent crystallisation, become increasingly important with increasing value of $\tau_{r} / \tau_{c}$, the broad range of lava viscosities inferred for the examined lunar mare domes reflects different evolutionary stages of basaltic magma, especially characterised by an increasing crystal content.

At this point, the steep and voluminous domes H5 and H6 appear to be somewhat exceptional, compared to other $\mathrm{R}_{3}$ domes, as they display very high lava viscosities of several $10^{7} \mathrm{~Pa}$ s but at the same time relatively small values of $\tau_{r} / \tau_{c}$ of about 20 . Hence, the influence of magma evolution processes is supposed to be comparable to that of the domes of rheologic group $\mathrm{R}_{1}$ with similar $\tau_{r} / \tau_{c}$ ratios but much lower lava viscosities. However, the very long durations of the lava effusion process of 18 and 15 years, respectively, may have favoured the assimilation of crustal wallrock into the magma, leading to heat transfer and thus more efficient cooling of the magma during ascent (Spera, 2000). The fraction of crustal material assimilated into the erupted lava can only be small since otherwise one would expect a corresponding spectral signature, especially a higher albedo $R_{750}$ than the surrounding mare surface, which was not detected in the Clementine UVVIS imagery. But it is well possible that a slight spectral contrast is hidden by the thin layer of ray material from the crater Copernicus covering the region in which the Hortensius domes are situated. A further possible reason for the exceptionally high lava viscosities of $\mathrm{H} 5$ and $\mathrm{H} 6$ may be their very long magma rise times $\tau_{r}$ (Schmincke, 2004) of several $10^{3}$ years, which is much longer than the corresponding durations of the effusion process. This may have resulted in the formation of larger crystals and a higher crystalline fraction in the magma than expected for similar values of $\tau_{r} / \tau_{c}$ but more typical, smaller values of $\tau_{r}$.

In addition to differences in magma evolution, the inferred variations of magma viscosity are possibly governed by compositional differences. While magma viscosity increases with increasing $\mathrm{SiO}_{2}$ content (Schmincke, 2004), it decreases with increasing $\mathrm{TiO}_{2}$ and $\mathrm{FeO}$ content (Melendrez et al., 1994; cf. also paper 1). On scales of $\sim 150 \mathrm{~km}$, the average $\mathrm{Si}$ abundance in the soil is not much different for the mare domes in the 
Hortensius/Milichius/T. Mayer region and those in the northern Mare Tranquillitatis region (cf. Section 3.2). However, the Lunar Prospector gamma ray spectrometer measures the fraction of atoms of a certain element in the soil and thus cannot distinguish between chemical states, e. g. "primitive" basaltic magma and highly crystalline suspensions with a much higher Si content in the melt, as long as the average fraction of Si atoms is identical. According to the inferred variable importance of magma evolution, one would expect soils containing different crystalline fractions and probably also crystal sizes for the domes of the different rheologic groups. At this point one might also expect spectral signatures displaying variations according to these quantities. In the Clementine UVVIS spectra of the examined mare domes, however, no dependence on the rheologic group is apparent, and all domes are spectrally indistinguishable from the surrounding plains of basaltic mare lava. Gillis and Lucey (2005) propose a dependence of the UV/VIS spectral ratio on ilmenite grain size, i. e. crystal size, but such a relation has not yet been established quantitatively. What is more, dome soils characterised by different degrees of magma evolution and thus by different average crystal sizes are supposed to be transformed into regoliths of uniform grain size in their uppermost layers (which determine their spectral properties) due to surface maturation processes when their exposure ages are high (McKay et al., 1991).

All three examined dome regions are characterised by a similarly high FeO content (Bussey and Spudis, 2004). The different minimal viscosity values observed in the Milichius/T. Mayer and in the northern Tranquillitatis region, respectively, may reflect different viscosities of the "primitive" magma at the dike source and are likely due to a different $\mathrm{TiO}_{2}$ content $(\sim 1.5 \mathrm{wt} \%$ in the Milichius/T. Mayer vs. $\sim 4$ wt $\%$ and more in the northern Tranquillitatis region). We conclude that despite the moderate $R_{415} / R_{750}$ ratios observed for the Hortensius domes, they also have a low $\mathrm{TiO}_{2}$ content similar to the Milichius/T. Mayer domes, which is well possible according to the $R_{415} / R_{750}$ vs. $\mathrm{TiO}_{2}$ content relation established by Gillis and Lucey (2005).

In contrast, the inferred variations of $\eta$ within the dome regions largely reflect varying degrees of magma evolution. Slightly different viscosities of the "primitive" magma at the dike source may have led to more pronounced viscosity differences at the surface. These were possibly further increased by different strengths of the impact- 
induced stress fields favouring the formation of dikes and ascent of magma, in turn influencing the magma rise speed $U$, the vertical extension of the dike, and thus the ratio $\tau_{r} / \tau_{c}$.

Petrycki and Wilson (1999) state a close relation between lunar dikes and linear depressions. A dike rising to shallow depths of a few kilometres but not reaching the surface causes a stress field leading to a linear graben. Typical examples are Rima Sirsalis, Rima Parry V, Rima Cauchy II, and Rima Hyginus (Head and Wilson, 1996; Head et al., 1997; Petrycki and Wilson, 1999). For Rima Hyginus, the presence of rimless crater pits along the graben indicates degassing activity. For lunar domes generated by dike intrusion, the dike reaches the surface at least at some points, such that magma erupts at high effusion rates. For a dike coming to rest with its top below the surface, the rise speed of its upper tip has to decrease as it approaches the equilibrium that causes it to stop rising, while a dike that erupts may propagate much faster. The response of the crustal rocks through which the dike propagates may comprise an inelastic component that responds in a different manner to these different timescales, leading to the formation of a linear depression in the first case while producing no surface manifestation except the effusive dome in the second case.

For the broadest dikes, belonging to the mare domes of rheologic group $\mathrm{R}_{3}$ with the highest lava viscosities around $10^{6} \mathrm{~Pa}$ s, we obtain widths of 30-240 m. Interestingly, these values are similar to the dike widths of some hundreds of metres inferred by Wilson and Head (1996) for the graben-forming dikes. Similarly, the dike lengths of the $\mathrm{R}_{3}$ domes amount to $100-200 \mathrm{~km}$ (cf. Table 7 ), which is of the same order as the lengths of Rima Sirsalis (380 km), Rima Parry V (50 km), Rima Cauchy II (45 km), and Rima Hyginus $(200 \mathrm{~km}$ ) presumably formed by dike intrusion to shallow depth.

Hence, the domes of rheologic group $\mathrm{R}_{3}$ appear to have been formed from dikes in which relatively cool, highly viscous magma nearly saturated with crystals ascended very slowly to the surface. Thus, these domes likely represent the highest level of evolution of basaltic magma obtainable under lunar conditions. Accordingly, still larger values of $\tau_{r} / \tau_{c}$ would have caused the magma to become so viscous and crystal-saturated that its ascent towards the surface would have stopped, probably leading to solidification of the dike in the crust and eventually to the formation of a linear graben instead 
of an effusive dome. Possibly these domes formed during the final stages of extensive effusion of mare lava, when the magma temperature at the dike source began to decrease. More quantitative insights into the interactions between magma ascent, stress field, and eruption style under lunar conditions may be obtained by future numerical simulations.

\subsection{Effects of weakly constrained model parameters}

The dike model by Rubin (1993a) is essentially governed by two parameters. The first parameter is the ratio $\eta / \eta_{r}$ between magma and host rock viscosity. The value $\eta_{r}=10^{18} \mathrm{~Pa} \mathrm{~s}$ is broadly accepted (Wilson and Head, 2003). For $p_{0} / G$, Rubin (1993a) gives no specific value but an interval between $10^{-4.0}$ and $10^{-3.0}$. In comparison to the value $p_{0} / G=10^{-3.5}$ assumed in our model calculations, for $p_{0} / G=10^{-3.0}$ the transition from viscous to elastic interaction between magma and host rock occurs at $\eta \approx 10^{7} \mathrm{~Pa} \mathrm{~s}$, the rise speed $U$ increases by a largely uniform factor of $\sim 3$, the dike width $W$ remains largely unchanged, and the dike length $L$ decreases by a factor of about two for viscosities below $10^{8} \mathrm{~Pa} \mathrm{~s}$ while remaining essentially unchanged for higher viscosities as found for the Gruithuisen and Mairan highland domes (cf. Section 5.4). The $\tau_{r} / \tau_{c}$ ratio still increases with $\eta$ but is constantly about an order of magnitude lower for viscosities below $10^{7} \mathrm{~Pa}$ s and remains largely unchanged for higher viscosities. However, as in the $p_{0} / G=10^{-3.5}$ case, the magma may obtain subliquidus temperatures, again resulting in an increasing degree of crystallinity for increasing $\eta$. For $p_{0} / G=10^{-4.0}$, the transition from viscous to elastic interaction between magma and host rock occurs at $\eta \approx 10^{4} \mathrm{~Pa}$ s. Rise speed $U$ and dike width $W$ remain largely unchanged, compared to $p_{0} / G=10^{-3.5}$, and the dike length $L$ decreases by a factor of about two for high $\eta$ and increases for low $\eta$. As a consequence, $\tau_{r} / \tau_{c}$ is in the range 1-10 for the examined mare domes, independent of $\eta$. In this scenario, the magma may reach subliquidus temperatures in the dike, and different degrees of crystallinity may still occur due to the fact that like in the $p_{0} / G=10^{-3.5}$ case, $\tau_{r}$ strongly increases with increasing $\eta$. Detailed numerical modelling of magma evolution processes in the dike is required to constrain the $p_{0} / G$ values valid during the formation of lunar mare domes. 


\section{ACCEPTED MANUSCRIPT}

The model by Wilson and Head (2003) utilised in this study to estimate the dimensions of the feeder dikes strongly depends on the pressure gradient $d p / d z$ driving the magma to the surface. The value $d p / d z=328 \mathrm{~Pa} \mathrm{~m}^{-1}$ reported by Wilson and Head (1996) for basaltic dikes is actually referred to as the lower limit required for an eruption of magma at the surface. Hence, in principle higher values of $d p / d z$ may have occurred. The general behaviour of the dike model, as already pointed out by Wilson and Head (2003), is such that an increase of $d p / d z$ implies narrower and shorter dikes, while the magma rise speed increases. Accordingly, the time scales $\tau_{r}$ and $\tau_{c}$ become shorter as well. However, the behaviour of the ratio $\tau_{r} / \tau_{c}$ is remarkably stable with respect to an increase of $d p / d z$, since although the multiplicative factor in Eq. (17) behaves approximately inversely proportional to $d p / d z$, the exponent remains largely unchanged even if $d p / d z$ is increased towards unrealistically high values of several $10^{3} \mathrm{~Pa} \mathrm{~m}^{-1}$. Hence, the line of thought followed in this study, concerning the importance of magma evolution processes with increasing viscosity, remains valid across a broad range of values for the driving pressure gradient $d p / d z$. However, under the assumption that the mare domes characterised by high lava viscosities formed from dikes in which the magma had become so viscous and crystal-saturated that it nearly ceased its upward motion (cf. Section 5.2) we may conclude that the driving pressure gradients did not significantly exceed the value of $328 \mathrm{~Pa} \mathrm{~m}^{-1}$ we adopted for modelling the dike dimensions.

\subsection{Comparison to other lunar domes}

The described mechanisms remain valid beyond the set of lunar mare domes examined so far in this study. For example, a dome chain formed by the three aligned domes designated A4-A6 in paper 1 is situated in western Mare Tranquillitatis north of the crater Arago and the nearby large and very complex volcanic edifice Arago $\alpha$ (cf. Fig. 1d). Like NTA1 and NTA2, these domes do not have summit crater pits. Similar to the NTA domes, their direction of alignment is radial with respect to the Imbrium basin, indicating their formation along a crustal fracture. Being typical representatives of class A (cf. Section 4.1), they show low flank slopes below $1^{\circ}$ and diameters of $8-$ $11 \mathrm{~km}$ (cf. paper 1), implying low lava viscosities of several $10^{3} \mathrm{~Pa}$, high effusion rates of $\sim 300 \mathrm{~m}^{3} \mathrm{~s}^{-1}$, and very short durations of the effusion process of $2-4$ months. Hence, 
these domes belong to rheologic group $\mathrm{R}_{2}$ and thus result from the eruption of hardly evolved basaltic magma, being of high $\mathrm{TiO}_{2}$ content indicated by their extraordinarily high $R_{415} / R_{750}$ spectral ratio. Magma rise speed and dike dimensions are also typical of rheologic group $\mathrm{R}_{2}$ (cf. Table 7 ). We found that with respect to the dike geometries, possibly two of these domes or all three of them may have shared a single dike during their formation. Wieczorek et al. (2006) determined a total crustal thickness of $35 \mathrm{~km}$ and an upper crustal thickness of $15 \mathrm{~km}$ for western Mare Tranquillitatis. Hence, the dike lengths of 14-22 km indicate that the magma that formed the domes A4-A6 originated from the border region between upper and lower crust.

Other low domes in Mare Tranquillitatis (cf. Fig. 1e), situated in the Cauchy region and designated $\mathrm{C} 1, \mathrm{C} 4$, and $\mathrm{C} 6$ in paper 1, also share the characteristic properties of rheologic group $\mathrm{R}_{2}$ (cf. Table 7 ). Their summit vents are too shallow to appear in the Lunar Orbiter images, such that an elongated shape of the summit vents can neither be confirmed nor excluded. The magma source regions are located in the upper crust, which is $32 \mathrm{~km}$ thick in this region (Wieczorek et al., 2006). The nearby domes C2 (Cauchy $\omega$ ), C3 (Cauchy $\tau$ ), and C5 belong to rheologic group $\mathrm{R}_{1}$. While the dome C3 does not have a summit vent, $\mathrm{C} 2$ has a pronounced elongated vent, whereas the vent of C5 is also elongated but so shallow that it is barely visible in Lunar Orbiter image IV073-H2. The vents are elongated into azimuthal directions of $72^{\circ}$ and $65^{\circ}$, respectively, thus being oriented in parallel with Rupes Cauchy and radially with respect to the Imbrium basin. Hence, the formation mechanisms correspond to those suggested for rheologic group $R_{1}$. The magma forming these domes originated from below the crust.

The Gruithuisen and Mairan highland domes, situated near the north-western border of Mare Imbrium, are characterised by higher lava viscosities, lower effusion rates, and longer durations of the effusion process than typical for the examined lunar mare domes. The magma forming these domes ascended at low speeds of $\sim 10^{-5} \mathrm{~m} \mathrm{~s}^{-1}$ through dikes of 100-200 m width and 25-35 km length (cf. Tables 6 and 7). For the highland domes, the ratio $\tau_{r} / \tau_{c}$ is close to 1 , such that the magma eruption temperature was presumably not much lower than the temperature at the dike source. If we assume magma temperatures above the liquidus point at the dike source, crystallisation due to cooling during ascent is not supposed to have played a more important 
role than e. g. for the domes of group $\mathrm{R}_{1}$. For the Mairan domes, where $\tau_{r}$ and $\tau_{c}$ are of the same order but $\tau_{r}>\tau_{c}$, cooling slightly below the liquidus temperature and subsequent crystallisation may have occurred, where the formation of crystals in the melt was additionally favoured by the very long rising times $\tau_{r}$ of up to 170 years. However, the magma temperature in the dike probably could not decrease closely enough towards the solidus temperature to generate the very high crystallinity $\phi / \phi_{m}$ required according to the Einstein-Roscoe equation (2) to explain the inferred very high lava viscosities of $10^{8}-10^{9} \mathrm{~Pa}$, which are higher by about six orders of magnitude than the viscosity of basaltic lava at liquidus temperature. Hence, it is plausible to assume for the magmas that formed the Gruithuisen and Mairan highland domes a substantially higher silica content than typical of basaltic magma, supporting the idea by Chevrel et al. (1999) of a non-mare volcanism of silica-rich and highly viscous lavas of low $\mathrm{TiO}_{2}$ and $\mathrm{FeO}$ content in this region. Chevrel et al. (1999) motivate this idea mainly with the observed spectral signatures of the highland domes, which are strongly different from those of basaltic mare lavas. The inferred dike lengths and the crustal thickness data by Wieczorek et al. (2006) indicate an origin of this lava in the lower crust.

\section{Summary and conclusion}

We have examined lunar mare domes located in the Hortensius/Milichius/T. Mayer region and in northern Mare Tranquillitatis with respect to their formation along crustal fractures, their rheologic properties, the dimensions of their feeder dikes, and the importance of magma evolution processes during dome formation.

The low domes in the Milichius/T. Mayer region display elongated summit vents or fissures oriented in parallel, radially with respect to both the Insularum basin (Spudis, 1993) and that of the Eastern Procellarum basin postulated by de Hon (1979). The locations of four of these domes are forming a linear chain of $210 \mathrm{~km}$ length in the same direction. Similarly, eight low domes situated in northern Mare Tranquillitatis form a linear chain of $100 \mathrm{~km}$ length aligned radially with respect to the Imbrium basin. Six of these domes display elongated summit vents oriented in the same direction.

Our proposed explanation for these observations is that the domes were formed 
along crustal fractures generated by major impact events, hence running radially with respect to the basin locations. In this context, the elongated summit vents are interpreted to indicate the direction of the dike through which the magma ascended to the lunar surface.

Our analysis of Clementine UVVIS imagery and the Lunar Prospector gamma ray spectrometer data reported by Berezhnoy et al. (2005) reveal that the examined mare domes formed from low-Si basaltic lavas of high $\mathrm{FeO}$ and low to moderate $\mathrm{TiO}_{2}$ content. Based on their morphometric properties, i. e. diameter, height, and edifice volume, obtained by photoclinometric and shape from shading analysis of telescopic CCD images, we have derived important rheologic quantities, i. e. lava viscosity during eruption, effusion rate, duration of the effusion process, and magma rise speed, and the dimensions of the feeder dikes. We have established three rheologic groups characterised by specific combinations of rheologic properties and dike dimensions, where the most relevant discriminative parameter is the lava viscosity $\eta$. The first group, $\mathrm{R}_{1}$, is characterised by lava viscosities of $10^{4}-10^{6} \mathrm{~Pa}$ s and contains the domes with elongated vents in the Milichius/T. Mayer region and two similar domes in northern Mare Tranquillitatis. Group $\mathrm{R}_{2}$ with $\eta$ between $10^{2}$ and $10^{4} \mathrm{~Pa}$ s comprises the very low aligned domes in northern Mare Tranquillitatis, and the third group, $\mathrm{R}_{3}$, with $\eta$ between $10^{6}$ and $10^{8} \mathrm{~Pa}$ s the relatively steep domes near Hortensius and in the T. Mayer region.

To the lunar dome classification scheme introduced in paper 1 we have added a new class E comprising domes with very small diameters below $6 \mathrm{~km}$, where domes with flank slopes steeper than $2^{\circ}$ are denoted by subclass $\mathrm{E}_{1}$ and lower domes by subclass $\mathrm{E}_{2}$. We found that the domes of rheologic group $R_{1}$ belong to classes $B_{2}, C$, and $E_{2}$, those of group $\mathrm{R}_{2}$ range from class $\mathrm{A}$ to $\mathrm{E}_{2}$, and the rheologic group $\mathrm{R}_{3}$ comprises domes of classes $\mathrm{B}_{1}$ and $\mathrm{E}_{1}$. Moreover, our new data about the domes in northern Mare Tranquillitatis indicate that for small dome diameters and low flank slopes, lunar mare domes are more continuously distributed in the space of spectral and morphometric quantities than previously assumed.

The dike dimensions inferred from the rheologic properties based on the geophysical model by Rubin (1993a) show that the dike width increases from a few metres for the NTA domes of rheologic group $\mathrm{R}_{2}$ to more than $200 \mathrm{~m}$ for the comparably steep 


\section{ACCEPTED MANUSCRIPT}

group $\mathrm{R}_{3}$ domes in the Hortensius region. The dike length increases from around $10 \mathrm{~km}$ for the NTA domes to $100-200 \mathrm{~km}$ for the domes of rheologic group $\mathrm{R}_{1}$ that were formed from lavas of viscosities of $\sim 10^{6} \mathrm{~Pa} \mathrm{~s}$ and the group $\mathrm{R}_{3}$ domes. If we assume a vertical extension of the dike that is similar to its length, the inferred dike dimensions indicate that the source regions are situated within the upper lunar crust for the domes in northern Mare Tranquillitatis except Diana and Grace, where the inferred dike dimensions indicate a dike source situated in the lower crust. For the domes in the Hortensius/Milichius/T. Mayer region, the dike source regions are likely to be located in the lower crust or below the border between lower crust and lunar mantle if we assume the crustal thickness values given by Wieczorek et al. (2006).

By comparing the time scale $\tau_{r}$ of magma ascent with the time scale $\tau_{c}$ on which heat is conducted from the magma into the host rock in the case of stationary magma in the dike, we have found evidence that the ratio $\tau_{r} / \tau_{c}$ is larger than but close to 1 for lava viscosities of $10^{2}-10^{4} \mathrm{~Pa}$ s while it reaches values around 50 and up to about 150 for viscosities of $\sim 10^{6} \mathrm{~Pa}$ s. We conclude that the importance of magma evolution processes during ascent such as cooling and crystallisation increases with lava viscosity. Different degrees of evolution of initially fluid basaltic magma may serve as an explanation for the broad range of lava viscosities inferred for the examined mare domes. We found that our line of thought remains valid for a broad range of essential but empirically not well-constrained model parameters, especially $p_{0} / G$, denoting the ratio between pressure at the dike source and elastic rock stiffness, and the driving pressure gradient $d p / d z$. The spectral data reveal that differences in $\mathrm{TiO}_{2}$ content might additionally account for the systematic difference in lava viscosity between the two examined volcanic regions, situated in eastern Oceanus Procellarum and in northern Mare Tranquillitatis, respectively.

The dike dimensions obtained for the domes of rheologic group $\mathrm{R}_{3}$ are very similar to those inferred by Wilson and Head (1996) for graben-forming dikes that reached shallow depths below the surface but solidified before lava effusion could occur. Hence, these domes were presumably formed from dikes in which relatively cool, highly viscous magma nearly saturated with crystals ascended very slowly to the surface.

We have shown that the three established rheologic groups and the described dome 
formation and magma evolution mechanisms are likely to be valid also for other lunar mare domes regarded for comparison, situated in Mare Tranquillitatis near the craters Cauchy (six domes with the typical properties of rheologic groups $R_{1}$ and $R_{2}$ ) and Arago (three low domes of rheologic group $\mathrm{R}_{2}$ forming a chain oriented radially with respect to the Imbrium basin). On the other hand, we have found for the Gruithuisen and Mairan highland domes that despite their inferred high lava viscosities of $10^{8}-10^{9} \mathrm{~Pa} \mathrm{~s}$ most probably no significant magma cooling in the dike occurred during ascent due to the fact that the timescales $\tau_{r}$ and $\tau_{c}$ are of the same order of magnitude. These results support ideas previously proposed e. g. by Chevrel et al. (1999) stating that the highland domes were formed during a specific phase of non-mare volcanism by highly silicic viscous lavas.

The proposed interdependencies between lava viscosity and magma evolution processes, illustrated by the ratio $\tau_{r} / \tau_{c}$, may still be regarded as largely qualitative. Hence, to gain further insights into the internal mechanisms that governed the formation of lunar mare domes, we suggest that future work in this field should involve detailed numerical modelling of the evolution processes undergone by the magma during its ascent to the surface. Such theoretical analyses should preferrably be accompanied by an acquisition of high-resolution visible and especially near and mid-infrared multiband spectrophotometric data, which will allow a refined compositional analysis of the lunar mare dome fields.

Acknowledgements: We are grateful to Dr. Lionel Wilson and Dr. R. Aileen Yingst for their reviews providing valuable comments and suggestions. Thanks are extended to Alexander Wöhler for producing the sketch shown in Fig. 10.

\section{References}

[1] Adams, J. B., McCord, T. B., 1970. Remote sensing of lunar surface mineralogy: implication from visible and near infrared reflectivity of Apollo 11 samples. Proc. Apollo 11 Lunar Sci. Conf., 1937-1945. 
[2] Basaltic Volcanism Study Project, 1981. Basaltic Volcanism on the Terrestrial Planets. Pergamon Press, Inc., New York.

[3] Baumgardner, J., Mendillo, M., Wilson, J. K., 2000. A digital high definition imaging system for spectral studies of extended planetary atmospheres, 1. Initial result in white light showing features on the hemisphere of Mercury unimaged by Mariner 10. Astronomical Journal 119, 2458-2464.

[4] Berezhnoy, A. A., Gasnault, O., Hasebe, N., Kobayashi, M., Michael, G., 2006. Correction of Lunar Prospector elemental maps. Lunar Planet. Sci. XXXVII, abstract \#1032.

[5] Burns, R. G., Parkin, K. M., Loeffler, B. M., Leung, I. S., Abu-Eid, R. M., 1976. Further characterization of spectral features attributable to titanium on the moon. Proc. Lunar Science Conf. 7, 2561-2578.

[6] Bussey, B., Spudis, P., 2004. The Clementine Atlas of the Moon. Cambridge University Press, Cambridge, UK.

[7] Cadogan, P. H., 1975. The Gargantuan Basin - Some Implications. Lunar Planet. Sci. VI, p. 123.

[8] Carrigan, C. R., 2000. Plumbing Systems. In: Sigurdsson, H. (Ed.), Encyclopedia of Volcanoes. Academic Press, San Diego.

[9] Carrigan, C. R., Schubert, G., Eichelberger, J. C., 1992. Thermal and dynamical regimes of single- and two-phase magmatic flow in dikes. J. Geophys. Res. 97(B12), $17377-17392$.

[10] Cattermole, P., 1996. Planetary Volcanism. 2nd edition, John Wiley and Sons, Chichester.

[11] Charette, M. P., McCord, T. B., Pieters, C., Adams, J. B., 1974. Application of remote spectral reflectance measurements to lunar geology classification and determination of titanium content of lunar soils. J. Geophys. Res. 79(11), 16051613. 
[12] Chevrel, S. D., Pinet, P. C., Head, J. W., 1999. Gruithuisen domes region: A candidate for an extended nonmare volcanism unit on the Moon. J. Geophys. Res. 104(E7), 16515-16529.

[13] De Hon, R. A., 1979. Thickness of the western mare basalts. Lunar Planet. Sci. X, 2935-2955.

[14] Eliason, E., Isbell, C., Lee, E., Becker, T., Gaddis, L., McEwen, A., Robinson, M., 1999. Mission to the Moon: the Clementine UVVIS global mosaic. PDS Volumes USA_NASA_PDS_CL_4001 4078. http://pdsmaps.wr.usgs.gov

[15] Fedotov, S. A., 1976. Ascent of basaltic magmas in the crust and the mechanism of basaltic fissure eruptions. Internat. Geol. Rev. 20, 33-48.

[16] Gaddis, L. R., Staid, M. I., Tyburczy, J. A., Hawke, B. R., Petro, N. E., 2003. Compositional analyses of lunar pyroclastic deposits. Icarus 161, 262-280.

[17] Gillis, J. J., Lucey, P. G., 2005. Evidence that UVVIS ratio is not a simple linear function of TiO2 content for lunar mare basalts. Lunar Planet. Sci. XXXVI, abstract \#2252.

[18] Head, J. W., Gifford, A., 1980. Lunar mare domes: classification and modes of origin. The Moon and Planets 22, 235-257.

[19] Head, J. W., Wilson, L., 1992. Lunar mare volcanism: Stratigraphy, eruption conditions, and the evolution of secondary crusts. Geochim. Cosmochim. Acta 56, 2155-2175.

[20] Head, J. W., Wilson, L., 1996. Lunar linear rilles as surface manifestation of dikes: predictions and observations. Lunar Planet. Sci. XXVII, abstract \#519.

[21] Head, J. W., Wilson, L., Anderson, K. A., Lin, R. P., 1997. Lunar linear rilles, models of dike emplacement and associated magnetization features. Lunar Planet. Sci. XXVIII, abstract \#1242.

[22] Hiesinger, H., Head, J. W., Jaumann, R., Neukum, G., 1999. Lunar mare volcanism. Lunar Planet. Sci. XXX, abstract \#1199. 
[23] Hiesinger, H., Head, J. W., Wolf, U., Jaumann, R., Neukum, G., 2003. Ages and stratigraphy of mare basalts in Oceanus Procellarum, Mare Nubium, Mare Cognitum, and Mare Insularum. J. Geophys. Res. 108(E7), 5065-5091.

[24] Jackson, P. A., Wilson, L., Head, J. W., 1997. The use of magnetic signatures in identifying shallow intrusions on the moon. Lunar Planet. Sci. XXVIII, abstract \#1429.

[25] Kapral, C., Garfinkle, R., 2005. GLR Lunar Dome Catalog. http://www.glrgroup.org/domes/kapralcatalog.htm

[26] Lena, R., Wöhler, C., Phillips, J., Bregante, M. T., 2006a. The HortensiusMilichius-Tobias Mayer region: An unlisted dome located at $25.17^{\circ} \mathrm{W}$ and $6.07^{\circ} \mathrm{N}$. Selenology Today 1, 4-10.

[27] Lena, R., Wöhler, C., Wöhler, A., Phillips, J., Pau, K. C., Lazzarotti, P., Bregante, M. T., 2006b. A study about two unlisted domes near Promontorium Laplace. Selenology Today 1, 11-17.

[28] Lepage, L. D., Pearce, T. H., 2002. Apparent Viscosity of Andesites Links Eruption Style to Crystallinity. American Geophysical Union, Fall Meeting 2002, abstract \#V72D-02.

[29] Lucey, P. G., Blewett, D. T., Hawke, B. R., 1998. Mapping the $\mathrm{FeO}$ and $\mathrm{TiO}_{2}$ content of the lunar surface with multispectral imagery. J. Geophys. Res. 103(E2), 3679-3699.

[30] Marsh, B. D., 1981. On the crystallinity, probability of occurrence, and rheology of lava and magma. Contribution to Mineralogy and Petrology 78, 85-98.

[31] Marsh, B. D., 2000. Magma chambers. In: Sigurdsson, H. (Ed.), Encyclopedia of Volcanoes. Academic Press, San Diego.

[32] McCord, T. B., Adams, J. B., 1973. Progress in optical analysis of lunar surface composition. The Moon 7, 453-474.

[33] McCord, T. B., Charette, M. P., Johnson, T. V., Lebofsky, L. A., Pieters, C., Adams, J. B., 1972. Lunar spectral types. J. Geophys. Res. 77, 1349-1359. 
[34] McCord, T. B., Pieters, C., Feierberg, M. A., 1976. Multispectral mapping of the lunar surface using ground-based telescopes. Icarus 29, 1-34.

[35] McEwen, A. S., 1991. Photometric Functions for Photoclinometry and Other Applications. Icarus 92, 298-311.

[36] McKay, D. S., Heiken, G., Basu, A., Blanford, G., Simon, S., Reedy, R., French, B. M., Papike, J., 1991. The Lunar regolith. In: G. Heiken, D. Vaniman, B. M. French (eds.). Lunar Sourcebook. Cambridge University Press, Cambridge, UK.

[37] Melendrez, D. E., Johnson, J. R., Larson, S. M., Singer, R. B., 1994. Remote sensing of potential lunar resources. 2. High spatial resolution mapping of spectral reflectance ratios and implications for nearside mare $\mathrm{TiO}_{2}$ content. J. Geophys. Res. 99(E3), 5601-5619.

[38] Murase, T., McBirney, A. R., 1970. Viscosity of lunar lavas. Science 167, 14911493.

[39] Mursky, G., 1996. Introduction to Planetary Volcanism. Prentice Hall, Upper Saddle River.

[40] Petrycki, J. A., Wilson, L., 1999. Volcanic Features and Age Relationships Associated with Lunar Graben. Proc. 30th Lunar Planet. Sci. Conf. abstract \#1335.

[41] Pieters, C. M., 1978. Mare basalt types on the front side of the Moon: A summary of spectral reflectance data. Lunar Planet. Sci. IX, 2825-2849.

[42] Richter, D. H., Eaton, J. P., Murata, K. J., Ault, W. H., Krivoy, H. L., 1970. Chronological narrative of the 1959-1960 eruption of Kilauea volcano, Hawaii. USGS Prof. Paper 537-E, 1-73.

[43] Ringwood, A. F., Kesson, S. E., 1976. A dynamic model for mare basalt petrogenesis. Lunar Sci. Conf. 7, 1697-1722.

[44] Rubin, A. S., 1993a. Dikes vs. diapirs in viscoelastic rock. Earth and Planet. Sci. Lett. 199, 641-659. 


\section{ACCEPTED MANUSCRIPT}

[45] Rubin, A. S., 1993b. Tensile fracture of rock at high confining pressure: Implications for dike propagation. J. Geophys. Res. 98, 15919-15935.

[46] Sato., H., 2005. Viscosity measurement of subliquidus magmas: 1707 basalt of Fuji volcano. J. Mineralogical and Petrological Sciences 100, 133-142.

[47] Schmincke, H. U., 2004. Volcanism. Springer Verlag, Berlin.

[48] Scott, R. S., Wilson, L., 2001. The stress state of the lunar lithosphere and the volumes of intruded and erupted magmas. Lunar Planet. Sci. XXXII, abstract \#1549.

[49] Spera, F. J., 2000. Physical properties of magma. In: Sigurdsson, H. (Ed.), Encyclopedia of Volcanoes. Academic Press, San Diego.

[50] Spudis, P., 1993. The Geology of Multi-Ring Impact Basins. Cambridge University Press, Cambridge, UK.

[51] Staid, M. I., Pieters, C. M., Head, J. W., 1996. Mare Tranquillitatis: Basalt emplacement history and relation to lunar samples. J. Geophys. Res. 101(E10), 213-227.

[52] Wada, Y., 1994. On the relationship between dike width and magma viscosity. J. Geophys. Res. 99(B9), 17743-17755.

[53] Weitz, C. M., Head, J. W., 1999. Spectral properties of the Marius Hills volcanic complex and implications for the formation of lunar domes and cones. J. Geophys. Res. 104(E8), 18933-18956.

[54] Wenker, A., 1999. Geologic Map of the Near Side of the Moon, based on the 1971 version by Don E. Wilhelms and John F. McCauley. USGS, Flagstaff, Arizona.

[55] Whitaker, E. A., 1981. The lunar Procellarum basin. In: Multi-ring basins: Formation and evolution. Lunar Planet. Sci. XI, 105-111.

[56] Whitford-Stark, J. L., Head, J. W., 1977. The Procellarum volcanic complexes: Contrasting styles of volcanism. Lunar Planet. Sci. VIII, 2705-2724. 
[57] Wieczorek, M. A., Phillips, R. J., 1998. Potential anomalies on a sphere: Applications to the thickness of the lunar crust. J. Geophys. Res. 103, 1715-1724.

[58] Wieczorek, M. A., Zuber, M. T., Phillips, R. J., 2001. The role of magma buoyancy on the eruption of lunar basalts. Earth Planet. Sci. Lett. 185, 71-83.

[59] Wieczorek, M. A., and 15 coauthors, 2006. The Constitution and Structure of the Lunar Interior. Rev. Mineralogy and Geochemistry 60, 221-364.

[60] Wilhelms, D. E., 1972. Geologic map of the Taruntius quadrangle of the Moon. USGS map I722, USGS, Flagstaff, Arizona.

[61] Wilhelms, D. E., 1987. The geologic history of the Moon. USGS Prof. Paper 1348.

[62] Wilhelms, D. E., McCauley, J. F., 1971. Geologic Map of the Near Side of the Moon. USGS, Flagstaff, Arizona.

[63] Williams, D. A., Fagents, S. A., Greeley, R., 2000. A reassessment of the emplacement and erosional potential of turbulent, low viscosity lavas on the moon. Lunar Planet. Sci. XXXI, abstract \#1102.

[64] Wilson, L., Head, J. W., 1996. Lunar linear rilles as surface manifestations of dikes: theoretical considerations. Lunar Planet. Sci. XXVII, abstract \#1445.

[65] Wilson, L., Head, J. W., 2003. Lunar Gruithuisen and Mairan domes: Rheology and mode of emplacement. J. Geophys. Res. 108(E2), 5012-5018.

[66] Wöhler, C., Lena, R., Lazzarotti, P., Phillips, J., Wirths, M., Pujic, Z., 2006. A combined spectrophotometric and morphometric study of the lunar mare dome fields near Cauchy, Arago, Hortensius, and Milichius. Icarus 183, 237-264.

[67] Wood, C. A., 1979. Monogenetic volcanoes of the terrestrial planets. Lunar Planet. Sci. X, 2815-2840.

[68] Yingst, R. A., Head, J. W., 1997. Volumes of lunar lava ponds in South Pole-Aitken and Orientale basins: Implications for eruption conditions, transport mechanism, and magma source regions. J. Geophys. Res. 102, 10909-10931. 
[69] Zuber, M. T., Smith, D. E., Lemoine, F. G., Neumann, G. A., 1994. The shape and internal structure of the Moon from the Clementine mission. Science 266, 1839-1843. 
Tables and Figures

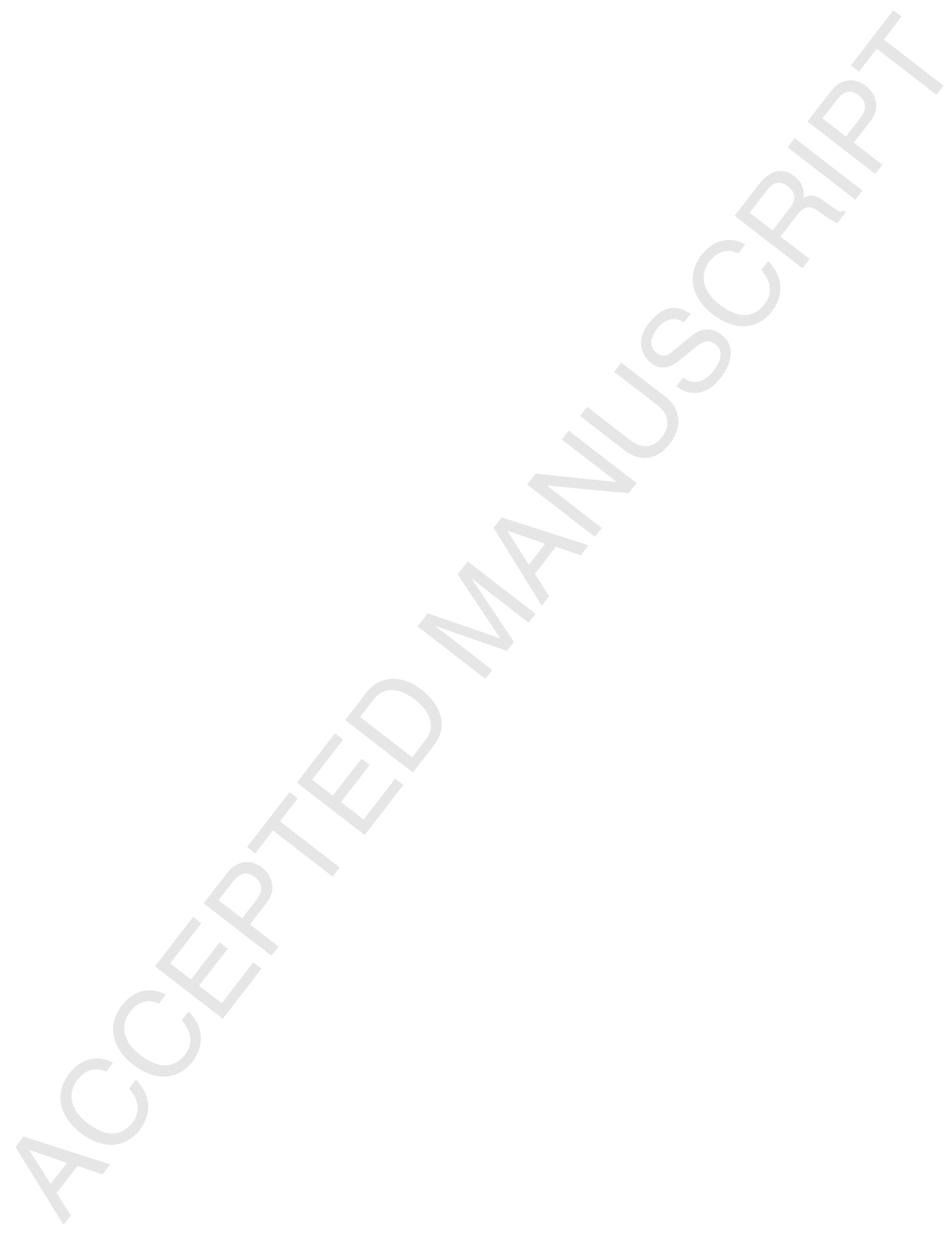




\section{ACCEPTED MANUSCRIPT}

\begin{tabular}{llll}
\hline Domes & $\begin{array}{l}\text { Spectral } \\
\text { properties }\end{array}$ & $\begin{array}{l}\text { Morphometric } \\
\text { and rheologic } \\
\text { properties }\end{array}$ & $\begin{array}{l}\text { Magma rise } \\
\text { speed, dike } \\
\text { dimensions }\end{array}$ \\
\hline $\begin{array}{l}\text { Hortensius/Milichius/ } \\
\text { T. Mayer domes } \\
\text { except M15 }\end{array}$ & paper 1 & paper 1 & this study \\
M15, Diana, Grace, & this study & this study & this study \\
NTA domes & & & paper 1 \\
$\begin{array}{l}\text { Arago/Cauchy domes } \\
\text { Gruithuisen and Mairan } \\
\text { highland domes }\end{array}$ & this study & $\begin{array}{l}\text { Wilson and } \\
\text { Head (2003) }\end{array}$ & this study
\end{tabular}

Table 1: Origin of the data about the lunar domes analysed in this study.

\begin{tabular}{lccrrrr}
\hline Dome & long. $\left[^{\circ}\right]$ & lat. $\left.{ }^{\circ}\right]$ & slope $\left.{ }^{\circ}\right]$ & $\mathrm{D}[\mathrm{km}]$ & $\mathrm{h}[\mathrm{m}]$ & $\mathrm{V}\left[\mathrm{km}^{3}\right]$ \\
\hline H1 & -28.41 & 7.18 & 1.89 & 8.48 & 140 & 3.4 \\
H2 & -28.01 & 7.12 & 3.45 & 7.63 & 230 & 6.3 \\
H3 & -27.78 & 7.59 & 2.05 & 12.3 & 220 & 17 \\
H4 & -27.51 & 7.47 & 3.21 & 6.78 & 190 & 5 \\
H5 & -27.54 & 7.87 & 5.39 & 8.48 & 400 & 18 \\
H6 & -27.34 & 7.82 & 3.57 & 12.5 & 390 & 32 \\
H7 & -25.17 & 6.07 & 1.47 & 7.82 & 100 & 2.4 \\
M1 & -31.58 & 12.76 & 0.86 & 13.4 & 100 & 8.2 \\
M2 & -30.05 & 12.79 & 1.80 & 20.1 & 320 & 50 \\
M3 & -30.43 & 13.78 & 1.40 & 15.6 & 190 & 12 \\
M4 & -27.39 & 12.04 & 1.27 & 15.3 & 170 & 21 \\
M5 & -31.01 & 13.24 & 0.60 & 15.3 & 80 & 6.8 \\
M6 & -32.74 & 11.48 & 1.34 & 19.7 & 230 & 33 \\
M7 & -30.96 & 13.75 & 0.99 & 5.2 & 45 & 0.37 \\
M8 & -29.50 & 14.06 & 3.46 & 4.3 & 130 & 1.2 \\
M9 & -29.40 & 13.98 & 3.15 & 4.0 & 110 & 0.88 \\
M10 & -31.70 & 14.06 & 0.84 & 19.0 & 140 & 21 \\
M11 & -31.08 & 14.77 & 2.80 & 6.0 & 150 & 2.3 \\
M12 & -31.20 & 10.08 & 2.72 & 9.7 & 230 & 11 \\
M15 & -25.17 & 6.07 & 0.60 & 21 & 110 & 17 \\
NTA1 & 35.10 & 14.66 & 0.34 & 17.1 & 50 & 3.9 \\
NTA2 & 35.40 & 14.30 & 0.70 & 5.7 & 35 & 0.60 \\
Diana & 35.64 & 14.24 & 1.31 & 6.1 & 70 & 1.1 \\
Grace & 35.90 & 14.17 & 2.00 & 8.0 & 140 & 4.7 \\
NTA3 & 36.19 & 13.95 & 0.62 & 9.2 & 50 & 2.0 \\
NTA4 & 36.45 & 13.63 & 0.62 & 8.3 & 45 & 0.83 \\
NTA5 & 36.72 & 13.54 & 0.50 & 5.7 & 25 & 0.35 \\
NTA6 & 37.51 & 13.01 & 0.49 & 7.0 & 30 & 0.55
\end{tabular}

Table 2: Selenographic positions and morphometric properties of the examined mare domes. 


\begin{tabular}{lcr}
\hline Dome & vent size $[\mathrm{km}]$ & orientation \\
\hline H7 & $3.2 \times 1.5$ & $73^{\circ}$ \\
M1 & $2.8 \times 0.9$ & $129^{\circ}$ \\
M3 & $2.6 \times 1.4$ & $71^{\circ}$ \\
M4 & $4.4 \times 1.6$ & $57^{\circ}$ \\
M5 & $3.5 \times 1.6$ & $51^{\circ}$ \\
M6 & $3.2 \times 2.1$ & $65^{\circ}$ \\
M10 & $3.5 \times 1.6$ & $59^{\circ}$ \\
M15 & $8.0 \times 0.8$ & $65^{\circ}$ \\
Diana & $1.8 \times 1.2$ & $65^{\circ}$ \\
Grace & $1.8 \times 1.2$ & $101^{\circ}$ \\
NTA3 & $2.3 \times 1.3$ & $67^{\circ}$ \\
NTA4 & $2.2 \times 1.2$ & $69^{\circ}$ \\
NTA5 & $3.5 \times 1.1$ & $61^{\circ}$ \\
NTA6 & $1.4 \times 0.9$ & $47^{\circ}$
\end{tabular}

Table 3: Vent sizes and orientations for domes with elongated vents.

\begin{tabular}{lccc}
\hline Dome & $R_{750}$ & $R_{415} / R_{750}$ & $R_{950} / R_{750}$ \\
\hline M15 & 0.141116 & 0.591995 & 1.038891 \\
NTA1 & 0.099862 & 0.599491 & 1.051952 \\
NTA2 & 0.094221 & 0.619716 & 1.048798 \\
NTA3 & 0.093711 & 0.626981 & 1.048218 \\
Diana & 0.098031 & 0.616127 & 1.036158 \\
Grace & 0.104691 & 0.615161 & 0.997091 \\
NTA4 & 0.105154 & 0.610256 & 0.991576 \\
NTA5 & 0.098477 & 0.604634 & 1.036572 \\
NTA6 & 0.094175 & 0.612411 & 1.056984
\end{tabular}

Table 4: Spectral properties of M15 and the domes in northern Mare Tranquillitatis.

\begin{tabular}{llccc}
\hline Class & $R_{415} / R_{750}$ & $\zeta\left[^{\circ}\right]$ & $D[\mathrm{~km}]$ & $V\left[\mathrm{~km}^{3}\right]$ \\
\hline $\mathrm{A}$ & $>0.64$ & $0.3-1.0$ & $5-13$ & $<3$ \\
$\mathrm{~B}_{1}$ & $0.55-0.64$ & $2.0-5.4$ & $6-15$ & $5-32$ \\
$\mathrm{~B}_{2}$ & $0.55-0.64$ & $1.3-1.9$ & $8-15$ & $2-21$ \\
$\mathrm{C}_{1}$ & $0.55-0.60$ & $0.6-1.8$ & $13-20$ & $7-50$ \\
$\mathrm{C}_{2}$ & $0.60-0.64$ & $1.0-2.5$ & $8-17$ & $4-17$ \\
$\mathrm{D}$ & $>0.64$ & $1.3-1.5$ & $\approx 25$ & $40-67$ \\
$\mathrm{E}_{1}$ & $0.58-0.62$ & $2.0-4.0$ & $<6$ & $<1.2$ \\
$\mathrm{E}_{2}$ & $0.58-0.62$ & $<2.0$ & $<6$ & $<1.2$ \\
$\mathrm{G}$ & $0.55-0.60$ & $>6.0$ & $7-30$ & $20-390$
\end{tabular}

Table 5: Approximate spectral and morphometric properties characterising the dome classes as defined in paper 1, extended according to Lena et al. (2006b) and this study (cf. Section 4.1). 


\begin{tabular}{|c|c|c|c|}
\hline Dome & $\eta[\mathrm{Pa} \mathrm{s}]$ & $E\left[\mathrm{~m}^{3} \mathrm{~s}^{-1}\right]$ & $T_{e}[$ years] \\
\hline $\mathrm{H} 1$ & $4.3 \times 10^{5}$ & 89 & 1.21 \\
\hline $\mathrm{H} 2$ & $6.0 \times 10^{6}$ & 44 & 4.54 \\
\hline H3 & $1.5 \times 10^{6}$ & 120 & 4.51 \\
\hline $\mathrm{H} 4$ & $3.2 \times 10^{6}$ & 42 & 3.77 \\
\hline H5 & $6.6 \times 10^{7}$ & 31 & 18.27 \\
\hline $\mathrm{H} 6$ & $2.3 \times 10^{7}$ & 70 & 14.57 \\
\hline $\mathrm{H} 7$ & $1.0 \times 10^{5}$ & 106 & 0.72 \\
\hline M1 & $2.8 \times 10^{4}$ & 312 & 0.83 \\
\hline M2 & $2.9 \times 10^{6}$ & 219 & 7.23 \\
\hline M3 & $4.3 \times 10^{5}$ & 223 & 1.71 \\
\hline M4 & $2.6 \times 10^{5}$ & 239 & 2.78 \\
\hline M5 & $7.1 \times 10^{3}$ & 509 & 0.42 \\
\hline M6 & $6.1 \times 10^{5}$ & 293 & 3.57 \\
\hline M7 & $6.0 \times 10^{3}$ & 104 & 0.11 \\
\hline M8 & $1.5 \times 10^{6}$ & 25 & 1.54 \\
\hline M9 & $8.2 \times 10^{5}$ & 25 & 1.10 \\
\hline M10 & $6.2 \times 10^{4}$ & 448 & 1.49 \\
\hline M11 & $1.4 \times 10^{6}$ & 42 & 1.75 \\
\hline M12 & $3.4 \times 10^{6}$ & 71 & 4.91 \\
\hline M15 & $1.5 \times 10^{4}$ & 704 & 0.90 \\
\hline NTA1 & $5.6 \times 10^{2}$ & 1016 & 0.12 \\
\hline NTA2 & $1.4 \times 10^{3}$ & 161 & 0.12 \\
\hline Diana & $3.4 \times 10^{4}$ & 92 & 0.38 \\
\hline Grace & $4.9 \times 10^{5}$ & 80 & 1.88 \\
\hline NTA3 & $2.5 \times 10^{3}$ & 294 & 0.21 \\
\hline NTA4 & $1.9 \times 10^{3}$ & 266 & 0.10 \\
\hline NTA5 & $2.8 \times 10^{2}$ & 226 & 0.05 \\
\hline NTA6 & $4.1 \times 10^{2}$ & 284 & 0.06 \\
\hline Gruithuisen $\gamma$ & $3.2 \times 10^{8}$ & 119 & 38 \\
\hline Gruithuisen $\delta$ & $9.7 \times 10^{8}$ & 50 & 38.7 \\
\hline (lower and upper NW part) & & 24 & 23.8 \\
\hline Gruithuisen NW & $9.9 \times 10^{8}$ & 24 & 23.8 \\
\hline (lower and upper part) & & 6 & 9.1 \\
\hline Mairan T & $1.2 \times 10^{8}$ & 48 & 41.5 \\
\hline Mairan "middle" & $2.5 \times 10^{8}$ & 52 & 18.4 \\
\hline Mairan "south" & $1.3 \times 10^{8}$ & 51 & 12.8 \\
\hline
\end{tabular}

Table 6: Rheologic properties of the examined mare domes. The corresponding values determined by Wilson and Head (2003) for the Gruithuisen and Mairan highland domes are listed for comparison. 


\begin{tabular}{|c|c|c|c|c|c|}
\hline Dome & Class & RG & $U\left[\mathrm{~m} \mathrm{~s}^{-1}\right]$ & $W[\mathrm{~m}]$ & $L[\mathrm{~km}]$ \\
\hline$\overline{\mathrm{H} 1}$ & $\mathrm{~B}_{2}$ & $\mathrm{R}_{3}$ & $2.3 \times 10^{-5}$ & 30 & 133 \\
\hline $\mathrm{H} 2$ & $\mathrm{~B}_{1}$ & $\mathrm{R}_{3}$ & $2.8 \times 10^{-6}$ & 89 & 176 \\
\hline H3 & $\mathrm{B}_{1}$ & $\mathrm{R}_{3}$ & $1.2 \times 10^{-5}$ & 51 & 187 \\
\hline $\mathrm{H} 4$ & $\mathrm{~B}_{1}$ & $\mathrm{R}_{3}$ & $3.6 \times 10^{-6}$ & 69 & 182 \\
\hline H5 & $\mathrm{B}_{1}$ & $\mathrm{R}_{3}$ & $9.2 \times 10^{-7}$ & 243 & 145 \\
\hline $\mathrm{H} 6$ & $\mathrm{~B}_{1}$ & $\mathrm{R}_{3}$ & $2.8 \times 10^{-6}$ & 157 & 160 \\
\hline $\mathrm{H} 7$ & $\mathrm{~B}_{2}$ & $\mathrm{R}_{1}$ & $8.7 \times 10^{-5}$ & 17 & 74 \\
\hline M1 & $\mathrm{C}_{1}$ & $\mathrm{R}_{1}$ & $7.4 \times 10^{-4}$ & 9.7 & 43 \\
\hline M2 & $\mathrm{C}_{1}$ & $\mathrm{R}_{3}$ & $1.8 \times 10^{-5}$ & 66 & 183 \\
\hline M3 & $\mathrm{C}_{1}$ & $\mathrm{R}_{1}$ & $5.7 \times 10^{-5}$ & 30 & 133 \\
\hline M4 & $\mathrm{B}_{2}$ & $\mathrm{R}_{1}$ & $9.1 \times 10^{-5}$ & 24 & 109 \\
\hline M5 & $\mathrm{C}_{1}$ & $\mathrm{R}_{1}$ & $3.7 \times 10^{-3}$ & 5.6 & 25 \\
\hline M6 & $\mathrm{C}_{1}$ & $\mathrm{R}_{1}$ & $5.4 \times 10^{-5}$ & 35 & 155 \\
\hline M7 & $\mathrm{E}_{2}$ & $\mathrm{R}_{1}$ & $9.2 \times 10^{-4}$ & 5.1 & 23 \\
\hline M8 & $\mathrm{E}_{1}$ & $\mathrm{R}_{3}$ & $2.4 \times 10^{-6}$ & 51 & 187 \\
\hline M9 & $\mathrm{E}_{1}$ & $\mathrm{R}_{3}$ & $3.8 \times 10^{-6}$ & 39 & 174 \\
\hline M10 & $\mathrm{C}_{1}$ & $\mathrm{R}_{1}$ & $5.6 \times 10^{-4}$ & 13 & 60 \\
\hline M11 & $\mathrm{B}_{1}$ & $\mathrm{R}_{3}$ & $4.6 \times 10^{-6}$ & 48 & 188 \\
\hline M12 & $\mathrm{B}_{1}$ & $\mathrm{R}_{3}$ & $5.6 \times 10^{-6}$ & 70 & 182 \\
\hline M15 & $\mathrm{C}_{1}$ & $\mathrm{R}_{1}$ & $2.7 \times 10^{-3}$ & 7.6 & 34 \\
\hline NTA1 & $\mathrm{A}-\mathrm{C}_{1}-\mathrm{C}_{2}$ & $\mathrm{R}_{2}$ & $4.4 \times 10^{-2}$ & 2.3 & 10 \\
\hline NTA2 & $\mathrm{A}-\mathrm{E}_{2}$ & $\mathrm{R}_{2}$ & $4.4 \times 10^{-3}$ & 2.8 & 13 \\
\hline Diana & $\mathrm{A}-\mathrm{C}_{2}-\mathrm{E}_{2}$ & $\mathrm{R}_{1}$ & $1.9 \times 10^{-4}$ & 10 & 46 \\
\hline Grace & $\mathrm{C}_{2}$ & $\mathrm{R}_{1}$ & $1.8 \times 10^{-5}$ & 32 & 141 \\
\hline NTA3 & $\mathrm{B}_{2}-\mathrm{C}_{1}$ & $\mathrm{R}_{2}$ & $5.0 \times 10^{-3}$ & 3.6 & 16 \\
\hline NTA4 & $\mathrm{B}_{2}-\mathrm{C}_{1}$ & $\mathrm{R}_{2}$ & $5.6 \times 10^{-3}$ & 3.3 & 15 \\
\hline NTA5 & $\mathrm{A}-\mathrm{E}_{2}$ & $\mathrm{R}_{2}$ & $2.1 \times 10^{-2}$ & 1.5 & 6.9 \\
\hline NTA6 & $\mathrm{A}-\mathrm{E}_{2}$ & $\mathrm{R}_{2}$ & $1.9 \times 10^{-2}$ & 1.8 & 8.1 \\
\hline C1 & A & $\mathrm{R}_{2}$ & $6.7 \times 10^{-2}$ & 1.2 & 5.5 \\
\hline $\mathrm{C} 2$ & $\mathrm{C}_{1}$ & $\mathrm{R}_{1}$ & $1.7 \times 10^{-4}$ & 17 & 74 \\
\hline C3 & $\mathrm{C}_{1}$ & $\mathrm{R}_{1}$ & $7.9 \times 10^{-5}$ & 27 & 123 \\
\hline $\mathrm{C} 4$ & A & $\mathrm{R}_{2}$ & $1.9 \times 10^{-2}$ & 2.7 & 12 \\
\hline C5 & $\mathrm{C}_{1}$ & $\mathrm{R}_{1}$ & $3.5 \times 10^{-4}$ & 12 & 52 \\
\hline C6 & A & $\mathrm{R}_{2}$ & $2.5 \times 10^{-3}$ & 4.3 & 19 \\
\hline $\mathrm{A} 4$ & A & $\mathrm{R}_{2}$ & $2.9 \times 10^{-3}$ & 5.0 & 22 \\
\hline A5 & A & $\mathrm{R}_{2}$ & $5.9 \times 10^{-3}$ & 3.2 & 14 \\
\hline A6 & A & $\mathrm{R}_{2}$ & $5.7 \times 10^{-3}$ & 3.5 & 16 \\
\hline Gruithuisen $\gamma$ & highland & & $2.3 \times 10^{-5}$ & 119 & 31 \\
\hline Gruithuisen $\delta$ & highland & me & $0.4 \times 10^{-6}$ & 204 & 25 \\
\hline Gruithuisen NW & highland & me & $4.9 \times 10^{-6}$ & 189 & 26 \\
\hline Mairan $\mathrm{T}$ & highland & me & $4.7 \times 10^{-6}$ & 201 & 25 \\
\hline Mairan "middle" & highland & me & $1.5 \times 10^{-5}$ & 107 & 31 \\
\hline Mairan "south" & highland & me & $1.8 \times 10^{-5}$ & 81 & 34 \\
\hline $\mathrm{H} 3+\mathrm{H} 4$ & - & & $1.4 \times 10^{-5}$ & 61 & 185 \\
\hline $\mathrm{H} 5+\mathrm{H} 6$ & - & & $3.2 \times 10^{-6}$ & 206 & 151 \\
\hline M8+M9 & - & & $5.9 \times 10^{-6}$ & 45 & 189 \\
\hline $\mathrm{M} 3+\mathrm{M} 10$ & - & & $2.7 \times 10^{-4}$ & 24 & 106 \\
\hline $\mathrm{M} 4+\mathrm{M} 15$ & - & & $6.0 \times 10^{-4}$ & 19 & 84 \\
\hline Diana+Grace & - & & $6.6 \times 10^{-5}$ & 24 & 108 \\
\hline Gruithuisen $\gamma+\mathrm{NW}$ & - & & $3.3 \times 10^{-5}$ & 155 & 28 \\
\hline Mairan "middle" + "south" & - & & $1.7 \times 10^{-5}$ & 93 & 33 \\
\hline
\end{tabular}

Table 7: Dome class, rheologic group (RG), magma rise speed, and dike dimensions inferred for the mare domes in the Hortensius/Milichius/T. Mayer region and the domes in northern Mare Tranquillitatis. For comparison, these values are also listed for the domes C1-C6 near Cauchy and A4-A6 near Arago and for the Gruithuisen and Mairan highland domes, computed based on the rheologic properties determined in paper 1 and by Wilson and Head (2003), respectively. 

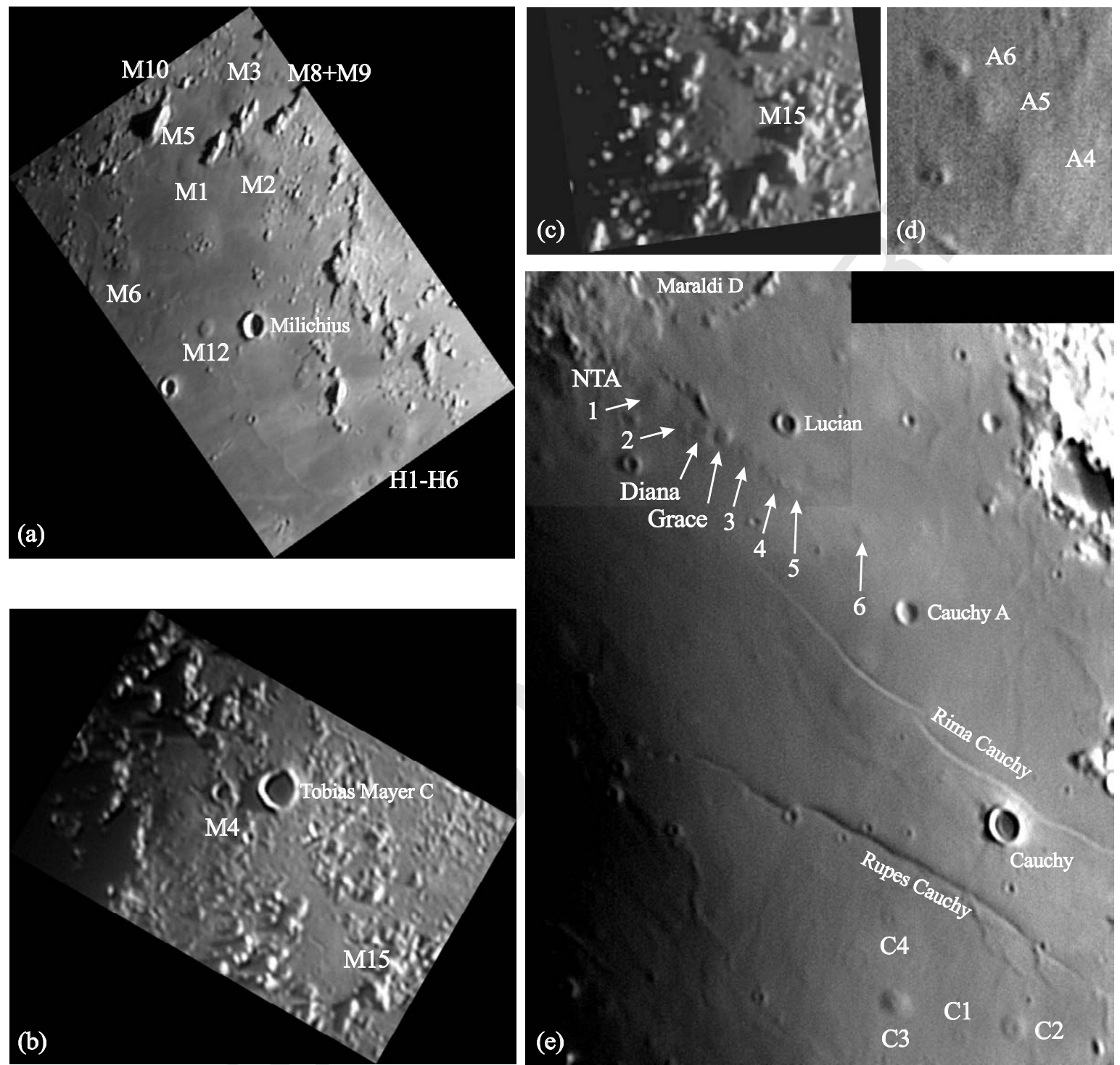

(b)

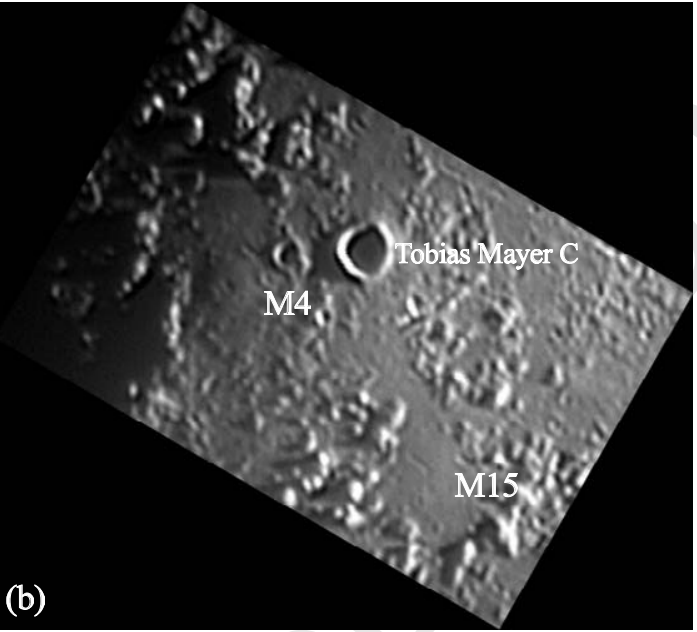

(e)

C3

Figure 1: Telescopic CCD images of the examined dome fields, oriented with north to the top and west to the left. (a) Overview image of the Hortensius/Milichius/T. Mayer region. (b) Overview image of the domes M4 and M15. (c) High-resolution image of the dome M15, used to determine the morphometric dome properties. (d) Aligned domes A4-A6 north of Arago in western Mare Tranquillitatis. (e) Image of northern Mare Tranquillitatis, used to determine the morphometric properties of Diana, Grace, and NTA1-NTA6. 


\section{ACCEPTED MANUSCRIPT}
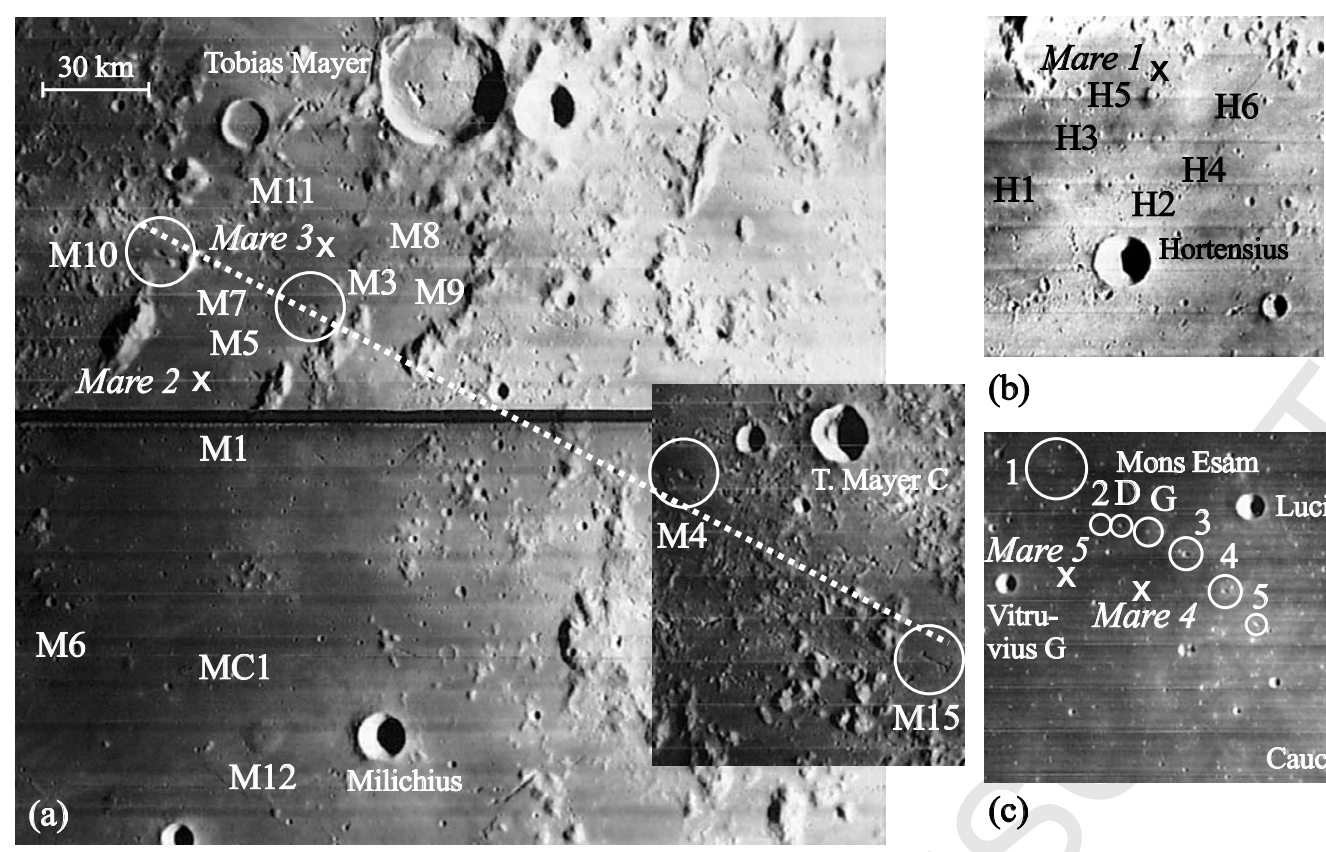

(b)

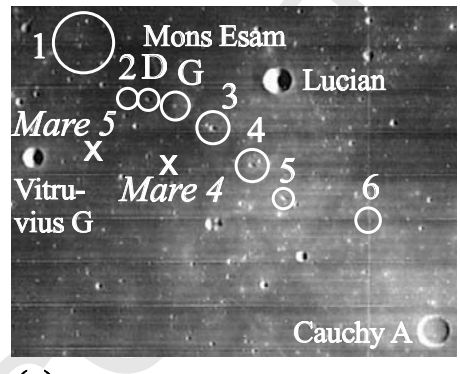

(c)

(d) $10 \mathrm{~km}$
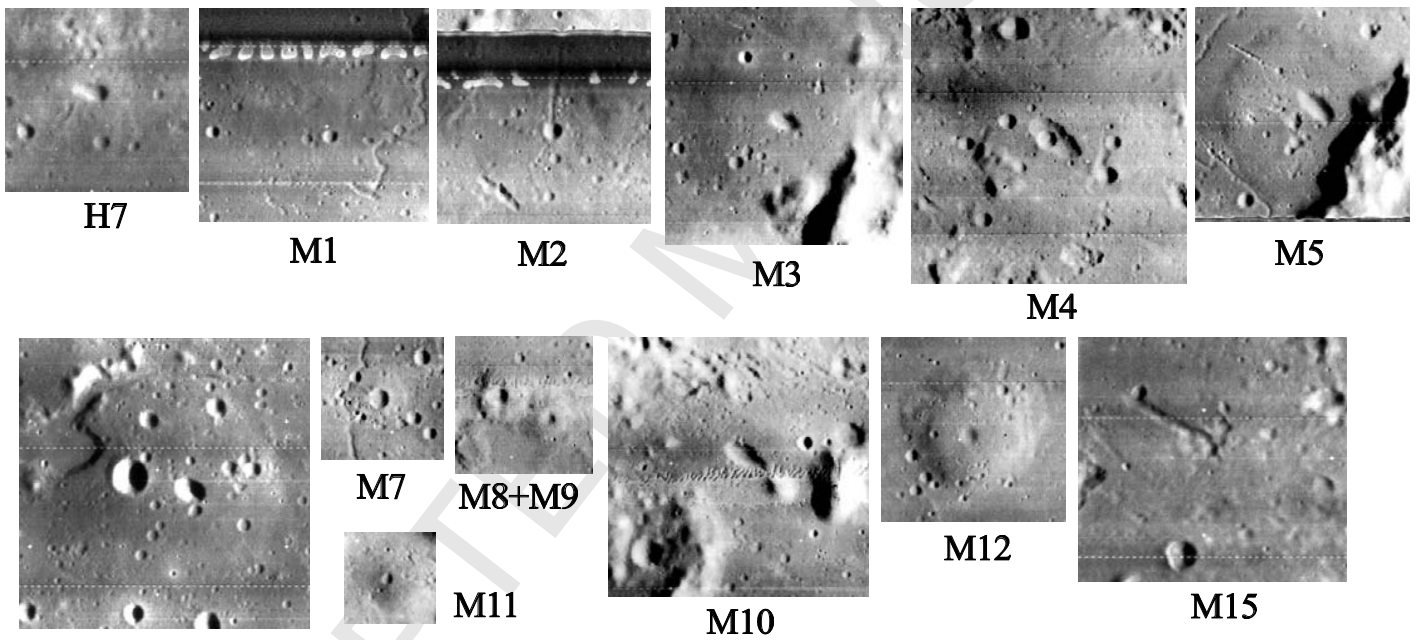

M11 M6
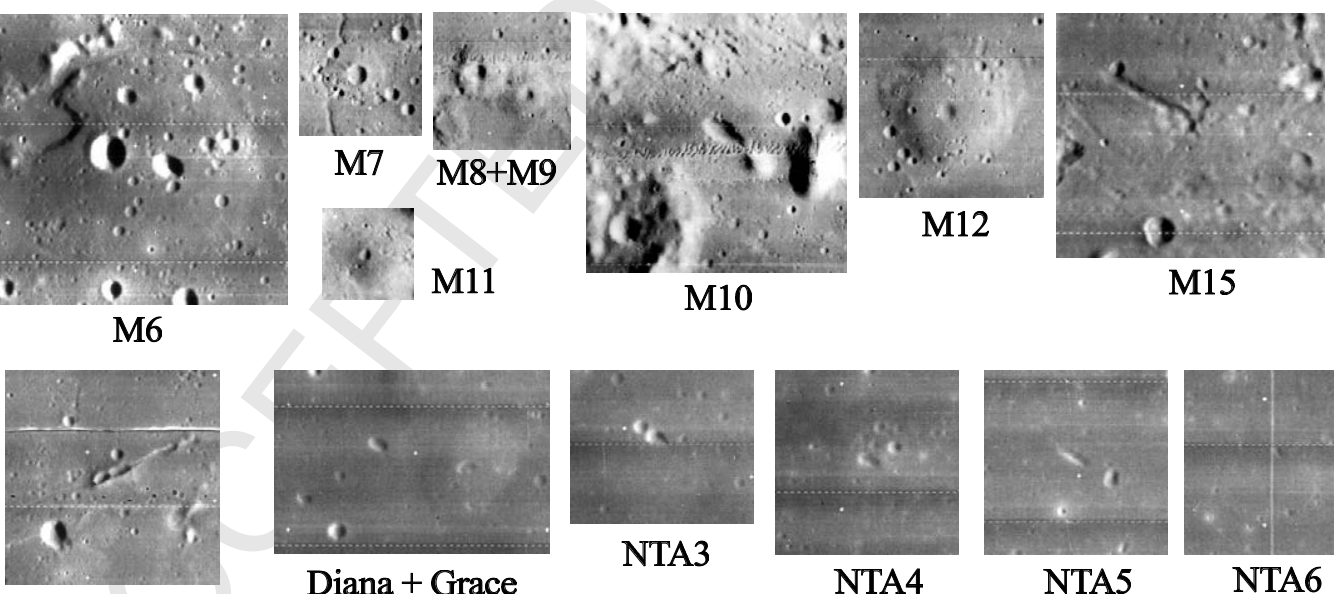

MC1

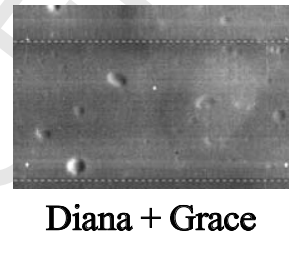

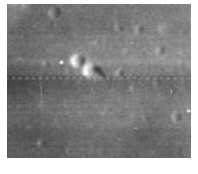

NTA3

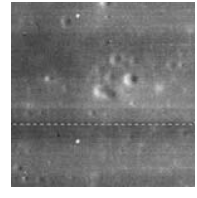

NTA4

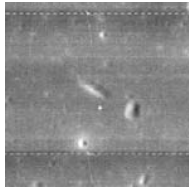

NTA5

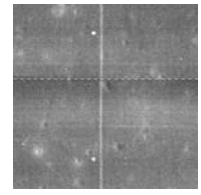

NTA6

Figure 2: (a) Lunar Orbiter images IV-133-H2 and IV-126-H2, showing the domes in the Milichius/T. Mayer region. The dashed line indicates the alignment of the domes M10, M3, M4, and M15. (b) Lunar Orbiter image IV-133-H1, showing the domes near Hortensius. (c) Lunar Orbiter image IV-073-H2, showing the domes Diana and Grace and the NTA domes. Circles indicate dome diameters, crosses indicate mare reference locations for which spectra are shown in Fig. 4. The three images in (a)(c) are reproduced at uniform scale. (d) Enlargements of all examined mare domes apparent in the Lunar Orbiter imagery, reproduced at larger uniform scale. 


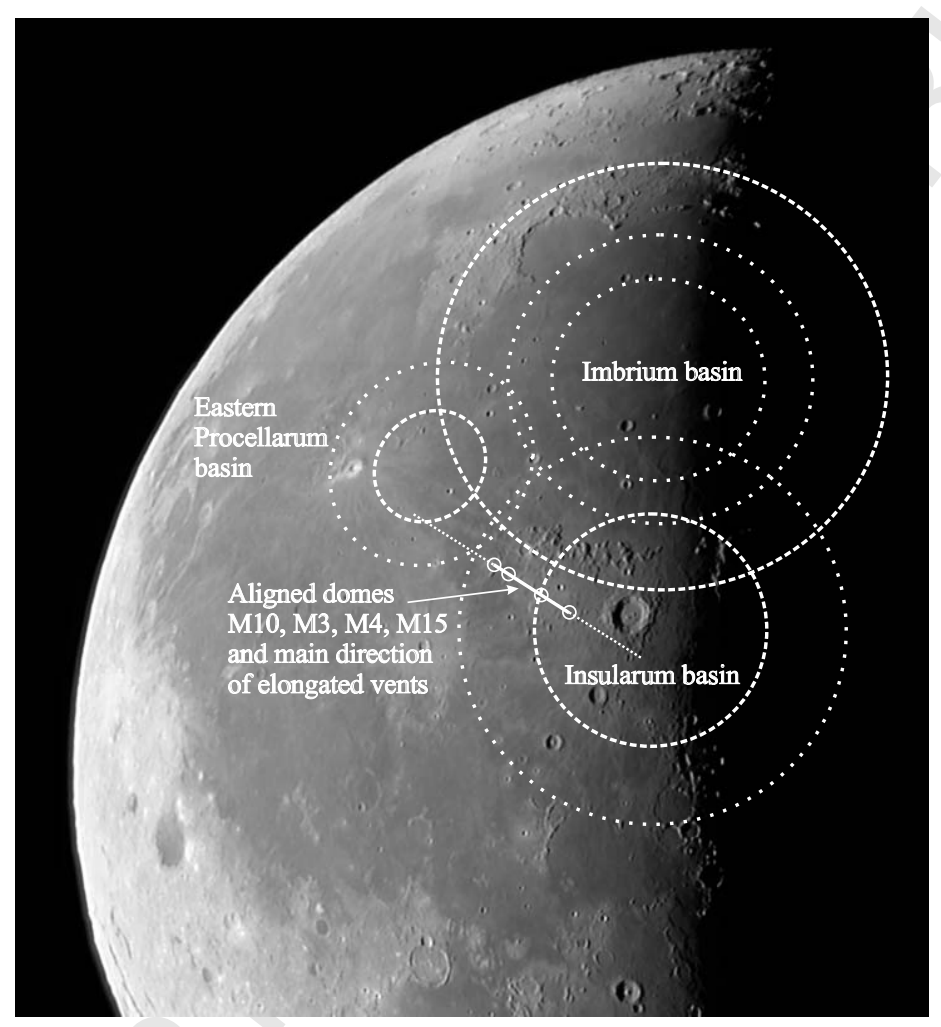

Figure 3: Aligned domes, also indicating the average direction of elongated vents, in the Hortensius/Milichius/T. Mayer region, and the neighbouring impact basins according to Spudis (1993) (Imbrium basin, Insularum basin) and de Hon (1979) (Eastern Procellarum basin). Main basin rings are drawn as dashed lines, secondary rings as dotted lines. 

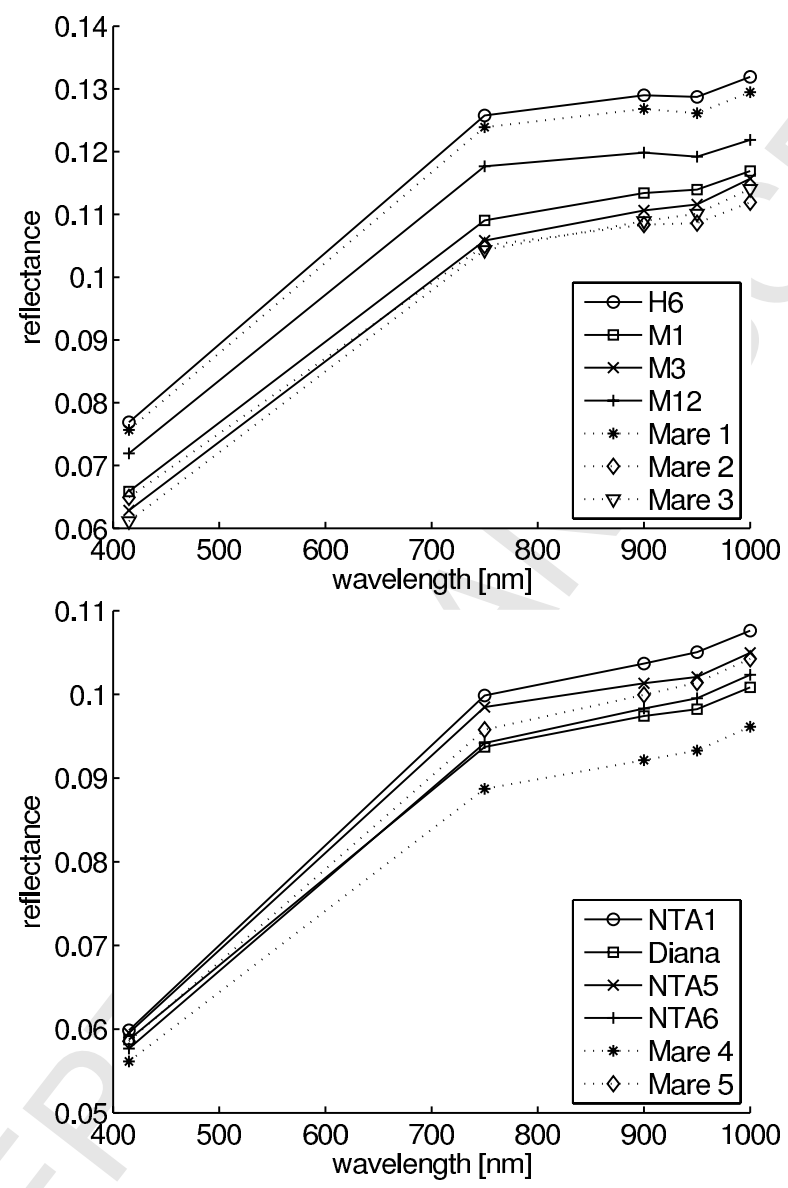

Figure 4: Clementine UVVIS spectra of domes in the Hortensius/Milichius/T. Mayer dome field and in northern Mare Tranquillitatis along with spectra of the five mare reference locations indicated in Fig. 2a-c. 

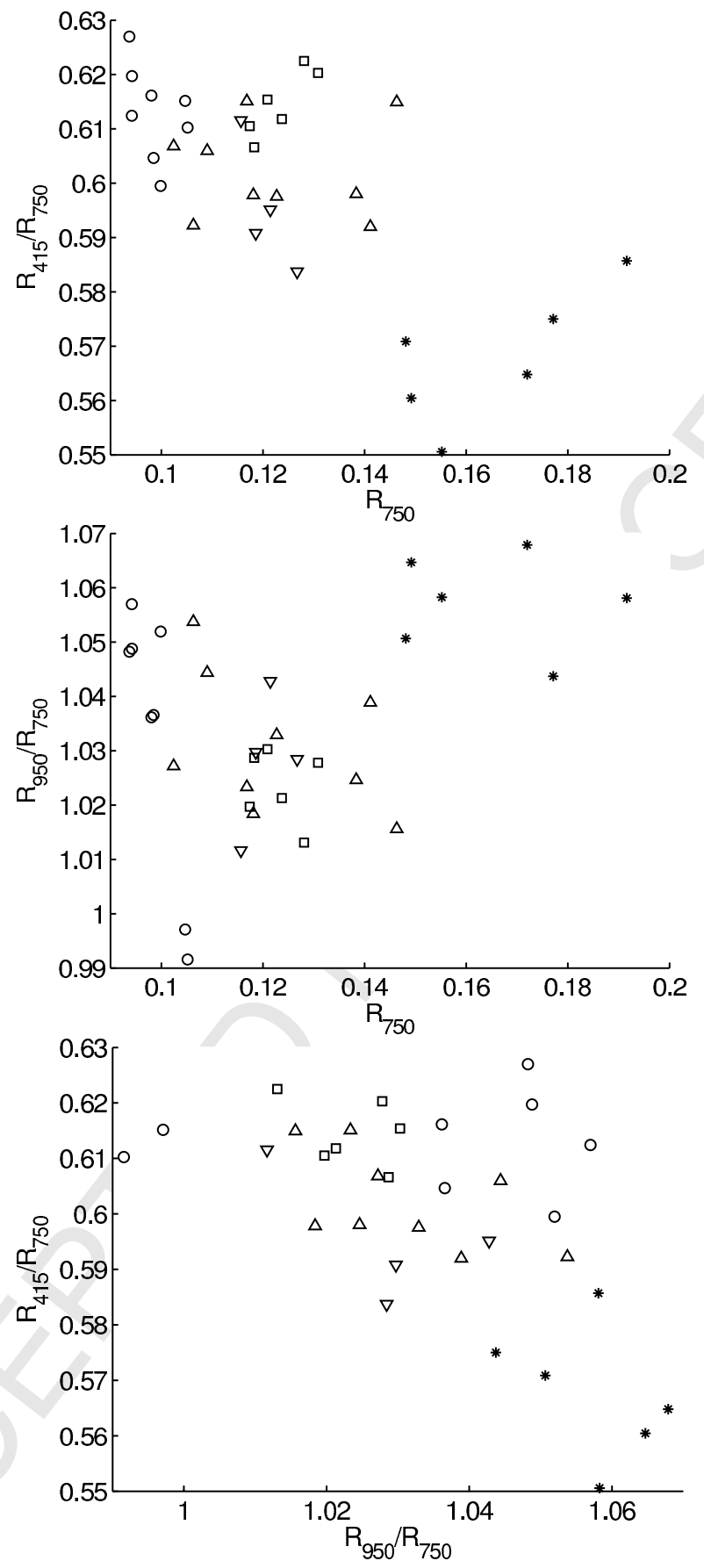

Figure 5: Spectral properties of the domes in the Milichius/T. Mayer region with (M1, M3-M7, M10, M15, H7; up-triangles) and without (M2, M8, M9, M11, M12; down-triangles) elongated vents, the domes in northern Mare Tranquillitatis (Diana, Grace, NTA1-NTA6; circles), the domes near Hortensius (H1-H6; squares), and the Gruithuisen and Mairan highland domes (stars). 


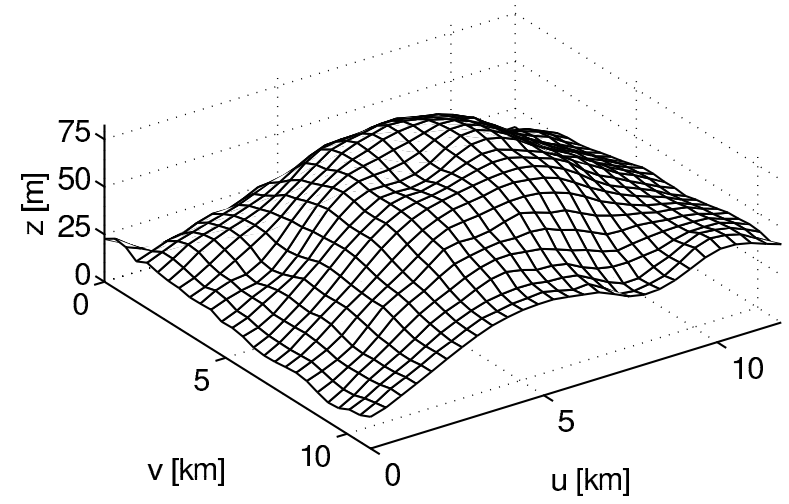

Figure 6: DEM of the dome NTA3, viewed from south-western direction, obtained with the combined photoclinometry and shape from shading method described in Section 3.3. The $z$ axis is 50 times exaggerated.
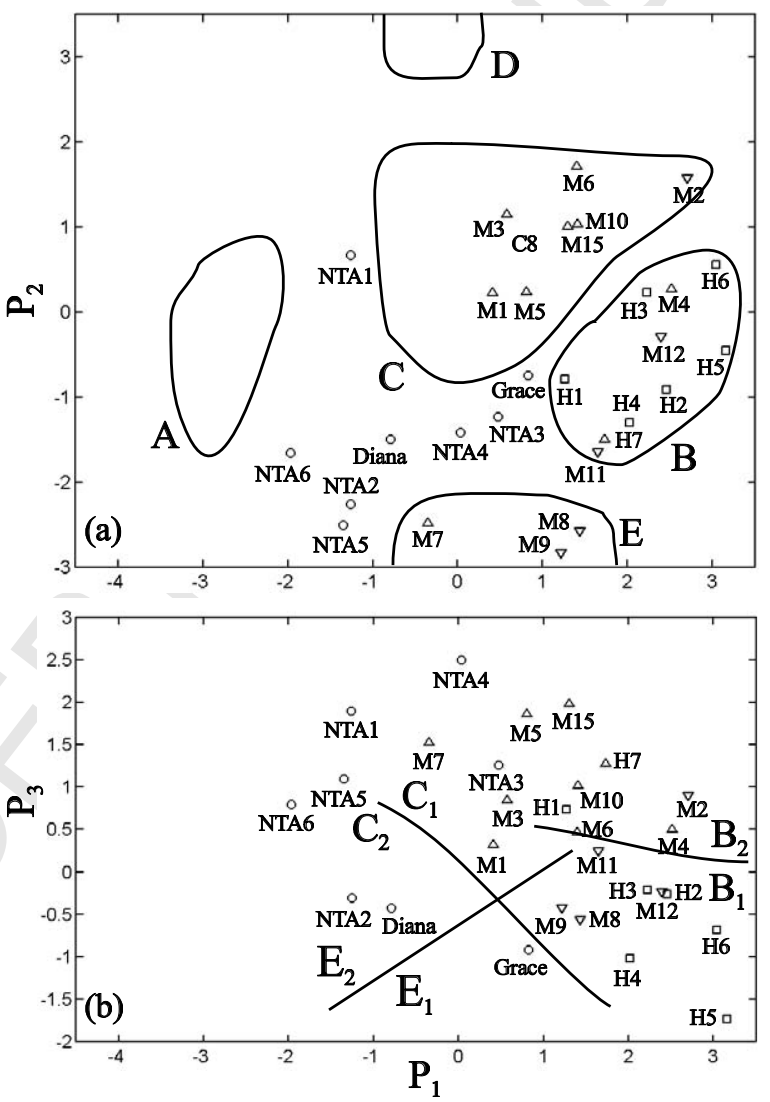

Figure 7: Classification of the domes examined in this study in terms of the lunar dome classification scheme introduced in paper 1, which is based on a principal component analysis in the space of spectrophotometric and morphometric features characterising a lunar dome. Class boundaries are taken from paper 1. 


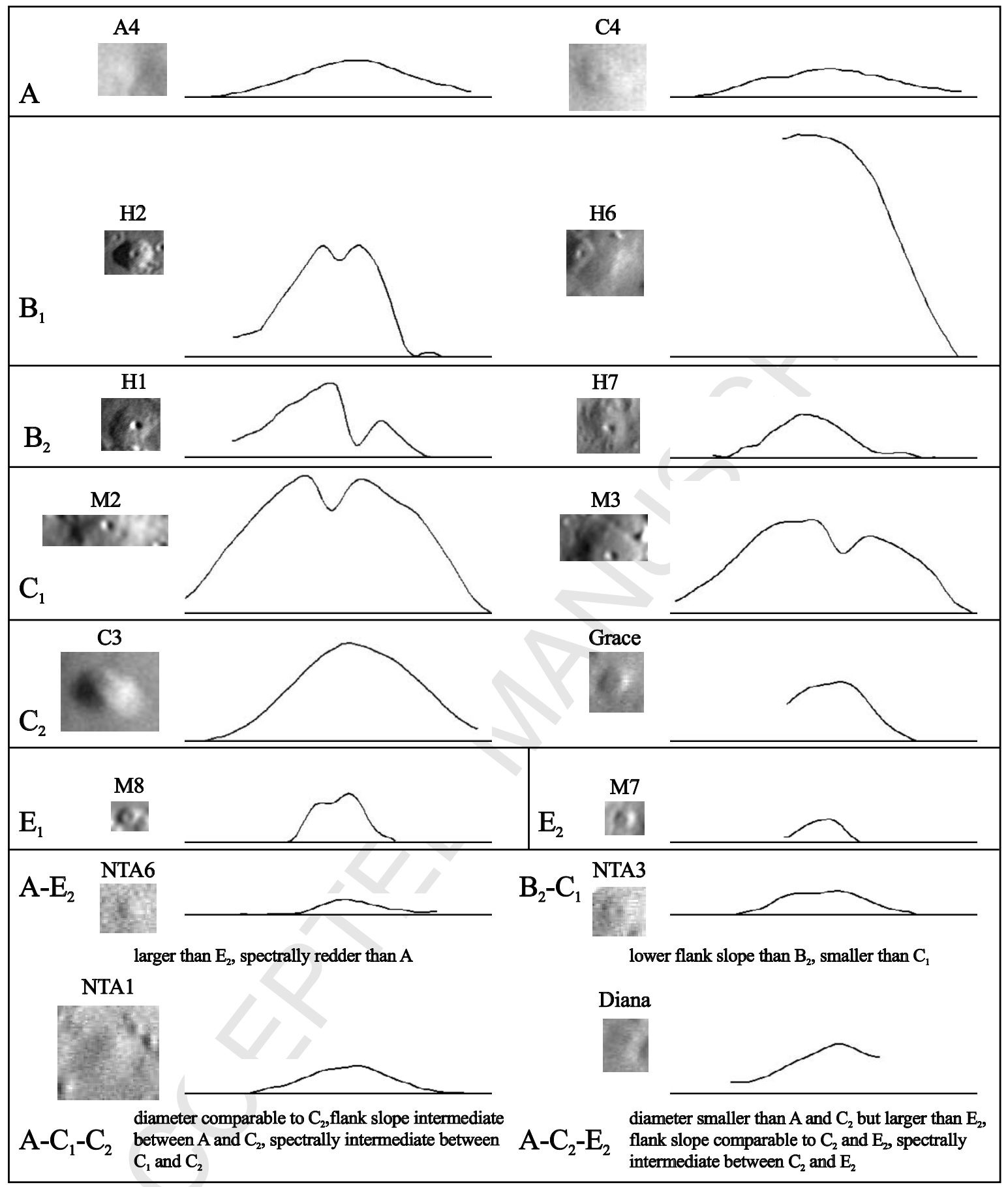

scale of the image patches:

Figure 8: Images and cross-sections of typical representatives of the monogenetic mare dome classes (cf. Table 5) and the continuum between them. All images are rectified to simple cylindrical projection. Images for classes $\mathrm{A}-\mathrm{C}$ except the dome Grace were taken from paper 1, all other images were extracted from Fig. 1e. The horizontal extension of the cross-sections is $20 \mathrm{~km}$, their vertical axes are 30 times exaggerated. 

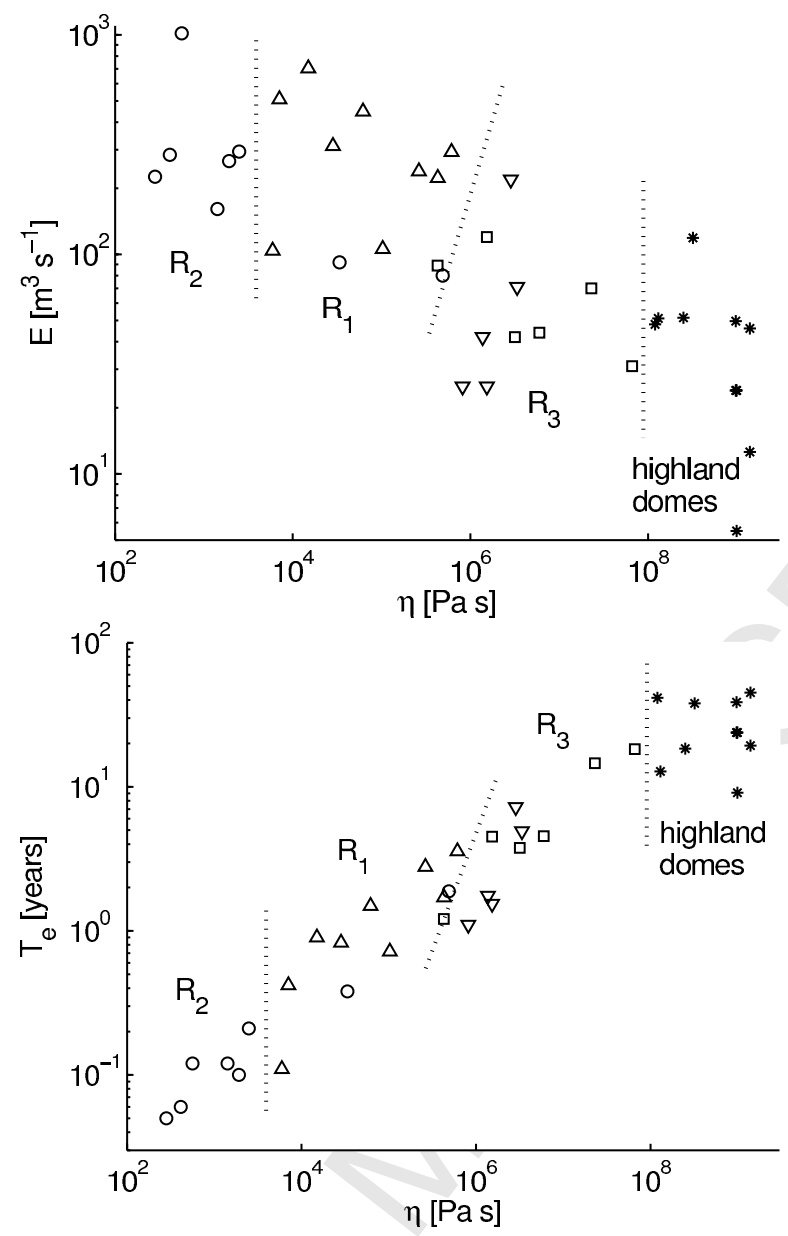

Figure 9: Rheologic properties of the examined set of mare domes, definition of the rheologic groups $R_{1}-R_{3}$ (cf. Section 4.2.3). Symbols are chosen as defined in Fig. 5.

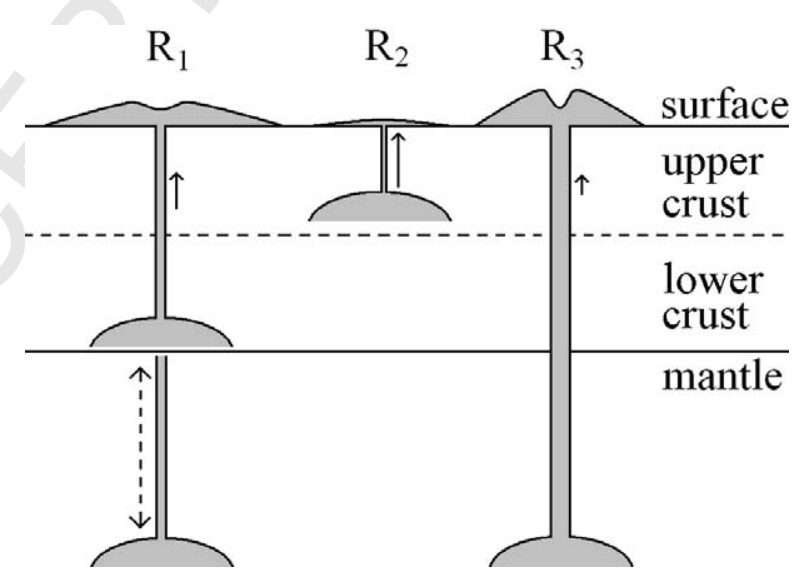

Figure 10: Illustration of rheologic groups $R_{1}-R_{3}$. The indicated dome diameters and heights, magma source depths, and dike widths are not to scale but illustrate relative properties. Solid arrows indicate magma rise speed. 


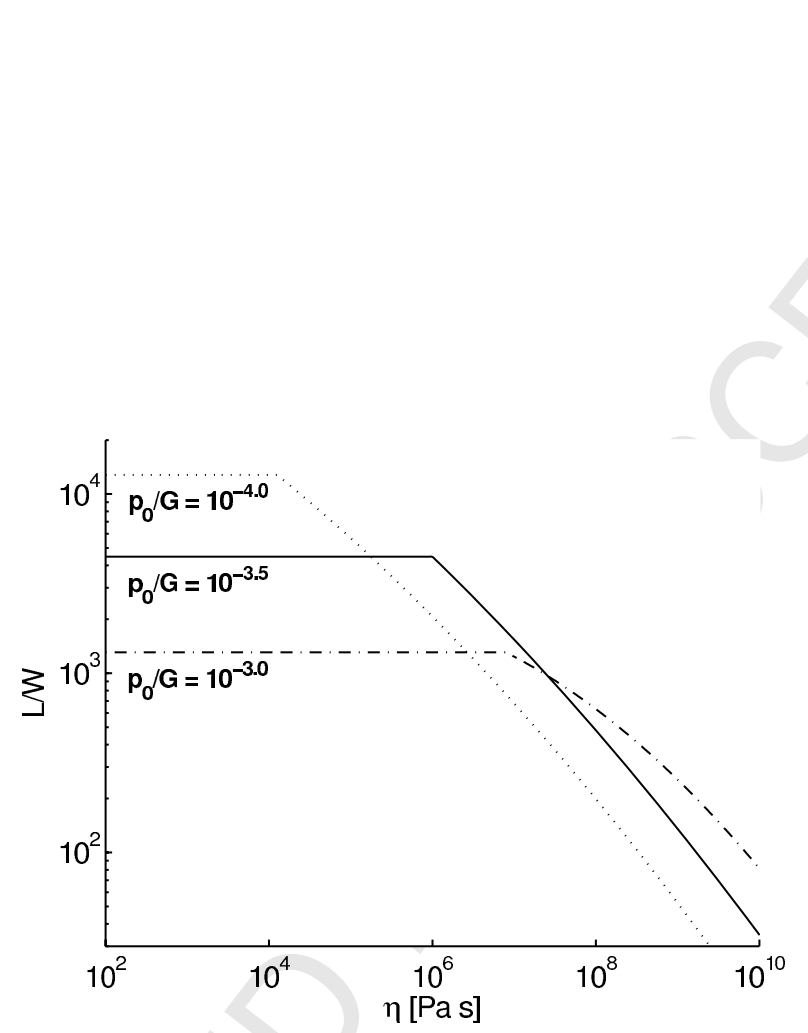

Figure 11: Dependence of the dike length-to-width ratio $L / W$ on magma viscosity $\eta$ according to the viscoelastic model by Rubin (1993) for $\eta_{r}=10^{18} \mathrm{~Pa}$ s and $p_{0} / G=$ $10^{-4.0}$ (dotted curve), $p_{0} / G=10^{-3.5}$ (solid curve), and $p_{0} / G=10^{-3.0}$ (dashed-dotted curve). 

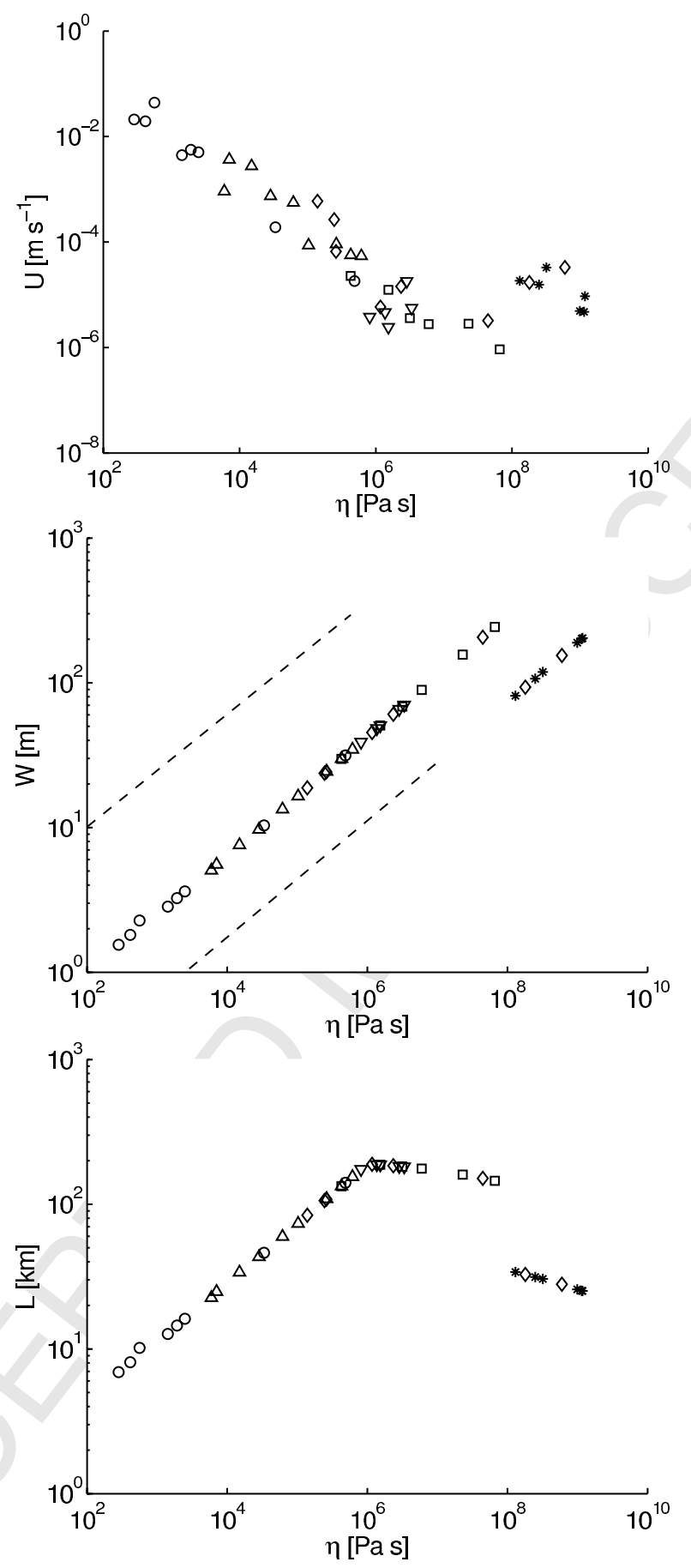

Figure 12: Dependence of magma rise speed $U$, dike width $W$, and dike length $L$ on magma viscosity $\eta$, according to the viscoelastic model by Rubin (1993) with $\eta_{r}=$ $10^{18} \mathrm{~Pa} \mathrm{~s}$ and $p_{0} / G=10^{-3.5}$. Symbols are chosen as defined in Fig. 5. Diamonds denote possible dome pairs sharing a single dike (cf. Section 4.3.2). The dashed lines in the $\eta$ vs. $W$ diagram indicate the interval established by Wada (1994) for terrestrial dikes. 

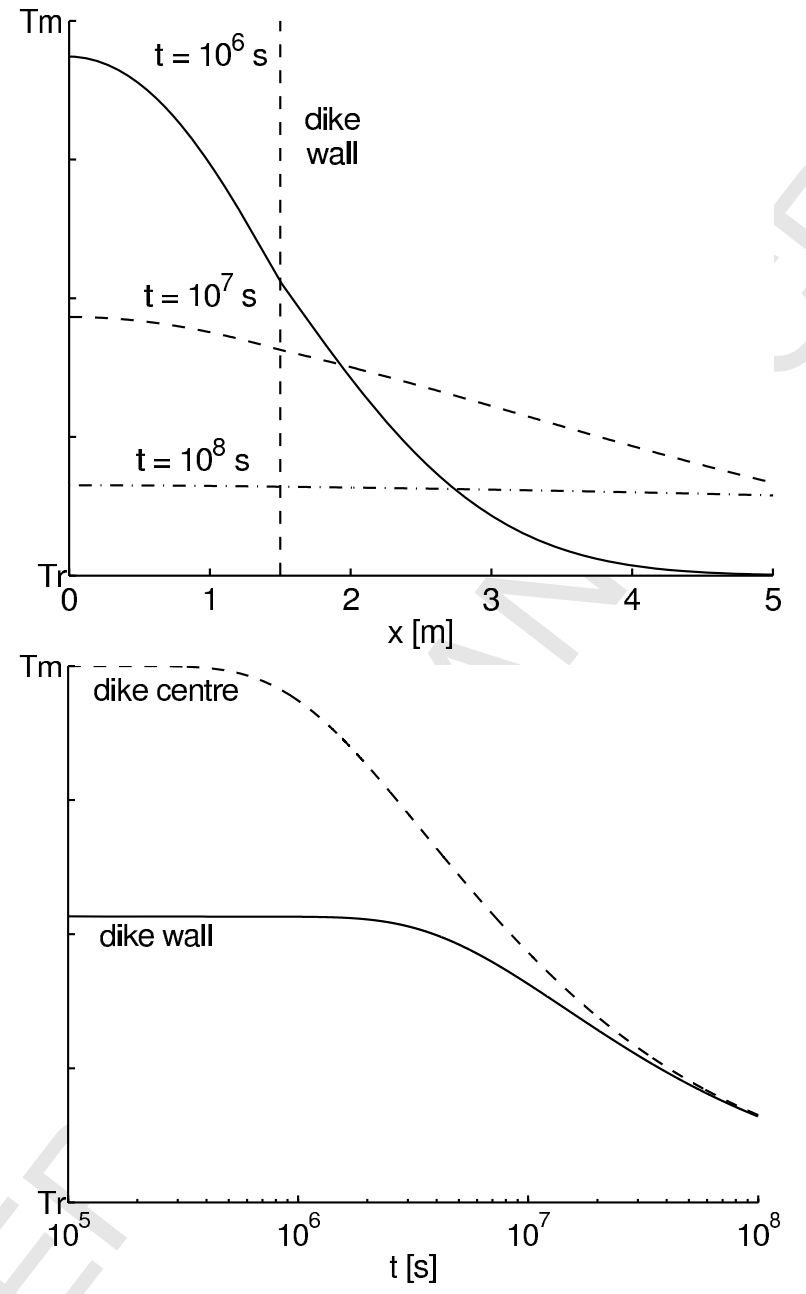

Figure 13: Magma temperature in a stationary dike of width $W=3 \mathrm{~m}$, with a cooling time scale $\tau_{c}=10^{6} \mathrm{~s}$. Top: Temperature distribution $T(x, t)$ after $t=10^{6} \mathrm{~s}, 10^{7} \mathrm{~s}$, and $10^{8} \mathrm{~s}$. Bottom: Temperatures $T(0, t)$ at the dike centre and $T( \pm W / 2, t)$ at the dike wall. 

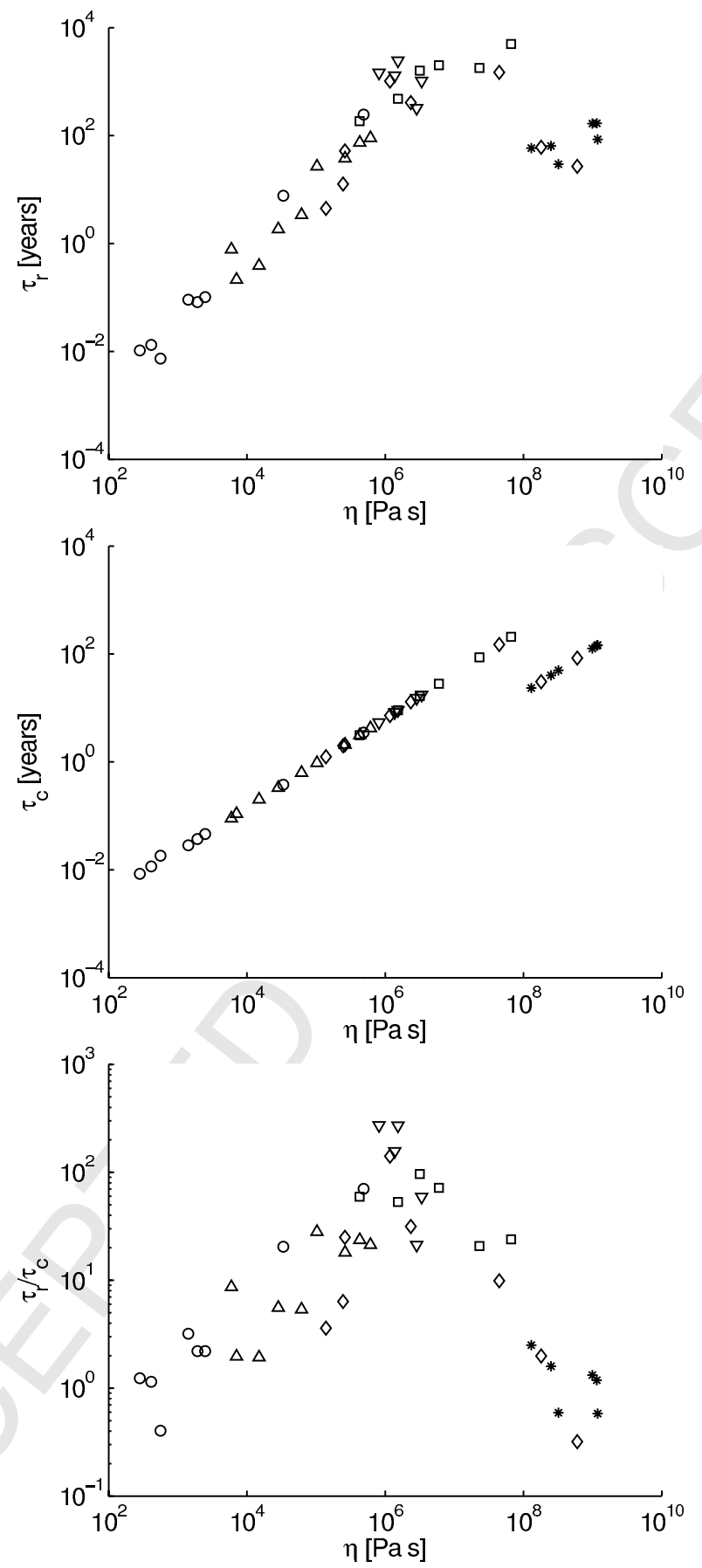

Figure 14: Dependence of time scales $\tau_{r}$ and $\tau_{c}$ and their ratio $\tau_{r} / \tau_{c}$ on magma viscosity $\eta$ for $\eta_{r}=10^{18} \mathrm{~Pa} \mathrm{~s}$ and $p_{0} / G=10^{-3.5}$. Symbols are chosen as defined in Fig. 5 . Diamonds denote possible dome pairs sharing a single dike. The relevance of magma evolution during ascent increases with increasing value of $\tau_{r} / \tau_{c}$. 